\title{
Polymerization and Depolymerization of Photoluminescent Polyarylene Chalcogenides
}

Zachary Nelson, ${ }^{1}$ Nathan Romero, ${ }^{1,2}$ Jan Tiepelt, ${ }^{3}$ Marc Baldo, ${ }^{3}$ Timothy M. Swager*1

${ }^{1}$ Department of Chemistry, Massachusetts Institute of Technology, Cambridge, MA 02139, USA

${ }^{2}$ Department of Chemistry \& Biochemistry, University of California, San Diego, La Jolla, CA 92093, USA

${ }^{3}$ Department of Electrical Engineering and Computer Science, Massachusetts Institute of Technology, Cambridge, MA 02139, USA

*Department of Chemistry, Massachusetts Institute of Technology,

77 Massachusetts Avenue

Cambridge, Massachusetts 02139

United States

tswager@mit.edu

\section{Supporting Information}

Table of Contents

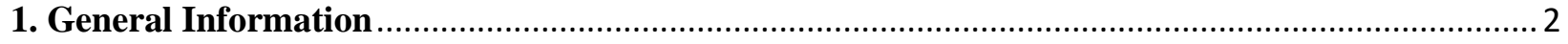

2. Synthesis of Disilyl(thio)ether Monomers (2) ............................................................................ 3

3. Synthesis of Difluorophthalonitrile Monomers (3) ................................................................ 4

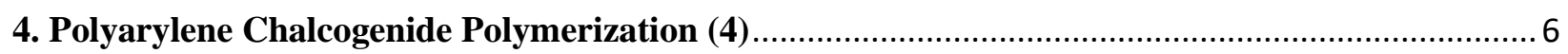

5. Synthesis of Tetrasubstituted Phthalonitriles (7) ................................................................ 9

6. Synthesis and Depolymerization of Crosslinked Network (8) ................................................ 11

7. Additional Photophysical Characterization of PACs ................................................................ 14

8. Studies of PAC Chemical Depolymerization ............................................................................ 15

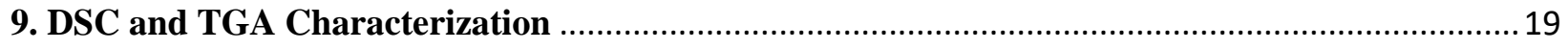

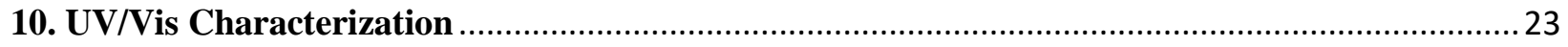

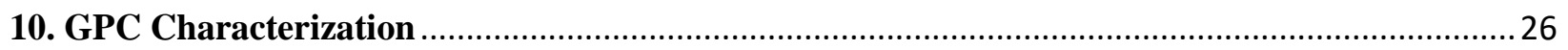

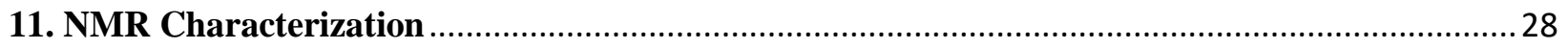

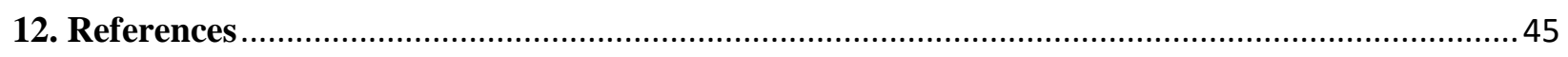




\section{General Information}

Unless otherwise stated, all reactions were carried out in oven-dried glassware under an atmosphere of argon using standard Schlenk techniques. Toluene and tetrahydrofuran (THF) were purified by passage through two alumina columns of an Inert solvent purification system. $N$ - $N$-dimethylformamide (DMF) was

dried over $4 \AA$ molecular sieves and degassed by sparging with argon. All other chemicals were of reagent grade and used as received.

${ }^{1} \mathrm{H}$ NMR spectra were recorded on a Bruker Avance $400 \mathrm{MHz}$, or Bruker Avance Neo 500 or $600 \mathrm{MHz}$ spectrometer. Chemical shifts $(\delta)$ are reported in ppm downfield from tetramethylsilane using the residual solvent signals $\left(\mathrm{CDCl}_{3}: \delta_{\mathrm{H}} 7.26 \mathrm{ppm}\right)$. Data for ${ }^{1} \mathrm{H}$ NMR are reported as follows: chemical shift $(\delta, \mathrm{ppm})$, multiplicity $(\mathrm{s}=$ singlet, $\mathrm{d}=$ doublet, $\mathrm{t}=$ triplet, and $\mathrm{m}=$ multiplet, coupling constant $(\mathrm{s})$ in $\mathrm{Hz}$, integration), ${ }^{13} \mathrm{C}$ NMR spectra were recorded on a Bruker Avance 400 (101 MHz), or Bruker Avance Neo 500 (126 $\mathrm{MHz})$ or $600(151 \mathrm{MHz})$ spectrometer. Chemical shifts $(\delta)$ are reported in ppm with residual solvent signals as a standard $\left(\mathrm{CDCl}_{3}: \delta_{\mathrm{C}} 77.16 \mathrm{ppm}\right) .{ }^{19} \mathrm{~F}$ NMR spectra were recorded on a Bruker Avance $600(565 \mathrm{MHz})$ spectrometer. Chemical Shifts $(\delta)$ are reported in ppm downfield from $\mathrm{CFCl}_{3}$ with hexafluorobenzene as a standard. $\left(\mathrm{C}_{6} \mathrm{~F}_{6}: \delta_{\mathrm{F}}-164.9\right)$.

High resolution mass spectra (HRMS) were obtained using a JEOL AccuTOF 4G equipped with an ionSense direct-analysis-in-real-time (DART) source. Mass spectra were calibrated using poly(ethylene glycol) of the appropriate mass range as external standards.

Gel Permeation Chromatography (GPC) characterization was performed on an Agilent 1260 Infinity system at a flow rate of $1 \mathrm{~mL} /$ minute at $35^{\circ} \mathrm{C}$, with three Agilent PLgel columns in series $(5 \mu \mathrm{m} \mathrm{10E5A,} \mathrm{10E4A,}$ and 10E3A). The signal from a refractive index detector (RID) was used for molecular weight analyses by comparison to polystyrene standards.

UV-vis spectra were recorded on an Agilent Cary 4000 spectrometer at room temperature using a quartz cuvette. Excitation and emission spectra were recorded on a HORIBA Fluorolog-3 spectrofluorometer using quartz cuvettes and HPLC-grade solvents for liquid samples, or HORIBA's universal fiber coupling solution for solid samples. In either case a UV bandpass filter was used in the path of the excitation beam to remove higher-order wavelengths. PAC thin films used in photophysical experiments were prepared via spin coating onto quartz substrates, using $20 \mathrm{mg} / \mathrm{mL}$ chloroform solutions of each PAC as the ink and spinning at a rate of $1000 \mathrm{rpm}$. The photoluminescent quantum yields (PLQY) of powdered PAC samples were calculated using a HORIBA Quanta- $\varphi$ integrating sphere attachment to a Fluorolog-3 spectrometer.

Time-resolved photoluminescent data were collected using a streak camera (Hamamatsu C11200). Excitation was carried out with a picosecond-pulsed diode laser at $\lambda=371 \mathrm{~nm}$. The laser pulse time and 
instrument response function allow for signal resolution up to $100 \mathrm{ps}$. Laser pulse repetition rate was set to $3 \mathrm{MHz}$ for both $2 \mu \mathrm{s}$ and $50 \mu \mathrm{s}$ measurement ranges in order to allow for the emission to fully decay in all cases. Emission was collected from thin films under nitrogen atmosphere and integrated over a wavelength range of $320 \mathrm{~nm}$ center wavelengths varying between $500 \mathrm{~nm}$ and $600 \mathrm{~nm}$. Transient lifetimes were obtained by fitting two exponential decay functions to match the prompt and delay components over manually selected ranges in the $2 \mu$ s measurements, as detailed below.

Thermal characterization was accomplished using a TA Instruments Discovery thermogravimetric analyzer (TGA) using a platinum pan at a ramp rate of $20^{\circ} \mathrm{C} / \mathrm{min}$, and differential scanning calorimeter (DSC) using aluminum pans at a ramp rate of $10^{\circ} \mathrm{C} / \mathrm{min}$. Analysis was performed on TRIOS software.

\section{Synthesis of Disilyl(thio)ether Monomers (2)}<smiles>CS(=O)(=O)c1ccc(Sc2ccc(S(C)(=O)=O)cc2)cc1</smiles>

Bis(4-((trimethylsilyl)thio)phenyl)sulfane (2a) To an oven-dried Schlenk flask topped by a short path distilling head and receiving flask, 4,4'-thiobisbenzenethiol (40 mmol, $10.0 \mathrm{~g}, 1$ equiv.), hexamethyldisilazane (HMDS) (200 mmol, $42 \mathrm{~mL}, 5$ equiv.), and a magnetic stirbar were added under an atmosphere of argon. The reaction was stirred at reflux for one hour. Upon cooling to room temperature, excess HMDS was removed by vacuum distillation with gentle heating. After removing most of the HMDS, the resulting white crystalline solid was dried in vacuo overnight at $50{ }^{\circ} \mathrm{C}$, giving the product as a white crystalline solid $(15.1 \mathrm{~g}, 95 \%)$. Characterization was consistent with previous report. ${ }^{1} \mathbf{H}$ NMR (600 MHz, Chloroform- $d$ ) $\delta 7.33(\mathrm{~d}, \mathrm{~J}=8.3 \mathrm{~Hz}, 4 \mathrm{H}), 7.20$ (d, J = 8.3 Hz, 4H), $0.28(\mathrm{~s}, 18 \mathrm{H})$.<smiles>COc1ccc(Sc2ccc(OC)cc2)cc1</smiles>

Bis(4-((trimethylsilyl)oxy)phenyl)sulfane (2c) To an oven-dried round-bottomed flask was added 4,4'thiodiphenol (4 mmol, $873 \mathrm{mg}, 1$ equiv.) and a magnetic stirbar under an atmosphere of argon. Then hexamethyldisilazane (HMDS) (9.6 mmol, $2.01 \mathrm{~mL}, 2.4$ equiv.), and trimethylsilyl chloride (TMSCl) (1 drop) were added. The reaction was stirred for 1 hour at room temperature, then the volatiles were removed under reduced pressure with gentle heating (ca. $40{ }^{\circ} \mathrm{C}$ ), followed by heating above $90{ }^{\circ} \mathrm{C}$ for 2 hours under high vacuum to decompose $\mathrm{NH}_{4} \mathrm{Cl}$. The resulting colorless oil was of acceptable purity (1.5 
g, 99\%).Characterization was consistent with previous report. ${ }^{2}{ }^{1} \mathbf{H}$ NMR (600 MHz, Chloroform- $d$ ) $\delta 7.21$ $(\mathrm{d}, \mathrm{J}=8.6 \mathrm{~Hz}, 4 \mathrm{H}), 6.77(\mathrm{~d}, \mathrm{~J}=8.6 \mathrm{~Hz}, 4 \mathrm{H}), 0.26(\mathrm{~s}, 18 \mathrm{H})$.<smiles>CCN(CC)CCSSc1ccc(Sc2ccc([SnH])cc2)cc1</smiles>

Bis(4-((triisopropylsilyl)oxy)phenyl)sulfane (2b) To a flame- dried round-bottomed flask was added 4,4'-thiobisbenzenethiol (1 mmol, $250 \mathrm{mg}, 1$ equiv.) under an atmosphere of argon. Then $10 \mathrm{~mL}$ THF and triisopropylsilyl chloride (TIPSCl) $(2.4 \mathrm{mmol}, 0.51 \mathrm{~mL}, 2.4$ equiv.) were added. Finally, triethylamine ( $2.2 \mathrm{mmol}, 0.30 \mathrm{~mL}, 2.2$ equiv.) was added dropwise with stirring. The reaction was stirred at room temperature overnight. Upon completion, the solution was filtered through a pad of Celite, washing with hexanes, and concentrated under reduced pressure. The white solid was sonicated in a 10:1 solution $\mathrm{MeOH} / \mathrm{CH}_{2} \mathrm{Cl}_{2}$, collected by vacuum filtration, and dried under vacuum giving a white solid (480 mg, $85 \%$ ). Characterization was consistent with previous report. ${ }^{3}{ }^{1} \mathbf{H}$ NMR (600 MHz, Chloroform- $d$ ) $\delta 7.40$ $(\mathrm{d}, \mathrm{J}=8.3 \mathrm{~Hz}, 4 \mathrm{H}), 7.14(\mathrm{~d}, \mathrm{~J}=8.3 \mathrm{~Hz}, 4 \mathrm{H}), 1.28-1.20(\mathrm{~m}, 6 \mathrm{H}), 1.07$ (d, J = 7.5 Hz, 36H).

\section{Synthesis of Difluorophthalonitrile Monomers (3)}

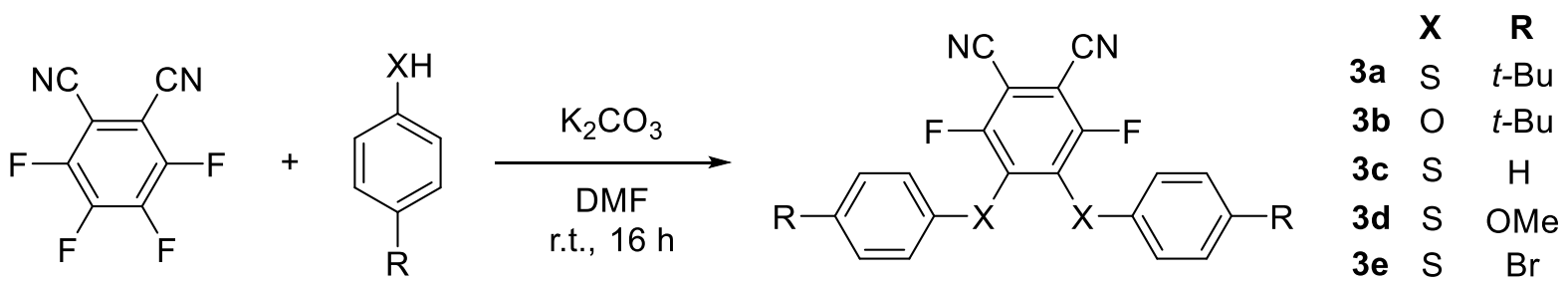

General Procedure To an oven-dried round bottomed flask was added tetrafluorophthalonitrile (1 equiv.), $\mathrm{K}_{2} \mathrm{CO}_{3}$ (4 equiv.) and a magnetic stirbar under an atmosphere of argon. Then dry, degassed DMF was added to form a $0.1 \mathrm{M}$ solution with respect to tetrafluorophthalonitrile. Finally, the phenol or thiophenol derivative ( 2 equiv.) was added dropwise or in portions over the course of 10 minutes. The reaction was stirred at room temperature overnight. Upon completion of the reaction, water and chloroform were added and the aqueous and organic partitions were separated. The aqueous layer was then extracted three times with chloroform. The combined organic fractions were then washed twice with $1 \mathrm{M}$ aqueous $\mathrm{NaOH}$, twice with $1 \mathrm{M}$ aqueous $\mathrm{HCl}$, thrice with water, and once with saturated aqueous $\mathrm{NaCl}$. The organic layer was then dried over anhydrous $\mathrm{Mg}_{2} \mathrm{SO}_{4}$, filtered, and concentrated under reduced pressure. The residue was then purified by silica gel column chromatography and/or recrystallization. 
4,5-bis((4-(tert-butyl)phenyl)thio)-3,6-difluorophthalonitrile (3a) Prepared following the general procedure using 4-tert-butylbenzenethiol $(40 \mathrm{mmol}, 6.90 \mathrm{~mL})$. The crude product was purified by recrystallization from hexanes three times, giving a fine needle-like yellow solid $(5.7 \mathrm{~g}, 58 \%)$. ${ }^{1} \mathbf{H}$ NMR $\left(600 \mathrm{MHz}\right.$, Chloroform- $d$ ) $\delta 7.35(\mathrm{~d}, \mathrm{~J}=8.5 \mathrm{~Hz}, 4 \mathrm{H}), 7.30(\mathrm{~d}, \mathrm{~J}=8.5 \mathrm{~Hz}, 4 \mathrm{H}), 1.31(\mathrm{~s}, 18 \mathrm{H}) .{ }^{13} \mathbf{C} \mathbf{N M R}$ (151 MHz, Chloroform- $d$ ) $\delta$ 159.12, 152.84, 137.22, 132.10, 128.04, 126.90, 110.06, 102.94, 34.93, 31.31. ${ }^{19}$ F NMR (565 MHz, Chloroform- $d$ ) $\delta$-99.48. HRMS (DART/AccuTOF) $\mathrm{m} / \mathrm{z}:[\mathrm{M}]^{+}$Calcd for $\mathrm{C}_{28} \mathrm{H}_{26} \mathrm{~F}_{2} \mathrm{~N}_{2} \mathrm{~S}_{2}$ 492.1505; Found 492.1504 .

4,5-bis((4-bromophenyl)thio)-3,6-difluorophthalonitrile (3e) Prepared following the general procedure using 4-bromothiophenol ( $4 \mathrm{mmol}, 0.756 \mathrm{~mL}$ ). The crude product was purified by silica gel column chromatography using $10 \%$ ethyl acetate in hexanes as the eluant, giving a yellow powder (330 mg, 30\%). ${ }^{1} \mathbf{H}$ NMR (600 MHz, Chloroform- $\left.d\right) \delta 7.48(\mathrm{~d}, \mathrm{~J}=8.5 \mathrm{~Hz}, 4 \mathrm{H}), 7.22(\mathrm{~d}, \mathrm{~J}=8.5 \mathrm{~Hz}, 4 \mathrm{H}) .{ }^{13} \mathbf{C}$ NMR $(151 \mathrm{MHz}$, Chloroform- $d) \delta 159.01,136.07,133.37,133.12,130.39,123.92,109.63,103.85 .{ }^{19} \mathbf{F}$ NMR $(565 \mathrm{MHz} \text {, Chloroform- } d \text { ) } \delta \text {-99.22. HRMS (DART/AccuTOF) m/z: [M] }]^{+}$Calcd for $\mathrm{C}_{20} \mathrm{H}_{8} \mathrm{Br}_{2} \mathrm{~F}_{2} \mathrm{~N}_{2} \mathrm{~S}_{2}$ 535.8464; Found 535.8459.

3,6-difluoro-4,5-bis((4-methoxyphenyl)thio)phthalonitrile (3d) Prepared following the general procedure using 4-methoxythiophenol $(4 \mathrm{mmol}, 0.492 \mathrm{~mL})$. The crude product was purified by silica gel column chromatography using $20 \%$ ethyl acetate in hexanes as the eluant, giving a yellow powder (442 mg, 50\%). ${ }^{1} \mathbf{H}$ NMR (600 MHz, Chloroform- $d$ ) $\delta 7.40(\mathrm{~d}, \mathrm{~J}=8.8 \mathrm{~Hz}, 4 \mathrm{H}), 6.88(\mathrm{~d}, \mathrm{~J}=8.8 \mathrm{~Hz}, 4 \mathrm{H}), 3.83$ (s, 6H). ${ }^{13}$ C NMR (151 MHz, Chloroform- $d$ ) $\delta$ 160.89, 158.83, 137.23, 134.96, 121.58, 115.37, 110.05, 102.63, 55.61. ${ }^{19}$ F NMR (565 MHz, Chloroform- $d$ ) $\delta-101.13$. HRMS (DART/AccuTOF) m/z: [M] ${ }^{+}$ Calcd for $\mathrm{C}_{22} \mathrm{H}_{14} \mathrm{~F}_{2} \mathrm{~N}_{2} \mathrm{O}_{2} \mathrm{~S}_{2} 440.0465$; Found 440.0464 .

3,6-difluoro-4,5-bis(phenylthio)phthalonitrile (3c) Prepared following the general procedure using thiophenol (200 mmol, $20.5 \mathrm{~mL})$ with modification to the workup due to scale. Upon completion of the reaction, the reaction mixture was poured into water, the precipitate was collected by vacuum filtration and washed with water. The solid was then dissolved in acetone, dried over anhydrous $\mathrm{Mg}_{2} \mathrm{SO}_{4}$, filtered, and concentrated under reduced pressure. The residue was then purified by recrystallization from isopropanol three times, giving a fine needle-like yellow solid (26.6 g, 70\%). ${ }^{1} \mathbf{H}$ NMR $(600 \mathrm{MHz}$, Chloroform- $d$ ) $\delta 7.40-7.32(\mathrm{~m}, 10 \mathrm{H}) .{ }^{13} \mathbf{C}$ NMR $(151 \mathrm{MHz}$, Chloroform- $d$ ) $\delta 159.12,136.81,131.86$, 131.65, 129.87, 129.25, 109.89, 103.30. ${ }^{19}$ F NMR (565 MHz, Chloroform- $d$ ) $\delta$-99.31. HRMS (DART/AccuTOF) m/z: [M] ${ }^{+}$Calcd for $\mathrm{C}_{20} \mathrm{H}_{10} \mathrm{~F}_{2} \mathrm{~N}_{2} \mathrm{~S}_{2} 380.0253$; Found 380.0252.

4,5-bis(4-(tert-butyl)phenoxy)-3,6-difluorophthalonitrile (3b) Prepared following the general procedure using 4-tert-butylphenol $(50 \mathrm{mmol}, 7.51 \mathrm{~g})$. The crude product was purified by silica gel 
column chromatography using 5\% ethyl acetate in hexanes as the eluant, followed by recrystallization from ethanol three times, giving a fine needle-like white solid (5.39 g, 47\%). ${ }^{1} \mathbf{H}$ NMR $(600 \mathrm{MHz}$, Chloroform- $d$ ) $\delta 7.24$ (d, J = 8.9 Hz, 4H), 6.70 (d, J = 8.8 Hz, 4H), 1.27 (s, 18H). ${ }^{13}$ C NMR (151 MHz, Chloroform- $d$ ) $\delta 154.73,153.98,147.80,143.33,126.72,115.66,109.66,100.48,34.51,31.52 .{ }^{19}$ F NMR (565 MHz, Chloroform- $d$ ) $\delta$-121.25. HRMS (DART/AccuTOF) m/z: [M] $]^{+}$Calcd for $\mathrm{C}_{28} \mathrm{H}_{26} \mathrm{~F}_{2} \mathrm{~N}_{2} \mathrm{O}_{2}$ 460.1962; Found 460.1970.

\section{Polyarylene Chalcogenide Polymerization (4)}

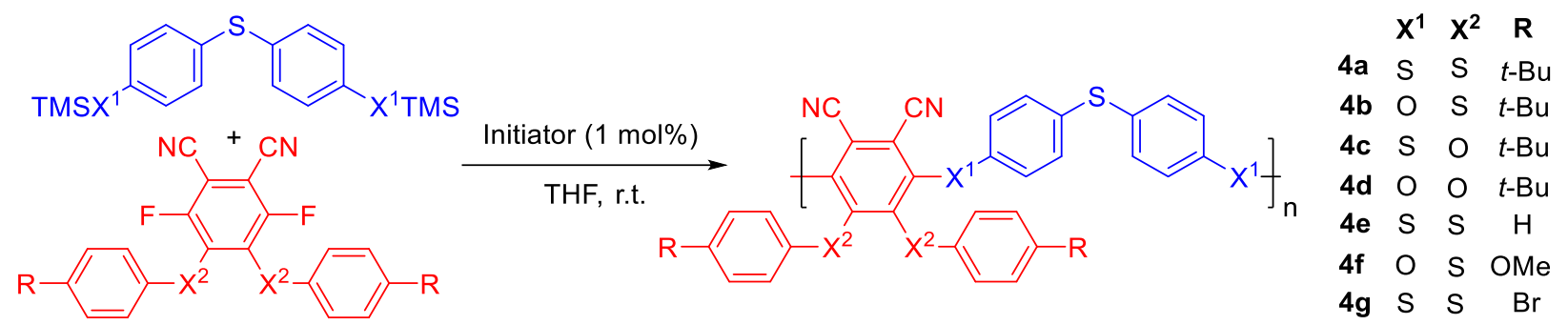

4a To a flame dried reaction tube was added 4,5-bis((4-(tert-butyl)phenyl)thio)-3,6-difluorophthalonitrile (3a) (0.4 mmol, $197 \mathrm{mg}, 1$ equiv.), bis(4-((trimethylsilyl)thio)phenyl)sulfane (2a) (0.4 mmol, $158 \mathrm{mg}, 1$ equiv.), and a magnetic stirbar. The reaction vessel was evacuated and purged with argon three times. Then THF $(0.5 \mathrm{~mL}, 0.8 \mathrm{M})$ and tetrabutylammonium difluorotriphenylsilicate solution (TBAT, $0.1 \mathrm{M}$ THF) (0.004 mmol, $0.40 \mu \mathrm{L}, 0.01$ equiv.) were added. The solution was stirred overnight at room temperature. Upon completion, the solution was added dropwise to rapidly stirred methanol, and the precipitate was collected by vacuum filtration. The precipitate was dissolved in chloroform and reprecipitated in rapidly stirred methanol, and collected by vacuum filtration. The solid was dried in a vacuum oven at $70{ }^{\circ} \mathrm{C}$ overnight to give an orange solid $(135 \mathrm{mg}, 48 \%) .{ }^{1} \mathbf{H} \mathbf{N M R}(600 \mathrm{MHz}$, Chloroform- $d$ ) $\delta 7.22(\mathrm{~d}, \mathrm{~J}=8.5 \mathrm{~Hz}, 4 \mathrm{H}), 7.17(\mathrm{~d}, \mathrm{~J}=8.3 \mathrm{~Hz}, 4 \mathrm{H}), 7.06(\mathrm{~d}, \mathrm{~J}=8.5 \mathrm{~Hz}, 4 \mathrm{H}), 6.92(\mathrm{~d}, \mathrm{~J}=$ $8.4 \mathrm{~Hz}, 4 \mathrm{H}), 1.25$ (s, 18H). ${ }^{13} \mathrm{C}$ NMR $(151 \mathrm{MHz}$, Chloroform- $d) \delta 152.66,151.36,145.32,135.78$, 133.26, 131.98, 131.90, 131.44, 129.72, 126.70, 122.56, 113.79, 34.79, 31.38 .

4c To a flame dried reaction tube was added 4,5-bis(4-(tert-butyl)phenoxy)-3,6-difluorophthalonitrile (23b) (0.25 mmol, $115 \mathrm{mg}, 1$ equiv.), bis(4-((trimethylsilyl)thio)phenyl)sulfane (2a) (0.25 mmol, $99 \mathrm{mg}$, 1 equiv.), and a magnetic stirbar. The reaction vessel was evacuated and purged with argon three times. Then THF ( $1 \mathrm{~mL}, 0.5 \mathrm{M})$ and tetrabutylammonium difluorotriphenylsilicate solution (TBAT, $0.1 \mathrm{M} \mathrm{THF}$ ) ( $0.0025 \mathrm{mmol}, 0.25 \mu \mathrm{L}, 0.01$ equiv.) were added. The solution was stirred overnight at room temperature. Upon completion, the solution was added dropwise to rapidly stirred methanol, and the precipitate was collected by vacuum filtration. The precipitate was dissolved in chloroform and reprecipitated in rapidly stirred methanol, and collected by vacuum filtration. The solid was dried in a vacuum oven to give a 
white solid (133 mg, 80\%). ${ }^{1} \mathbf{H}$ NMR (600 MHz, Chloroform- $d$ ) $\delta 7.20(\mathrm{~d}, \mathrm{~J}=8.4 \mathrm{~Hz}, 4 \mathrm{H}), 7.09$ (d, J = $8.4 \mathrm{~Hz}, 4 \mathrm{H}), 7.06(\mathrm{~d}, \mathrm{~J}=8.8 \mathrm{~Hz}, 4 \mathrm{H}), 6.22(\mathrm{~d}, \mathrm{~J}=8.8 \mathrm{~Hz}, 4 \mathrm{H}), 1.23(\mathrm{~s}, 18 \mathrm{H}) .{ }^{13} \mathrm{C}$ NMR $(151 \mathrm{MHz}$, Chloroform- $d$ ) $\delta 153.52,152.72,146.62,137.49,136.23,132.82,131.62,131.38,126.13,119.14,114.88$, 113.60, 34.38, 31.59 .

4b To a flame dried reaction tube was added 4,5-bis((4-(tert-butyl)phenyl)thio)-3,6-difluorophthalonitrile (3a) (0.15 mmol, $74 \mathrm{mg}, 1$ equiv.), bis(4-((trimethylsilyl)oxy)phenyl)sulfane $2 \mathrm{c}(0.15 \mathrm{mmol}, 54 \mathrm{mg}, 1$ equiv.), and a magnetic stirbar. The reaction vessel was evacuated and purged with argon three times. Then THF $(0.3 \mathrm{~mL}, 0.5 \mathrm{M})$ and tetrabutylammonium difluorotriphenylsilicate solution (TBAT, $0.1 \mathrm{M}$ THF) ( $0.0015 \mathrm{mmol}, 0.15 \mu \mathrm{L}, 0.01$ equiv.) were added. The solution was stirred overnight at room temperature. Upon completion, the solution was added dropwise to rapidly stirred methanol, and the precipitate was collected by vacuum filtration. The precipitate was dissolved in chloroform and reprecipitated in rapidly stirred methanol, and collected by vacuum filtration. The solid was dried in a vacuum oven at $70{ }^{\circ} \mathrm{C}$ overnight to give a white solid (94 mg, 93\%). ${ }^{1} \mathbf{H}$ NMR (600 MHz, Chloroform- $d$ ) $\delta 7.20(\mathrm{~d}, \mathrm{~J}=8.5 \mathrm{~Hz}, 4 \mathrm{H}), 7.17(\mathrm{~d}, \mathrm{~J}=8.8 \mathrm{~Hz}, 4 \mathrm{H}), 7.05(\mathrm{~d}, \mathrm{~J}=8.4 \mathrm{~Hz}, 4 \mathrm{H}), 6.51(\mathrm{~d}, \mathrm{~J}=8.8 \mathrm{~Hz}, 4 \mathrm{H}), 1.25$ $(\mathrm{s}, 18 \mathrm{H}) .{ }^{13} \mathrm{C}$ NMR $(151 \mathrm{MHz}$, Chloroform- $d$ ) $\delta$ 155.78, 154.20, 152.04, 143.70, 132.52, 131.30, 130.57, $129.34,126.47,116.64,111.72,110.71,34.81,31.36$.

4d To a flame dried reaction tube was added 4,5-bis(4-(tert-butyl)phenoxy)-3,6-difluorophthalonitrile (3b) (0.25 mmol, $115 \mathrm{mg}, 1$ equiv.), bis(4-((trimethylsilyl)oxy)phenyl)sulfane (2c) (0.25 mmol, $91 \mathrm{mg}, 1$ equiv.), and a magnetic stirbar. The reaction vessel was evacuated and purged with argon three times. Then THF ( $1 \mathrm{~mL}, 0.5 \mathrm{M})$ and tetrabutylammonium difluorotriphenylsilicate solution (TBAT, $0.1 \mathrm{M} \mathrm{THF}$ ) ( $0.0025 \mathrm{mmol}, 0.25 \mu \mathrm{L}, 0.01$ equiv.) were added. The solution was stirred overnight at room temperature. Upon completion, the solution was added dropwise to rapidly stirred methanol, and the precipitate was collected by vacuum filtration. The precipitate was dissolved in chloroform and reprecipitated in rapidly stirred methanol, and collected by vacuum filtration. The solid was dried in a vacuum oven at $70{ }^{\circ} \mathrm{C}$ overnight to give a white solid (150 mg, 94\%). ${ }^{1} \mathbf{H}$ NMR $(600 \mathrm{MHz}$, Chloroform- $d) \delta 7.16(\mathrm{~d}, \mathrm{~J}=8.8 \mathrm{~Hz}$, 4H), $7.08(\mathrm{~d}, \mathrm{~J}=8.9 \mathrm{~Hz}, 4 \mathrm{H}), 6.69(\mathrm{~d}, \mathrm{~J}=8.8 \mathrm{~Hz}, 4 \mathrm{H}), 6.43(\mathrm{~d}, \mathrm{~J}=8.8 \mathrm{~Hz}, 4 \mathrm{H}), 1.20(\mathrm{~s}, 18 \mathrm{H}) .{ }^{13} \mathbf{C} \mathbf{N M R}$ (151 MHz, Chloroform- $d$ ) $\delta 155.86,153.54,149.08,147.59$, 147.08, 132.58, 131.10, 126.24, 117.10, $115.47,111.62,107.74,34.38,31.52$.

4g To a flame dried reaction tube was added 4,5-bis((4-bromophenyl)thio)-3,6-difluorophthalonitrile (3e) (0.15 mmol, 81 mg, 1 equiv.), bis(4-((trimethylsilyl)oxy)phenyl)sulfane (2c) (0.15 mmol, 54 mg, 1 equiv.), and a magnetic stirbar. The reaction vessel was evacuated and purged with argon three times. Then THF ( $0.30 \mathrm{~mL}, 0.5 \mathrm{M})$ and tetrabutylammonium difluorotriphenylsilicate solution (TBAT, 0.1 M THF) (0.0015 mmol, $0.15 \mu \mathrm{L}, 0.01$ equiv.) were added. The solution was stirred overnight at room 
temperature. Upon completion, the solution was added dropwise to rapidly stirred methanol, and the precipitate was collected by vacuum filtration. The precipitate was dissolved in chloroform and reprecipitated in rapidly stirred methanol, and collected by vacuum filtration. The solid was dried in a vacuum oven at $70{ }^{\circ} \mathrm{C}$ overnight to give a yellow solid (86 mg, 80\%). ${ }^{1} \mathbf{H}$ NMR (600 MHz, Chloroformd) $\delta 7.32(\mathrm{~d}, \mathrm{~J}=6.9 \mathrm{~Hz}, 4 \mathrm{H}), 7.21(\mathrm{~d}, \mathrm{~J}=8.1 \mathrm{~Hz}, 4 \mathrm{H}), 6.96(\mathrm{~d}, \mathrm{~J}=7.5 \mathrm{~Hz}, 4 \mathrm{H}), 6.56(\mathrm{~d}, \mathrm{~J}=8.9 \mathrm{~Hz}$, 4H). ${ }^{13}$ C NMR (151 MHz, Chloroform- $d$ ) $\delta 155.62,154.35,142.60,132.86,132.64,132.36,131.85$, $131.14,122.84,116.63,111.58,111.42$.

4f To a flame dried reaction tube was added 3,6-difluoro-4,5-bis((4-methoxyphenyl)thio)phthalonitrile (3d) (0.15 mmol, $66 \mathrm{mg}, 1$ equiv.), bis(4-((trimethylsilyl)oxy)phenyl)sulfane (2c) (0.15 mmol, $54 \mathrm{mg}, 1$ equiv.), and a magnetic stirbar. The reaction vessel was evacuated and purged with argon three times. Then THF (0.30 mL, 0.5 M) and tetrabutylammonium difluorotriphenylsilicate solution (TBAT, $0.1 \mathrm{M}$ THF) ( $0.0015 \mathrm{mmol}, 0.15 \mu \mathrm{L}, 0.01$ equiv.) were added. The solution was stirred overnight at room temperature. Upon completion, the solution was added dropwise to rapidly stirred methanol, and the precipitate was collected by vacuum filtration. The precipitate was dissolved in chloroform and reprecipitated in rapidly stirred methanol, and collected by vacuum filtration. The solid was dried in a vacuum oven at $70{ }^{\circ} \mathrm{C}$ overnight to give a yellow solid (80 mg, 86\%). ${ }^{1} \mathbf{H}$ NMR (600 MHz, Chloroformd) $\delta 7.20(\mathrm{~d}, \mathrm{~J}=8.8 \mathrm{~Hz}, 4 \mathrm{H}), 7.11(\mathrm{~d}, \mathrm{~J}=8.8 \mathrm{~Hz}, 4 \mathrm{H}), 6.72(\mathrm{~d}, \mathrm{~J}=8.8 \mathrm{~Hz}, 4 \mathrm{H}), 6.55(\mathrm{~d}, \mathrm{~J}=8.8 \mathrm{~Hz}, 4 \mathrm{H})$, 3.74 (s, 6H). ${ }^{13}$ C NMR (151 MHz, Chloroform- $d$ ) $\delta 160.26,155.82,153.95,143.89,133.78,132.59$, $130.60,123.23,116.61,115.02,111.72,110.60,55.61$.

4e To an oven-dried round bottomed flask was added 3c (20 mmol, $7.61 \mathrm{~g}, 1$ equiv.), 2a (20 mmol, 7.900 g, 1 equiv.), and a magnetic stirbar. The reaction vessel was evacuated and purged with argon three times. Then THF (80 mL) was added. After all solid had dissolved, 1,8-diazabicyclo[5.4.0]undec-7-ene (DBU) ( $0.1 \mathrm{mmol}, 0.03 \mathrm{~mL}, 0.01$ equiv.) was added, upon which slow color change from yellow to orange was observed. The reaction was stirred overnight at room temperature. Upon completion, the reaction mixture was added dropwise via addition funnel to $500 \mathrm{~mL}$ rapidly stirred methanol. The precipitate was collected via vacuum filtration, washed with methanol, and dried overnight in vacuo at $100{ }^{\circ} \mathrm{C}$, giving an orange solid (11.2 g, 95\%). ${ }^{1} \mathbf{H}$ NMR (600 MHz, Chloroform- $d$ ) $\delta 7.23-7.15$ (m, 10H), $7.11-7.04$ (m, 4H), $7.00-6.91(\mathrm{~m}, 4 \mathrm{H}) .{ }^{13} \mathrm{C}$ NMR $(151 \mathrm{MHz}$, Chloroform- $d) \delta 152.06,145.54,135.94,135.43,133.03$, $131.97,131.64,129.72,129.39,127.86,122.66,113.75$. 


\section{Synthesis of Tetrasubstituted Phthalonitriles (7)}

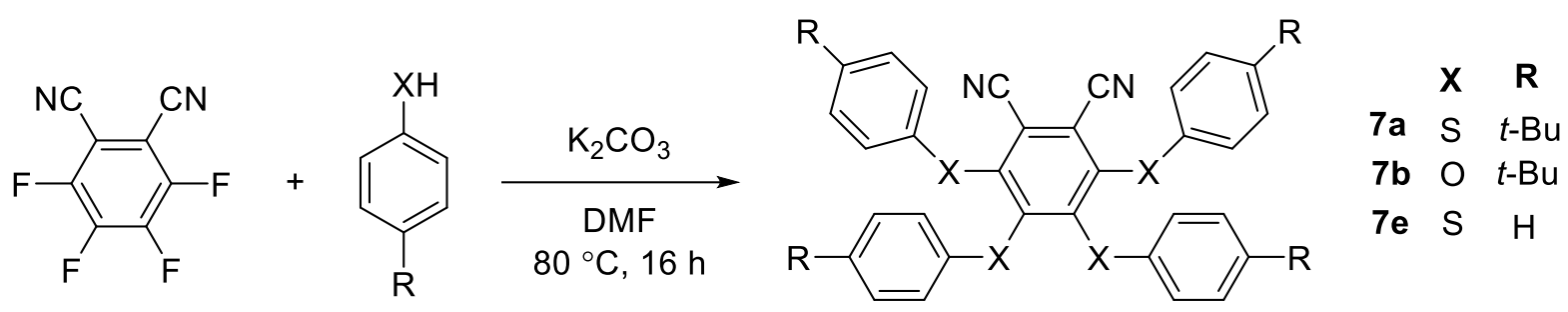

3,4,5,6-tetrakis(phenylthio)phthalonitrile (7e) To an oven-dried round bottomed flask was added tetrafluorophthalonitrile (5 mmol, $1.0 \mathrm{~g}, 1$ equiv.) and a magnetic stirbar under an atmosphere of argon. Then dry, degassed DMF (25 mL) was added, followed by thiophenol (20.2 mmol, $2.07 \mathrm{~mL}, 4.04$ equiv.) and $\mathrm{K}_{2} \mathrm{CO}_{3}$ (4.15 g, $30 \mathrm{mmol}, 6$ equiv.). The reaction was stirred at $80{ }^{\circ} \mathrm{C}$ overnight. After cooling to room temperature, the reaction mixture was poured into $1 \mathrm{M}$ aqueous $\mathrm{HCl}$, after which the precipitate was collected by vacuum filtration and washed with water. The residue was then purified by recrystallization from ethanol, giving a fine needle-like orange solid $(2.21 \mathrm{~g}, 79 \%)$. Characterization consistent with the literature. ${ }^{4}{ }^{1} \mathbf{H}$ NMR $(600 \mathrm{MHz}$, Chloroform- $d$ ) $\delta 7.31-7.27(\mathrm{~m}, 6 \mathrm{H}), 7.25-7.21(\mathrm{~m}, 6 \mathrm{H}), 7.21-7.19$ (m, 4H), 6.99 - $6.96(\mathrm{~m}, 4 \mathrm{H}) .{ }^{13} \mathbf{C}$ NMR (151 MHz, Chloroform- $\left.d\right) \delta 152.21,145.87,135.70,134.06$, 130.94, 129.73, 129.60, 129.37, 128.42, 127.67, 122.85, 113.77. HRMS (DART/AccuTOF) m/z: [M] Calcd for $\mathrm{C}_{32} \mathrm{H}_{20} \mathrm{~N}_{2} \mathrm{~S}_{4} 560.0509$; Found 560.0514.

3,4,5,6-tetrakis((4-(tert-butyl)phenyl)thio)phthalonitrile (7a) To an oven-dried round bottomed flask was added tetrafluorophthalonitrile (10 mmol, $2.0 \mathrm{~g}, 1$ equiv.) and a magnetic stirbar under an atmosphere of argon. Then dry, degassed DMF (100 mL) was added, followed by 4-tert-butylbenzenethiol (41 mmol, $7.07 \mathrm{~mL}, 4.1$ equiv.) and $\mathrm{K}_{2} \mathrm{CO}_{3}\left(60 \mathrm{mmol}, 8.29 \mathrm{~g}, 6\right.$ equiv.). The reaction was stirred at $80{ }^{\circ} \mathrm{C}$ overnight. After cooling to room temperature, water and chloroform were added and the aqueous and organic partitions were separated. The aqueous layer was then extracted three times with chloroform. The combined organic fractions were then washed four times with with water and once with saturated aqueous $\mathrm{NaCl}$. The organic layer was then dried over anhydrous $\mathrm{Mg}_{2} \mathrm{SO}_{4}$, filtered, and concentrated under reduced pressure. The residue was purified by recrystallization from acetonitrile, giving a fine needle-like orange solid (6.34 g, 81\%). ${ }^{1} \mathbf{H}$ NMR (400 MHz, Chloroform- $d$ ) $\delta 7.29$ (d, J = 8.1 Hz, 4H), 7.25 (d, J = 8.3 Hz, 4H), $7.13(\mathrm{~d}, \mathrm{~J}=8.2 \mathrm{~Hz}, 4 \mathrm{H}), 6.95(\mathrm{~d}, \mathrm{~J}=8.1 \mathrm{~Hz}, 4 \mathrm{H}), 1.29(\mathrm{~d}, \mathrm{~J}=2.7 \mathrm{~Hz}, 36 \mathrm{H}) .{ }^{13} \mathbf{C}$ NMR $(101 \mathrm{MHz}$, Chloroform- $d$ ) $\delta 152.65,151.78,150.99,146.16,132.57,131.13,130.70,129.68,126.70,126.57,123.03$, 113.96, 34.81, 34.75, 31.37, 31.33. HRMS (DART/AccuTOF) m/z: [M] ${ }^{+}$Calcd for $\mathrm{C}_{48} \mathrm{H}_{52} \mathrm{~N}_{2} \mathrm{~S}_{4} 784.3013$; Found 784.3017.

3,4,5,6-tetrakis(4-(tert-butyl)phenoxy)phthalonitrile (7d) To an oven-dried round bottomed flask was added tetrafluorophthalonitrile (10 mmol, $2.0 \mathrm{~g}, 1$ equiv.) and a magnetic stirbar under an atmosphere of 
argon. Then dry, degassed DMF (100 mL) was added, followed by 4-tert-butylphenol (40 mmol, $6.0 \mathrm{~g}, 4$ equiv.) and $\mathrm{K}_{2} \mathrm{CO}_{3}\left(60 \mathrm{mmol}, 8.29 \mathrm{~g}, 6\right.$ equiv.). The reaction was stirred at $80{ }^{\circ} \mathrm{C}$ overnight. After cooling to room temperature, water and chloroform were added and the aqueous and organic partitions were separated. The aqueous layer was then extracted three times with chloroform. The combined organic fractions were then washed four times with water and once with saturated aqueous $\mathrm{NaCl}$. The organic layer was then dried over anhydrous $\mathrm{Mg}_{2} \mathrm{SO}_{4}$, filtered, and concentrated under reduced pressure. The residue was purified by recrystallization from acetonitrile, giving a fine needle-like white solid ( $4.59 \mathrm{~g}$, 64\%). ${ }^{1} \mathbf{H}$ NMR (600 MHz, Chloroform- $d$ ) $\delta 7.23$ (d, J = 8.8 Hz, 4H), 7.08 (d, J = 8.9 Hz, 4H), 6.69 (d, J $=8.8 \mathrm{~Hz}, 4 \mathrm{H}), 6.42(\mathrm{~d}, \mathrm{~J}=8.8 \mathrm{~Hz}, 4 \mathrm{H}), 1.27(\mathrm{~s}, 18 \mathrm{H}), 1.22(\mathrm{~s}, 18 \mathrm{H}) .{ }^{13} \mathbf{C}$ NMR $(151 \mathrm{MHz}$, Chloroform- $d$ ) $\delta 154.53,153.70,149.67,147.59,147.02,146.64,126.54,126.05,115.82,115.44,111.93,107.70,34.43$, 34.34, 31.55, 31.53. HRMS (DART/AccuTOF) m/z: [M] ${ }^{+}$Calcd for $\mathrm{C}_{48} \mathrm{H}_{52} \mathrm{~N}_{2} \mathrm{O}_{4}$ 720.3927; Found 721.3933.
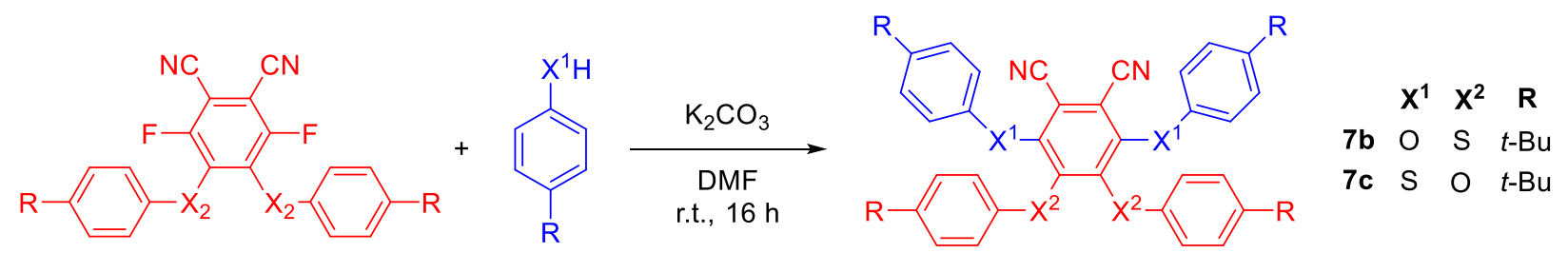

4,5-bis(4-(tert-butyl)phenoxy)-3,6-bis((4-(tert-butyl)phenyl)thio)phthalonitrile (7c) To an oven-dried round bottomed flask was added $\mathbf{3 b}(1 \mathrm{mmol}, 461 \mathrm{mg}, 1$ equiv. $)$ and a magnetic stirbar under an atmosphere of argon. Then dry, degassed DMF ( $5 \mathrm{~mL}$ ) was added, followed by 4-tert-butylbenzenethiol ( $2 \mathrm{mmol}, 0.345 \mathrm{~mL}, 2$ equiv.) and $\mathrm{K}_{2} \mathrm{CO}_{3}$ (4 mmol $553 \mathrm{mg}$, 4 equiv.). The reaction was stirred at room temperature overnight. Upon completion of the reaction, water and chloroform were added and the aqueous and organic partitions were separated. The aqueous layer was then extracted three times with chloroform. The combined organic fractions were then washed twice with $1 \mathrm{M}$ aqueous $\mathrm{NaOH}$, twice with $1 \mathrm{M}$ aqueous $\mathrm{HCl}$, thrice with water, and once with saturated aqueous $\mathrm{NaCl}$. The organic layer was then dried over anhydrous $\mathrm{Mg}_{2} \mathrm{SO}_{4}$, filtered, and concentrated under reduced pressure. The residue was purified by recrystallization from acetonitrile three times, giving a fine needle-like yellow solid (116 mg, 16\%). ${ }^{1} \mathbf{H}$ NMR (600 MHz, Chloroform- $d$ ) $\delta 7.25(\mathrm{~d}, \mathrm{~J}=8.4 \mathrm{~Hz}, 4 \mathrm{H}), 7.20$ (d, J = 8.5 Hz, 4H), 7.03 (d, J $=8.8 \mathrm{~Hz}, 4 \mathrm{H}), 6.15(\mathrm{~d}, \mathrm{~J}=8.8 \mathrm{~Hz}, 4 \mathrm{H}), 1.23(\mathrm{~d}, \mathrm{~J}=1.0 \mathrm{~Hz}, 36 \mathrm{H}) .{ }^{13} \mathbf{C}$ NMR $(151 \mathrm{MHz}$, Chloroform- $d) \delta$ 153.47, 152.43, 152.17, 146.17, 138.15, 132.45, 128.80, 126.46, 125.88, 118.89, 114.91, 113.91, 34.75, 34.33, 31.56, 31.31. HRMS (DART/AccuTOF) m/z: [M] ${ }^{+}$Calcd for $\mathrm{C}_{48} \mathrm{H}_{52} \mathrm{~N}_{2} \mathrm{O}_{2} \mathrm{~S}_{2} 752.347$; Found 752.3485 . 
3,6-bis(4-(tert-butyl)phenoxy)-4,5-bis((4-(tert-butyl)phenyl)thio)phthalonitrile (7b) To an oven-dried round bottomed flask was added 3a (1 mmol, $491 \mathrm{mg}, 1$ equiv.) and a magnetic stirbar under an atmosphere of argon. Then dry, degassed DMF (5 mL) was added, followed by 4-tert-butylphenol (2 mmol, $300 \mathrm{mg}, 2$ equiv.) and $\mathrm{K}_{2} \mathrm{CO}_{3}$ (4 mmol $553 \mathrm{mg}$, 4 equiv.). The reaction was stirred at room temperature overnight. Upon completion of the reaction, water and chloroform were added and the aqueous and organic partitions were separated. The aqueous layer was then extracted three times with chloroform. The combined organic fractions were then washed twice with $1 \mathrm{M}$ aqueous $\mathrm{NaOH}$, twice with $1 \mathrm{M}$ aqueous $\mathrm{HCl}$, thrice with water, and once with saturated aqueous $\mathrm{NaCl}$. The organic layer was then dried over anhydrous $\mathrm{Mg}_{2} \mathrm{SO}_{4}$, filtered, and concentrated under reduced pressure. The residue was purified by recrystallization from acetonitrile three times, giving a fine needle-like yellow solid (578 $\mathrm{mg}$, 78\%). ${ }^{1} \mathbf{H}$ NMR (600 MHz, Chloroform- $d$ ) $\delta 7.25$ (d, J = 8.1 Hz, 4H), 7.23 (d, J = 8.4 Hz, 4H), 7.06 (d, J $=8.4 \mathrm{~Hz}, 4 \mathrm{H}), 6.51(\mathrm{~d}, \mathrm{~J}=8.8 \mathrm{~Hz}, 4 \mathrm{H}), 1.30(\mathrm{~s}, 18 \mathrm{H}), 1.28(\mathrm{~s}, 18 \mathrm{H}) .{ }^{13} \mathbf{C}$ NMR $(151 \mathrm{MHz}$, Chloroform- $d)$ $\delta 154.81,154.51,151.65,146.55,143.76,131.17,129.92,126.62,126.30,115.18,111.95,110.84,34.78$, 34.44, 31.60, 31.37. HRMS (DART/AccuTOF) m/z: [M] ${ }^{+}$Calcd for $\mathrm{C}_{48} \mathrm{H}_{52} \mathrm{~N}_{2} \mathrm{O}_{2} \mathrm{~S}_{2}$ 752.347; Found 752.3456.

\section{Synthesis and Depolymerization of Crosslinked Network (8)}
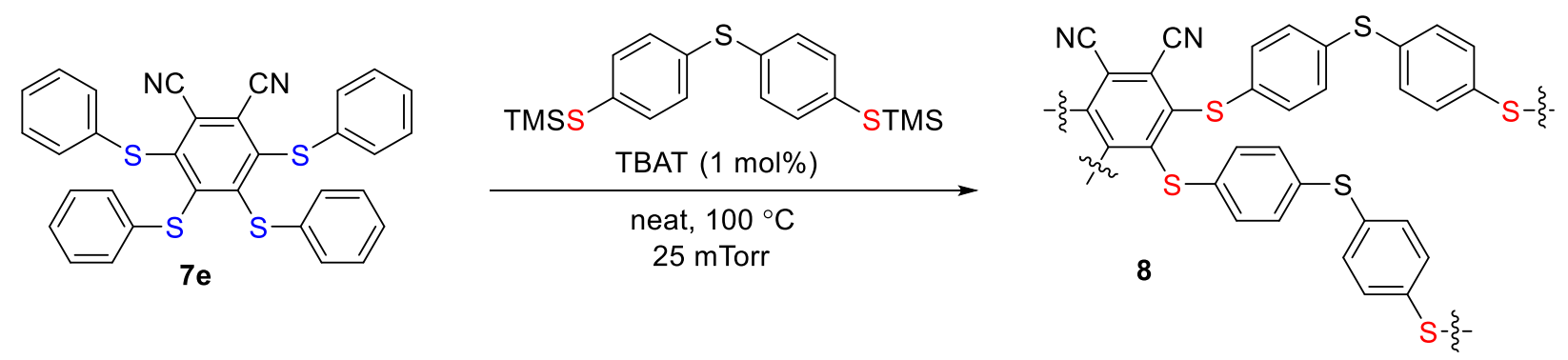

8 To a flame dried Schlenk flask fitted with a bulb-to-bulb distillation apparatus was added 3,4,5,6tetrakis(phenylthio)phthalonitrile (7e) $(0.5 \mathrm{mmol}, 280 \mathrm{mg}, 1$ equiv.), bis(4((trimethylsilyl)thio)phenyl)sulfane (2a) (0.1 mmol, $395 \mathrm{mg}, 2$ equiv.), and a magnetic stirbar. The reaction vessel was evacuated and purged with argon three times. Then the apparatus was heated with stirring until melting and complete homogeneity was reached (about $100{ }^{\circ} \mathrm{C}$ ). Under counter flow of argon, a small grain ( $<0.5 \mathrm{mg}$ ) of tetrabutylammonium difluorotriphenylsilicate (TBAT) was added, and the septum replaced. The melt was stirred for 5 minutes during which time an evolution of condensate was observed. Then the collection flask of the distillation apparatus was cooled to $-78{ }^{\circ} \mathrm{C}$, and the volatiles were collected under vacuum distillation ( $25 \mathrm{mTorr})$ for 30 minutes. During this time stirring ceased due to the viscosity of the mixture. Subsequently, the reaction flask was allowed to cool to room temperature and stand overnight. Then chloroform was added to the glassy solid, and the mixture was 
stirred for 1 hour, after which the insoluble portion was collected by vacuum filtration and rinsed extensively with chloroform. The solids were dried under vacuum at $75^{\circ} \mathrm{C}$ overnight, giving the product as an orange glassy solid (221 $\mathrm{mg}, 71 \%)$. The distillate was also recovered (115 mg), and contained a mixture of thiophenol $(0.27 \mathrm{mmol})$ and trimethyl(phenylthio)silane $(0.68 \mathrm{mmol})$, for a total recovery of $48 \%$, as determined by ${ }^{1} \mathrm{H}$ NMR.

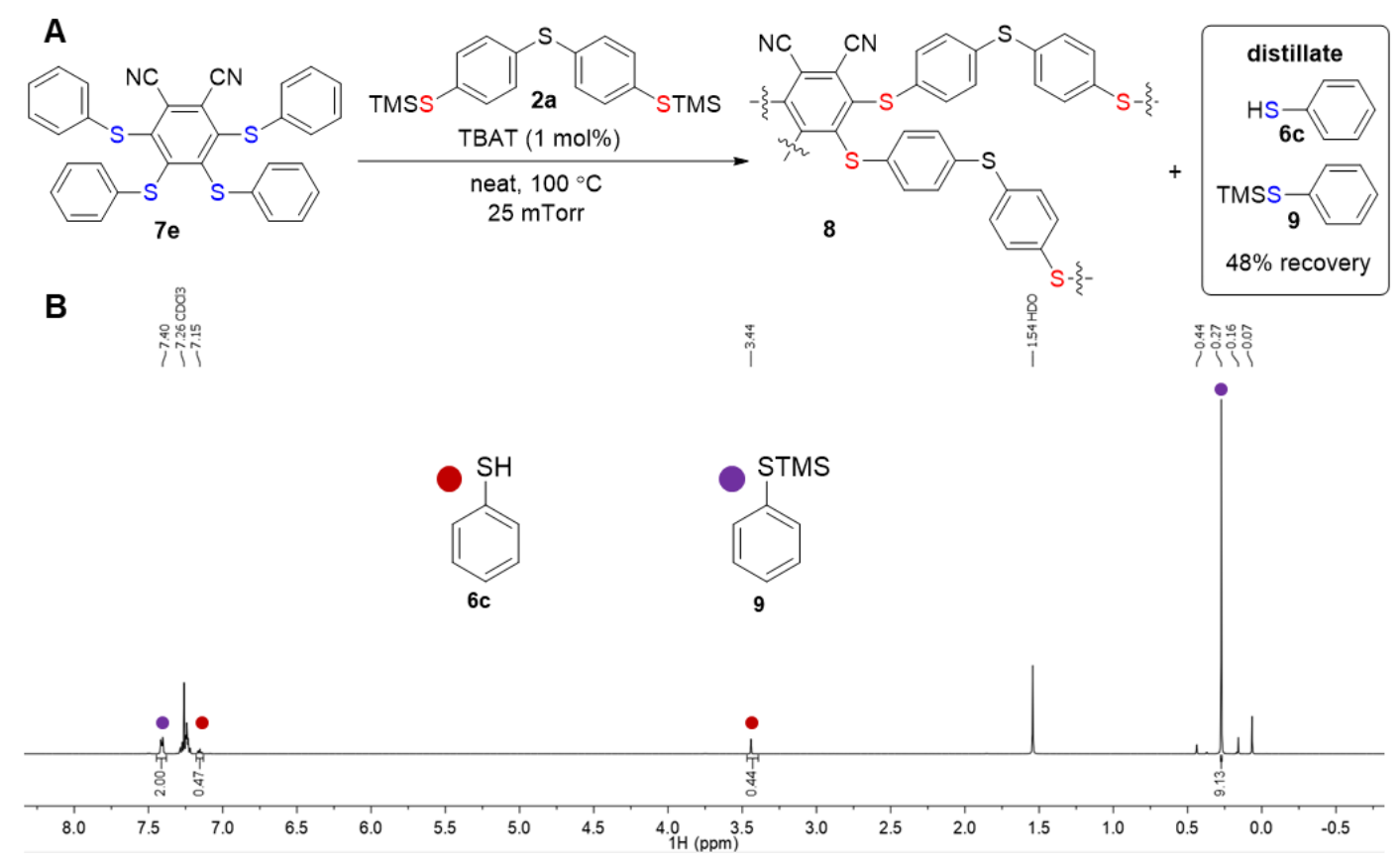

Figure S1 (A) The synthesis of crosslinked PAC 8 from phthalonitrile 7e and disilylthioether 2a, with side products thiophenol (6c) and TMS-protected thiophenol (9) removed via distillation. (B) ${ }^{1} \mathrm{H}$ NMR of crude distillate with integrations indicating a 1.00:0.47 molar ratio of 9:6c, from which the percent recovery was calculated.
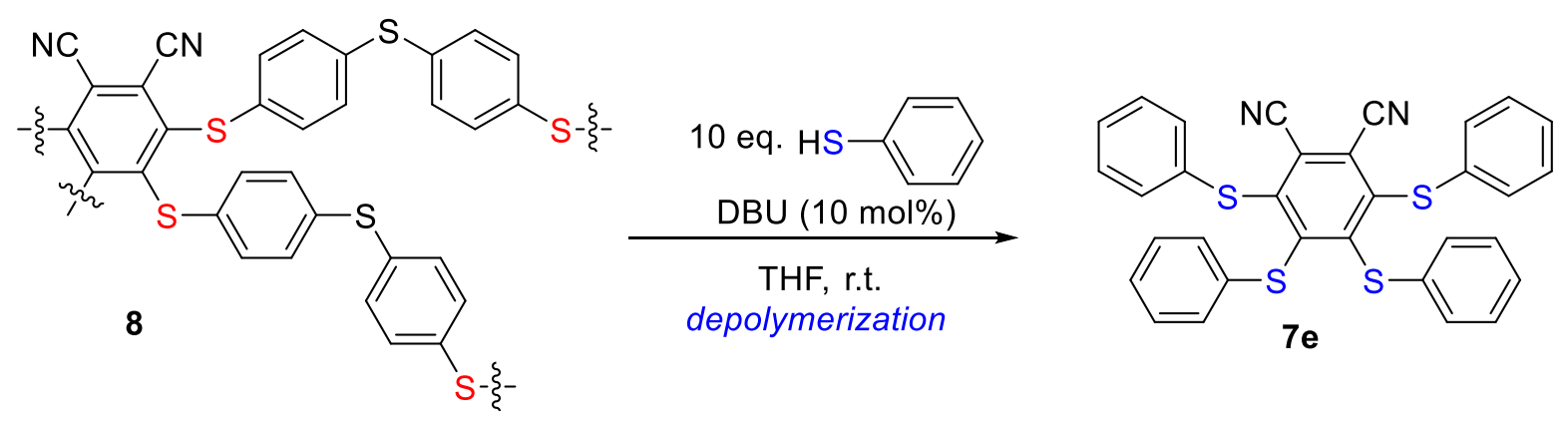

Depolymerization of 8 To a 1 dram vial was added 8 ( $\sim 0.50 \mathrm{mmol}, 31 \mathrm{mg}, 1$ equiv.), thiophenol (2 mmol, $0.2 \mathrm{~mL}, 40$ equiv.), and a stirbar. The vial was purged with argon. Then THF (1.0 mL, $0.5 \mathrm{M})$ and diazabicyclo[5.4.0]undec-7-ene (DBU) in a THF solution $(0.1 \mathrm{M})(0.005 \mathrm{mmol}, 0.5 \mu \mathrm{L}, 0.1$ equiv.) were 
added. The reaction was stirred at room temperature overnight, during which all material dissolved. The solution was added to 1:9 water/ $\mathrm{MeOH}$, and the precipitate was collected by filtration. The crude product was analyzed by NMR, and found to contain diphenyl disulfide, thiophenol, and 3,4,5,6tetrakis(phenylthio)phthalonitrile (7e), all determined by comparison with authentic samples.
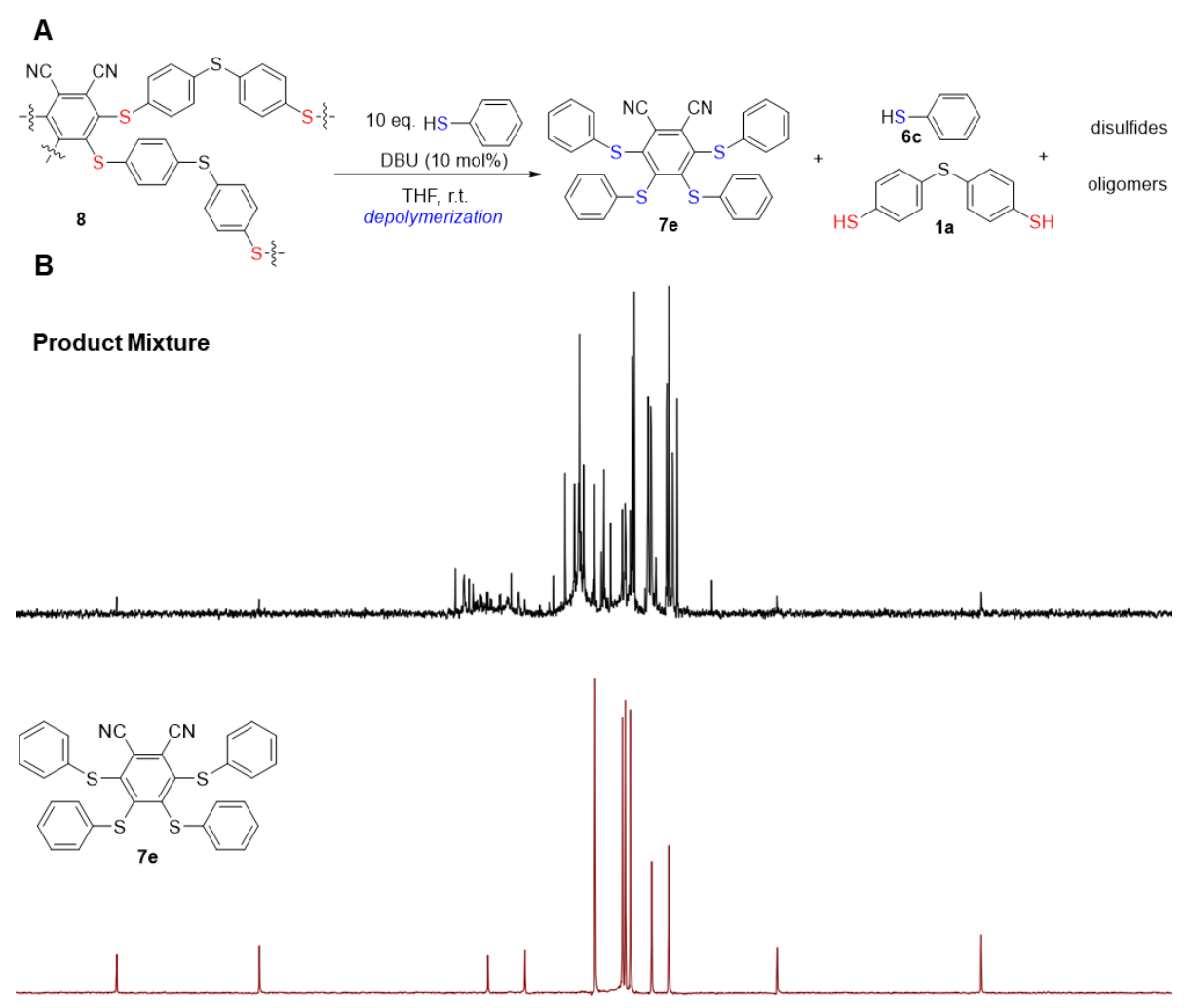

$\begin{array}{llllllllllllllllllllllllllllll}156 & 154 & 152 & 150 & 148 & 146 & 144 & 142 & 140 & 138 & 136 & 134 & 132 & 130 & 128 & 126 & 124 & 122 & 120 & 118 & 116 & 114 & 112 & 110 & 108 & 106\end{array}$

Figure S2 (A) Room temperature depolymerization of crosslinked PAC $\mathbf{8}$ by thiophenol (6c) yielding a crude mixture of phthalonitrile 7e, thiophenol (6c), 4,4'-thiobisbenzenethiol (1a), the disulfides thereof, and oligomers. (B) The presence of phthalonitrile $7 \mathbf{e}$ is confirmed by ${ }^{13} \mathrm{C}$ NMR by comparison with an authentic sample. 


\section{Additional Photophysical Characterization of PACs}
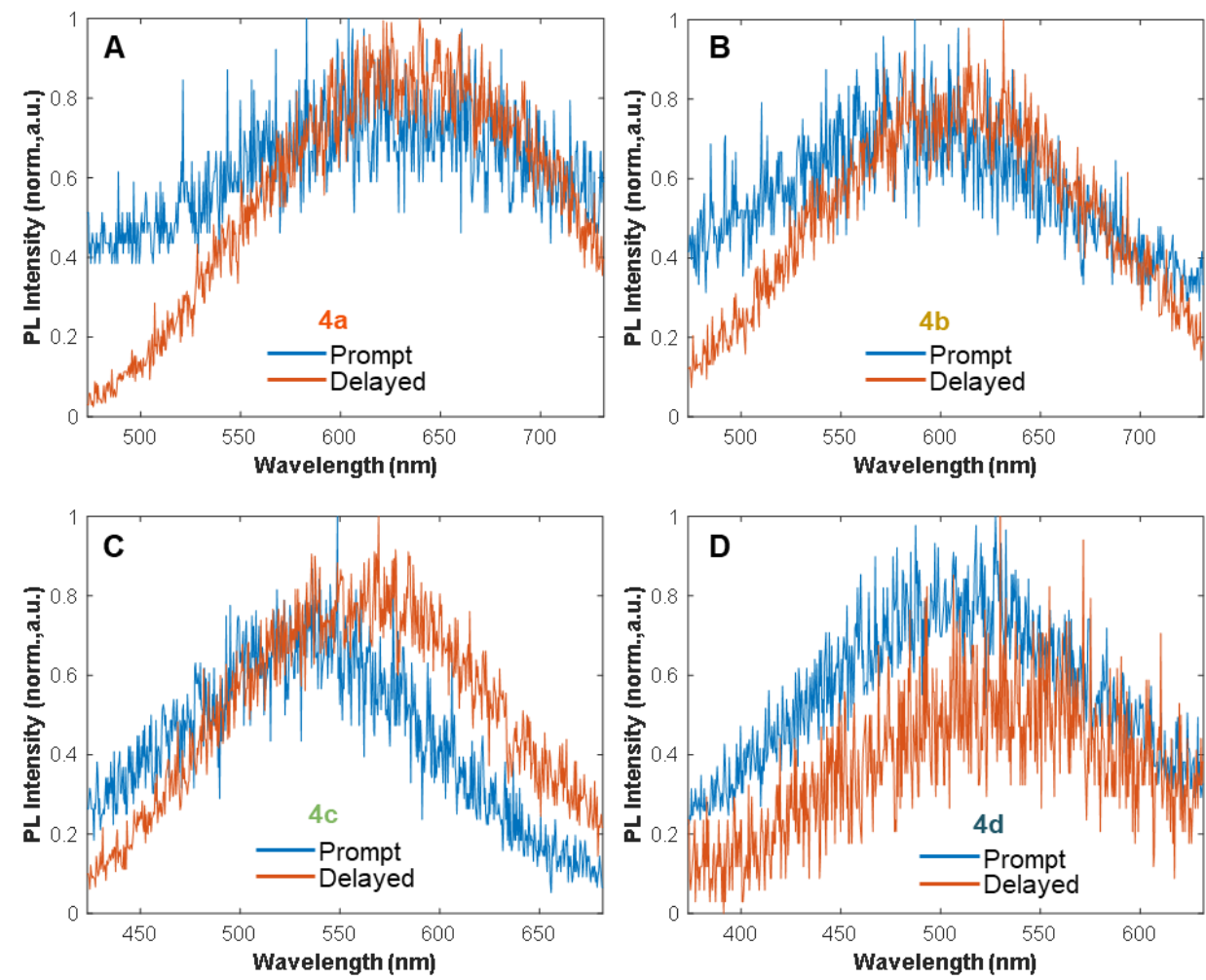

Figure S3 Photoluminescence spectra of both the prompt and delayed emission, extracted from the time resolved photoluminescent spectra, of thin films of (A) $\mathbf{4 a},(B) \mathbf{4 b},(\mathrm{C}) \mathbf{4 c}$, and (D) $\mathbf{4 d}$ in a nitrogen atmosphere. The significant overlap, especially in $\mathbf{4} \mathbf{a}_{s}$ is indicative of photoluminescence by a delayed fluorescence mechanism. The integration range for the prompt component was $0.27-0.3$ us and $0.35-2$ us for the delayed component.

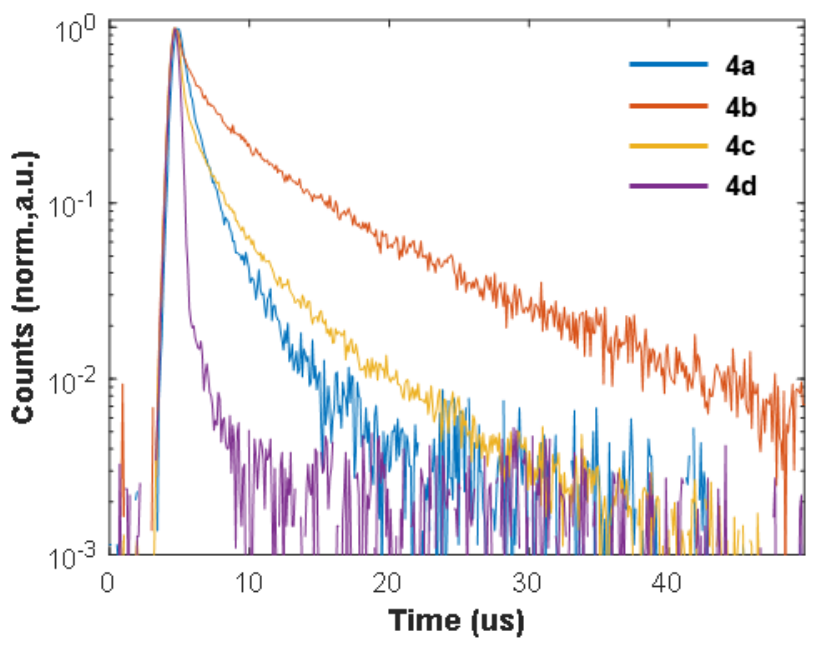

Figure S4 Time resolved photoluminescence spectra of $\mathbf{4 a - d}$ acquired across a longer $50 \mu$ s range (cf. Figure 4). Emission was collected from thin films under nitrogen atmosphere and integrated over a 
wavelength range of $320 \mathrm{~nm}$ with varying center wavelengths (600 $\mathrm{nm}$ for $\mathbf{4 a}$ and $\mathbf{4 b}$, respectively, 550 $\mathrm{nm}$ for $\mathbf{4 c}$, and $500 \mathrm{~nm}$ for $\mathbf{4 d}$ ).

Table S1 Summary of the photophysical properties of the PACs.

\begin{tabular}{cccccc}
\hline Sample & $\begin{array}{c}\boldsymbol{\lambda}_{\mathrm{ex}}{ }^{a} \\
(\mathrm{~nm})\end{array}$ & $\begin{array}{c}\boldsymbol{\Lambda}_{\mathrm{em}^{a}} \\
(\mathrm{~nm})\end{array}$ & $\begin{array}{c}\mathbf{P L Q Y}^{\mathbf{b}} \\
(\%)\end{array}$ & $\begin{array}{c}\text { Prompt Lifetime }^{c} \\
(\mathrm{~ns})\end{array}$ & $\begin{array}{c}\text { Delayed Lifetime }^{\boldsymbol{d}} \\
(\mu \mathrm{s})\end{array}$ \\
\hline $\mathbf{4 a}$ & 364 & 604 & 1.5 & 38 & 0.9 \\
$\mathbf{4 b}$ & 368 & 571 & 2.0 & 18 & 2.2 \\
$\mathbf{4 c}$ & 354 & 519 & 3.4 & 16 & 1.5 \\
$\mathbf{4 d}$ & 336 & 484 & 4.7 & 15 & $0.4-2$ \\
$\mathbf{4 f}$ & 373 & 592 & 0.8 & n.d. & n.d. \\
$\mathbf{4 g}$ & 369 & 575 & 2.9 & n.d. & n.d.
\end{tabular}

${ }^{a}$ Thin film, ambient atmosphere. ${ }^{b}$ Calc'd by integrating sphere (powder, ambient atmosphere). ${ }^{c}$ Fitted to $0-2 \mu$ s measurements with fitting range: $27-30 \mathrm{~ns}$. Fitted to $0-2 \mu \mathrm{s}$ measurements with fitting range: $0.35-2 \mu \mathrm{s}$.

\section{Studies of PAC Chemical Depolymerization}

Depolymerization with 4-tertbutylthiophenol To an $8 \mathrm{~mL}$ threaded vial was added PAC 4 (0.05 mmol, 1 equiv.), 4-tert-butylthiophenol ( $0.5 \mathrm{mmol}, 10$ equiv.), and a stirbar. Then deuterated tetrahydrofuran $\left(\mathrm{d}_{8}{ }^{-}\right.$ THF) (0.5 mL) containing 1,3,5-trimethoxybenzene (TMB) (0.005 M) was added and a ${ }^{1} \mathrm{H}$ NMR spectrum was taken. After retuning the solution to the threaded vial, a screw cap and septa were applied to the vial, and the atmosphere was purged for 10 minutes under a slow stream of argon.

Diazabicyclo(5.4.0)undec-7-ene (DBU) (0.005 mmol, 0.1 equiv.) was added, the purge needle was removed, the vial was sealed with vinyl tape, and the solution was stirred at room temperature overnight. Immediate color change was observed upon addition of DBU. Upon completion, the crude mixture was analyzed by ${ }^{1} \mathrm{H}$ NMR spectroscopy, and then concentrated under vacuo. The viscous orange liquid was purified by silica gel column chromatography using 5\% ethyl acetate in hexanes as the eluant, giving small-molecule chromophores $\mathbf{7}$ with yields and estimated purities detailed in Table $\mathbf{S 2}$.

Table S2 NMR and isolated yields of 7 from the chemical depolymerization of 4 .

\begin{tabular}{ccccc}
\hline Polymer & Product & Yield (NMR) $^{\mathbf{a}}$ & Yield (Isolated) & Purity $^{\boldsymbol{b}}$ \\
\hline $\mathbf{4 a}$ & $\mathbf{7 a}$ & quant. & $42 \%$ & $>95 \%$ \\
$\mathbf{4 b}$ & $\mathbf{7 a}$ & $89 \%$ & $29 \%$ & $>95 \%$ \\
4c & $\mathbf{7 c}$ & $79 \%$ & $96 \%$ & $>80 \%$ \\
4d & $\mathbf{7 c}$ & $38 \%$ & $23 \%$ & $>80 \%$ \\
a Determined by comparison with internal standard. ${ }^{b}$ Estimated by integration of oligomeric contaminants in ${ }^{1} \mathrm{H}$ NMR spectra.
\end{tabular}


A
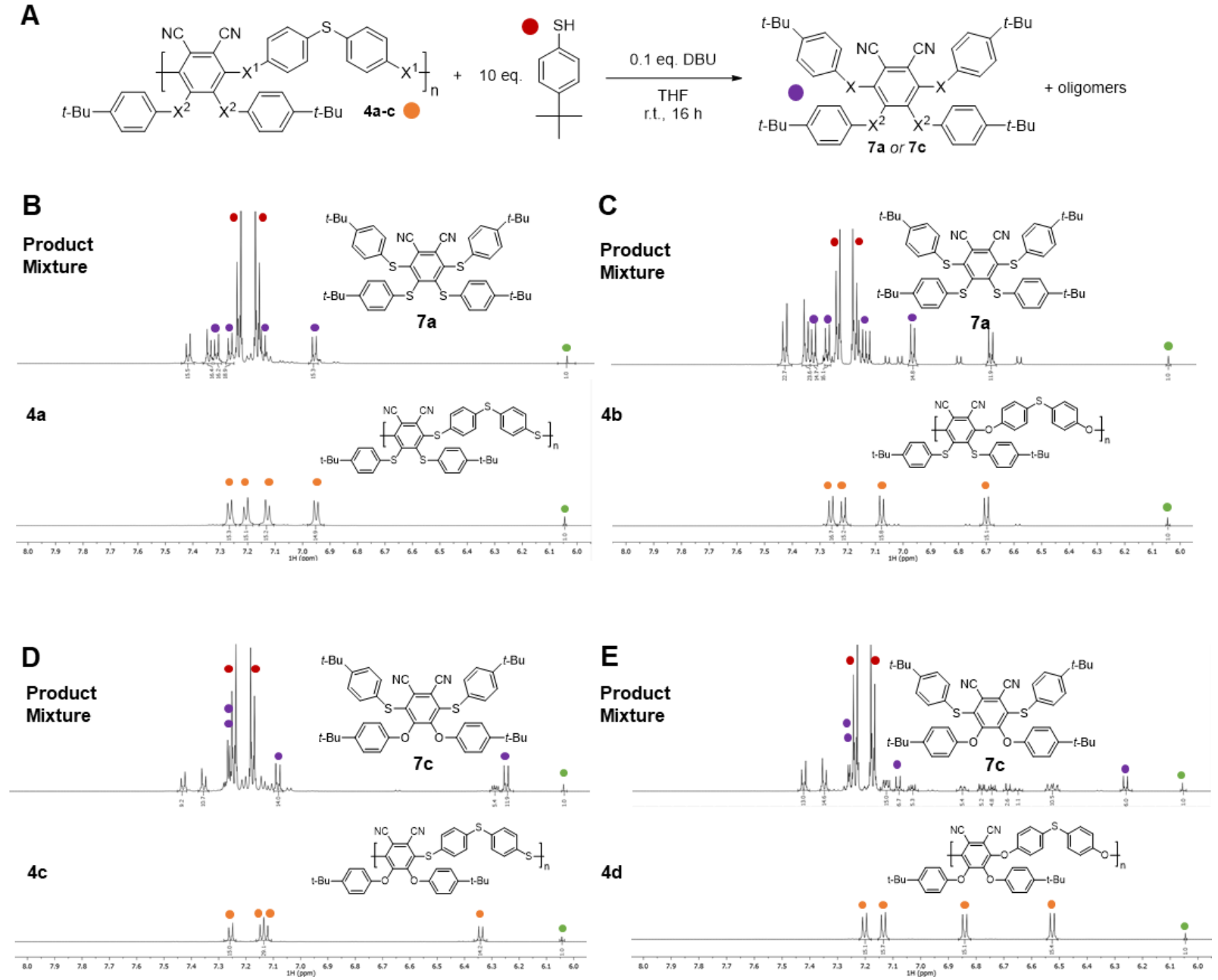

Figure S5 Chemical decomposition of PACs with thiolate nucleophile. (A) Reaction scheme. ${ }^{1} \mathrm{H}$ NMR spectra ( $\left.d_{8}-T H F\right)$ of the PAC starting material and the product mixture for (B) $\mathbf{4 a},(C) \mathbf{4 b},(\mathrm{D}) \mathbf{4 c}$, and (E) 4d. Major products are identified, including small molecules which are identified via comparison with ${ }^{1} \mathrm{H}$ NMR spectra of authentic samples. The resonances marked by the green dot were attributed to the internal standard 1,3,5-trimethoxybenzene (TMB).

Depolymerization with 4-tertbutylphenol To an $8 \mathrm{~mL}$ threaded vial was added PAC 4 (0.05 mmol, 1 equiv.), 4-tert-butylphenol (0.5 mmol, 10 equiv.), and a stirbar. A screw cap and septa were applied to the vial, and the atmosphere was purged under a flow of argon for 10 minutes. Then a solution of diazabicyclo(5.4.0)undec-7-ene (DBU) $(0.005 \mathrm{mmol}, 0.1$ equiv.) in THF $(0.5 \mathrm{~mL})$ was added. The purge needle was removed, the vial was sealed with vinyl tape, and the solution was stirred at room temperature overnight. Upon completion, $100 \mu \mathrm{L}$ of the solution was removed and placed in another vial, and then concentrated under a flow of nitrogen. The crude mixture was then dissolved in $1 \mathrm{~mL} \mathrm{CDCl}_{3}$ and analyzed by ${ }^{1} \mathrm{H}$ NMR spectroscopy. 

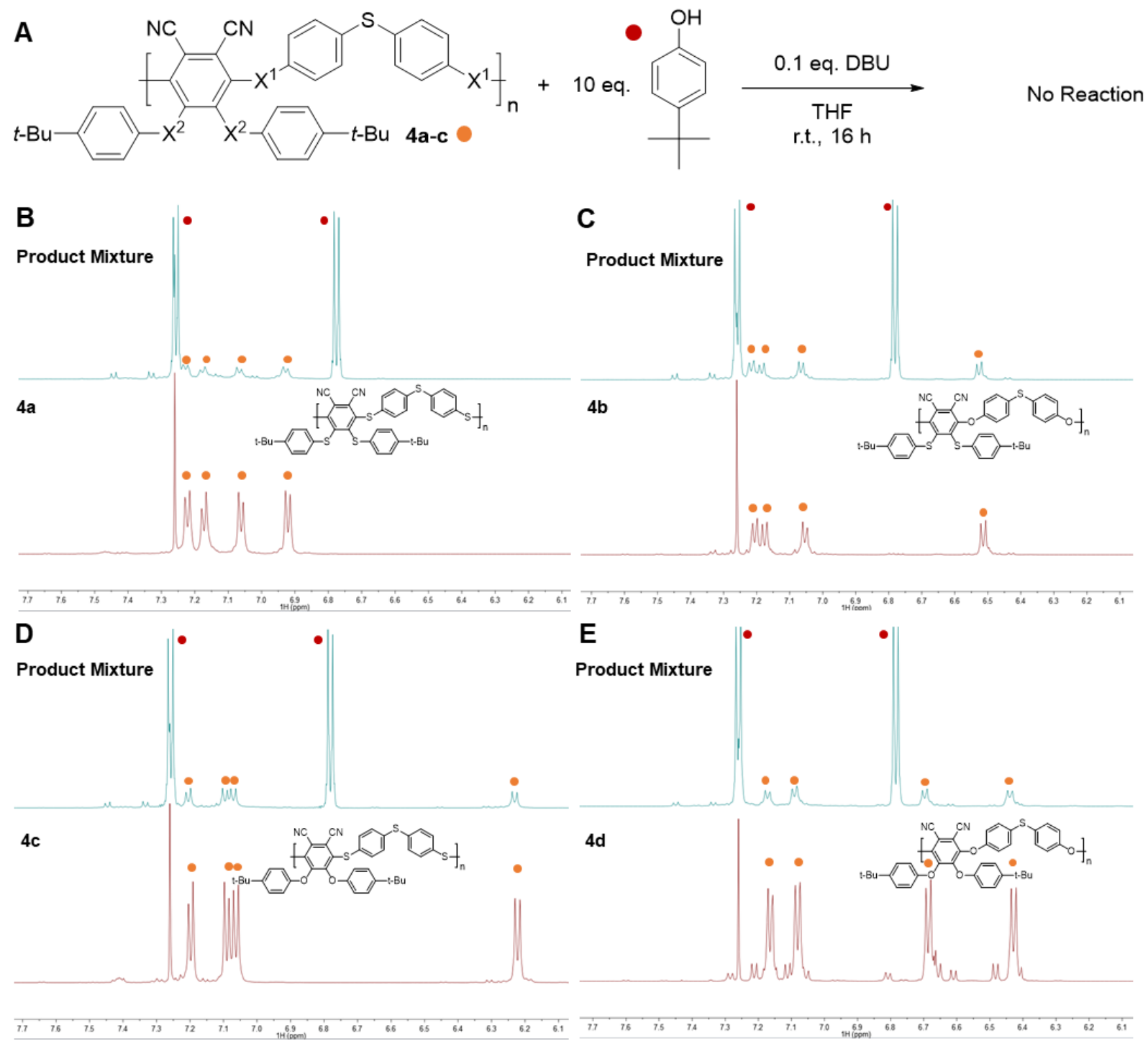

Figure S6 Chemical stability of PACs when exposed to phenolate nucleophiles. (A) Reaction scheme. ${ }^{1} \mathrm{H}$ NMR spectra $\left(\mathrm{CDCl}_{3}\right)$ of the PAC starting material and the product mixture for (B) $4 \mathbf{a}$, (C) $4 \mathbf{b}$, (D) $4 \mathbf{c}$, and (E) $4 \mathbf{d}$.

Attempted Polymerization of $7 \mathbf{a}$ and $7 \mathbf{c}$ To an $8 \mathrm{~mL}$ threaded vial was added $7 \mathbf{a}$ or $7 \mathbf{c}(0.2 \mathrm{mmol}, 1$ equiv.), 2a or $\mathbf{2 c}(0.2 \mathrm{mmol}, 1$ equiv.), and a magnetic stirbar. A screw cap with a septum was applied the vial, and the atmosphere was purged with argon for 10 minutes. Then THF $(0.4 \mathrm{~mL})$ and tetrabutylammonium difluorotriphenylsilicate solution (TBAT, $0.1 \mathrm{M}$ THF) (0.004 mmol, $0.40 \mu \mathrm{L}, 0.02$ equiv.) were added, and the vial was sealed with vinyl tape. The solution was stirred overnight at room temperature. Upon completion, $20 \mu \mathrm{L}$ of the solution was removed and placed in another vial, and then concentrated under high vacuum. The crude mixture was then dissolved in $1 \mathrm{~mL} \mathrm{CDCl}_{3}$ and analyzed by ${ }^{1} \mathrm{H}$ NMR spectroscopy. The remaining solution was added dropwise to rapidly stirred methanol, and the 
precipitate was collected by vacuum filtration. The solid was dried under high vacuum to give an a colored solid.

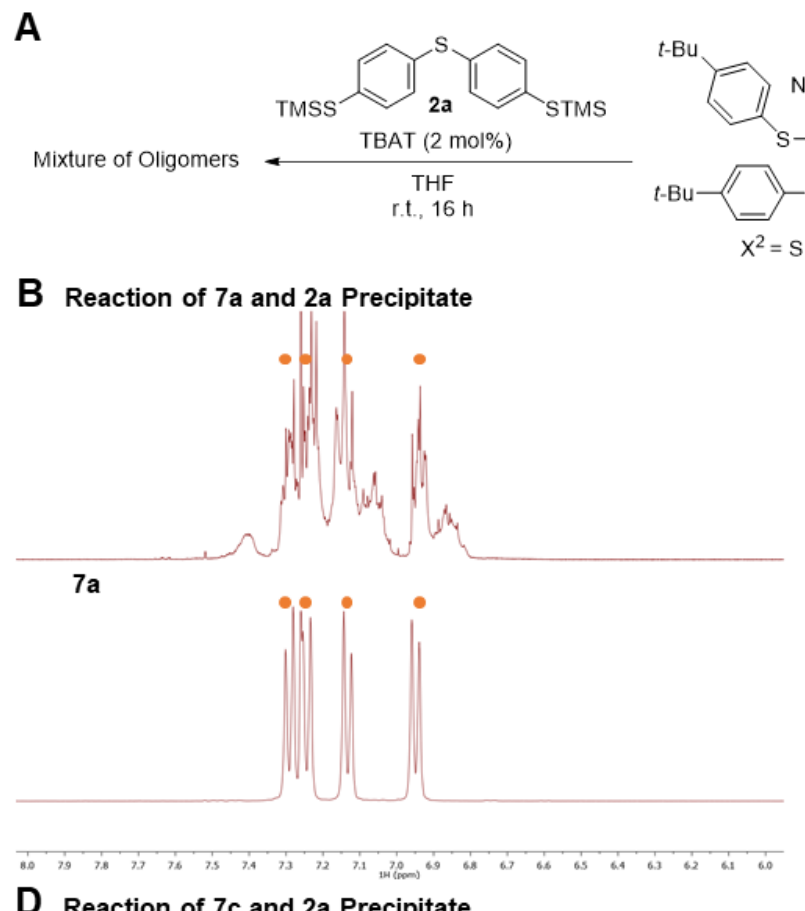

D Reaction of $7 c$ and $2 a$ Precipitate
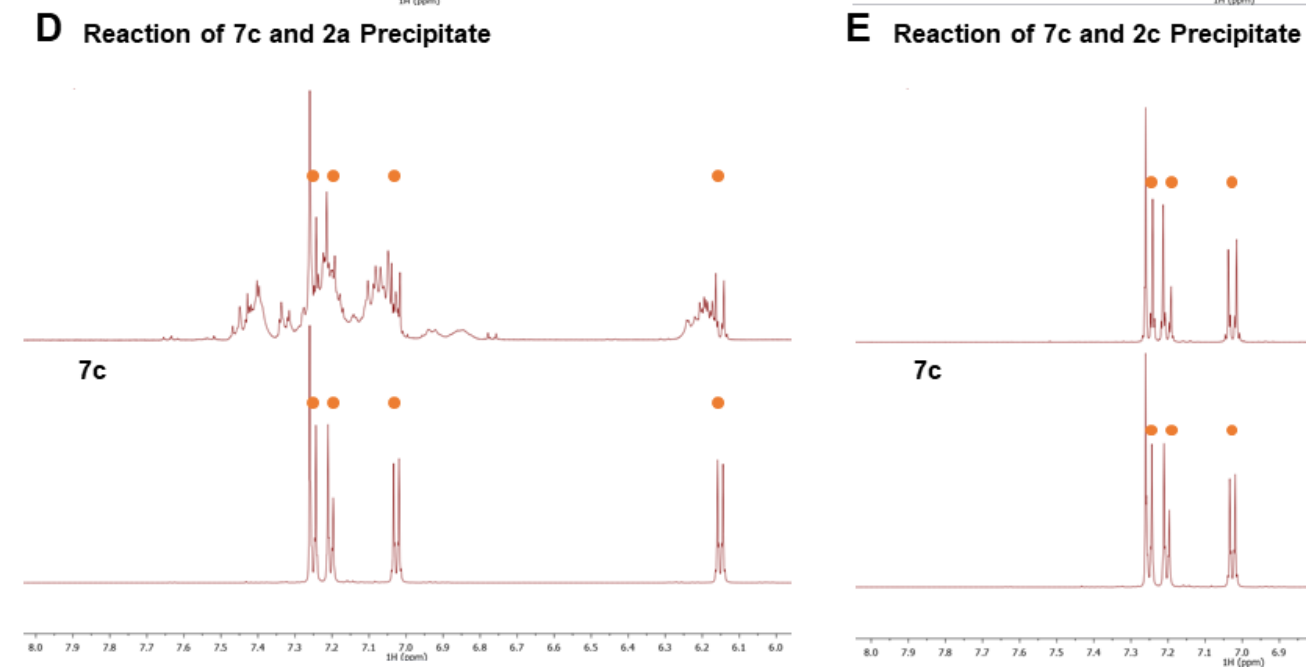

C Reaction of $7 a$ and $2 c$ Precipitate

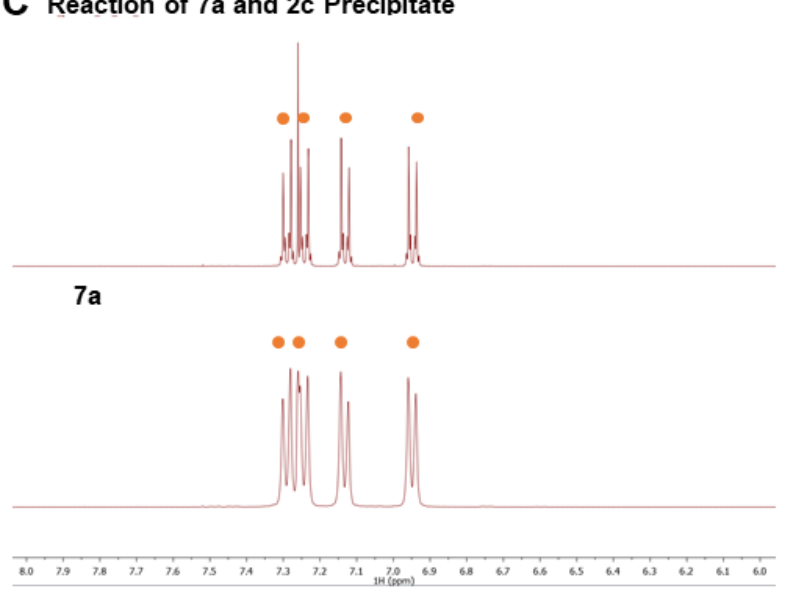

E Reaction of $7 \mathrm{c}$ and $2 \mathrm{c}$ Precipitate

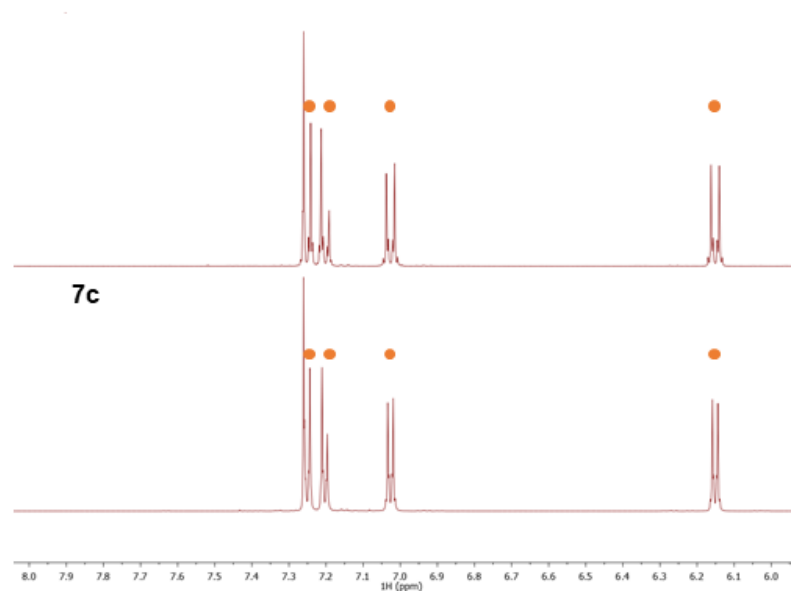

Figure S7 Attempted polymerization using electrophiles 7a and 7c. (A) Reaction scheme. ${ }^{1} \mathrm{H}$ NMR spectra $\left(\mathrm{CDCl}_{3}\right)$ of the small molecule starting materials and precipitated reaction mixture for the reaction of (B) 7a and 2a, (C) 7a and 2c, (D) 7c and 2a, and (E) 7c and 2c.

Attempted Degradation of PAC 4a in Aqueous Sodium Hydroxide To an $8 \mathrm{~mL}$ threaded vial was added $4 \mathbf{a}$ ( $0.5 \mathrm{mmol}, 35.1 \mathrm{mg}, 1$ equiv.), sodium hydroxide ( $1 \mathrm{mmol}, 40 \mathrm{mg}, 20$ equiv.), and a magnetic stirbar. A screw cap with a septum was applied the vial, and the atmosphere was purged with argon for 10 minutes. Then $1 \mathrm{~mL}$ deionized water was added, and the vial was sealed with vinyl tape. The solution was stirred for 16 hours at room temperature. Upon completion, suspension was added dropwise to rapidly 
stirred methanol, and the precipitate was collected by vacuum filtration. The solid rinsed with methanol and was dried under high vacuum to give an orange solid (33.6 mg, 96\%).

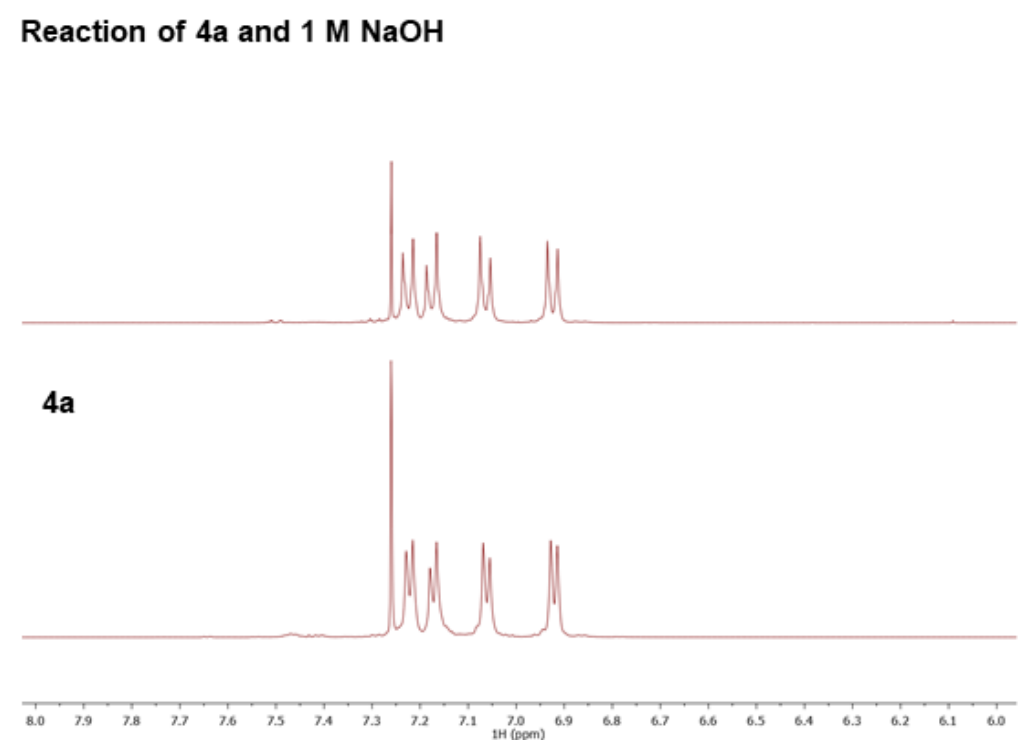

Figure S8 ${ }^{1} \mathrm{H}$ NMR spectra of isolated PAC 4a before and after immersion in $1 \mathrm{M}$ aqueous sodium hydroxide, showing no evidence for chemical degradation under these conditions.

\section{DSC and TGA Characterization}
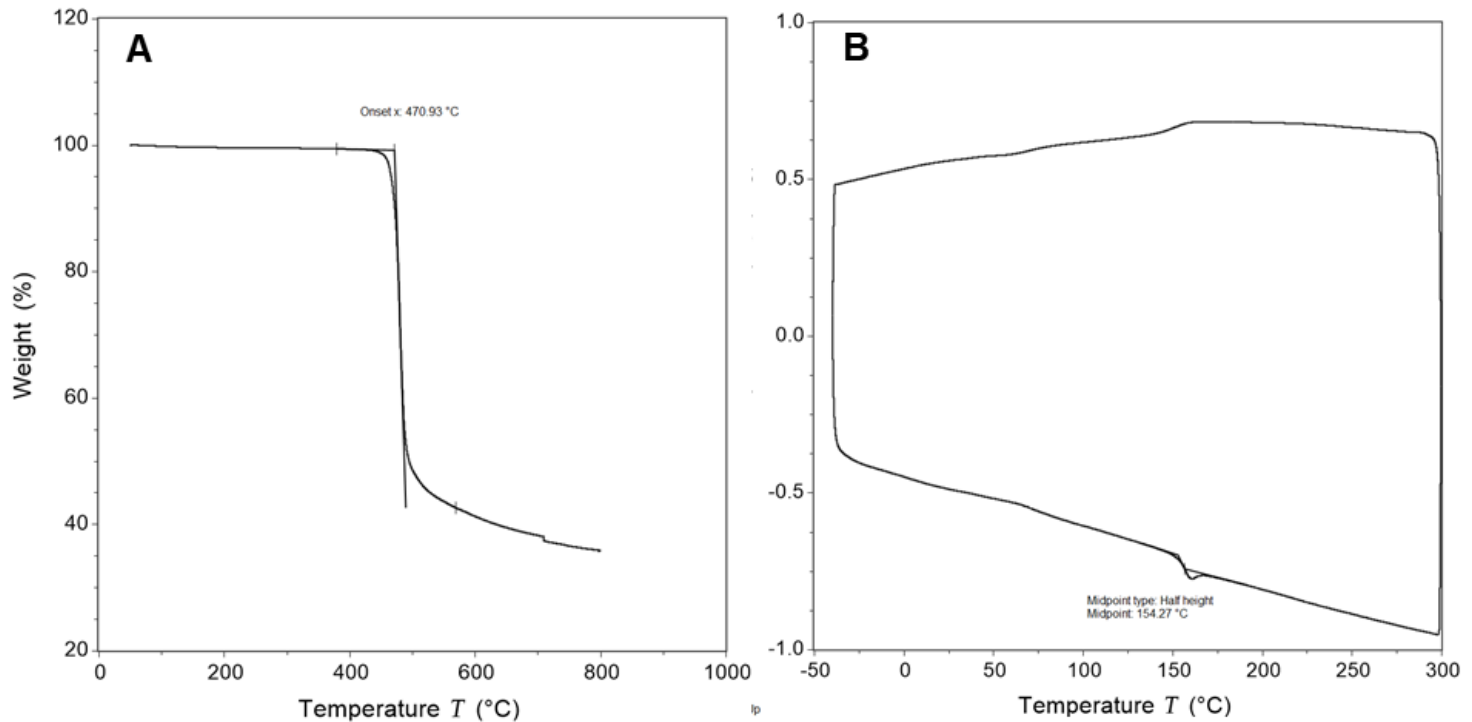

Figure S9 Thermal characterization of 4d. (A) TGA graph acquired under a nitrogen atmosphere and at a rate of $20^{\circ} \mathrm{C} / \mathrm{min}$. (B) DSC graph acquired under a nitrogen atmosphere at a rate of $10{ }^{\circ} \mathrm{C} / \mathrm{min}$, and only the second thermal cycle is shown. 

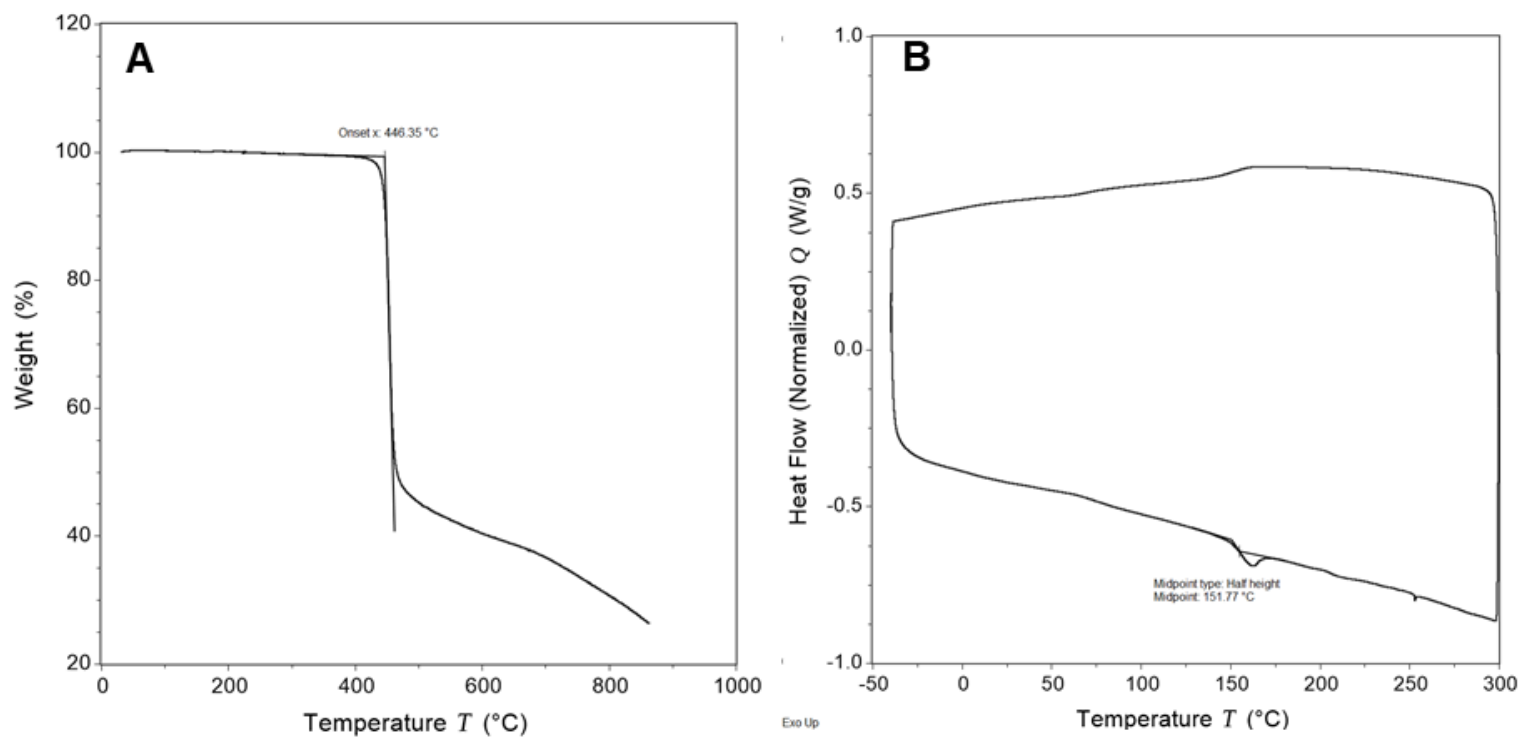

Figure S10 Thermal characterization of $\mathbf{4 b}$. (A) TGA graph acquired under a nitrogen atmosphere and at a rate of $20^{\circ} \mathrm{C} / \mathrm{min}$. (B) DSC graph acquired under a nitrogen atmosphere at a rate of $10{ }^{\circ} \mathrm{C} / \mathrm{min}$, and only the second thermal cycle is shown.
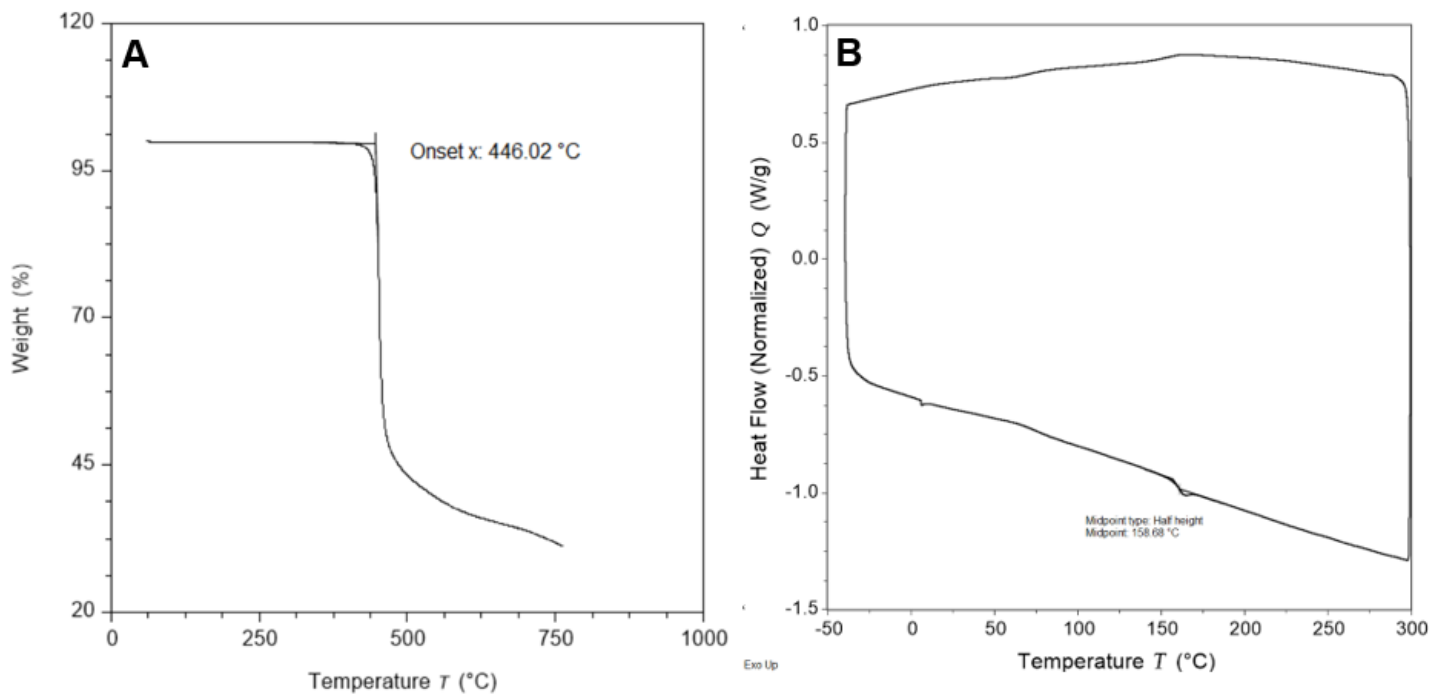

Figure S11 Thermal characterization of 4c. (A) TGA graph acquired under a nitrogen atmosphere and at a rate of $20^{\circ} \mathrm{C} / \mathrm{min}$. (B) DSC graph acquired under a nitrogen atmosphere at a rate of $10{ }^{\circ} \mathrm{C} / \mathrm{min}$, and only the second thermal cycle is shown. 

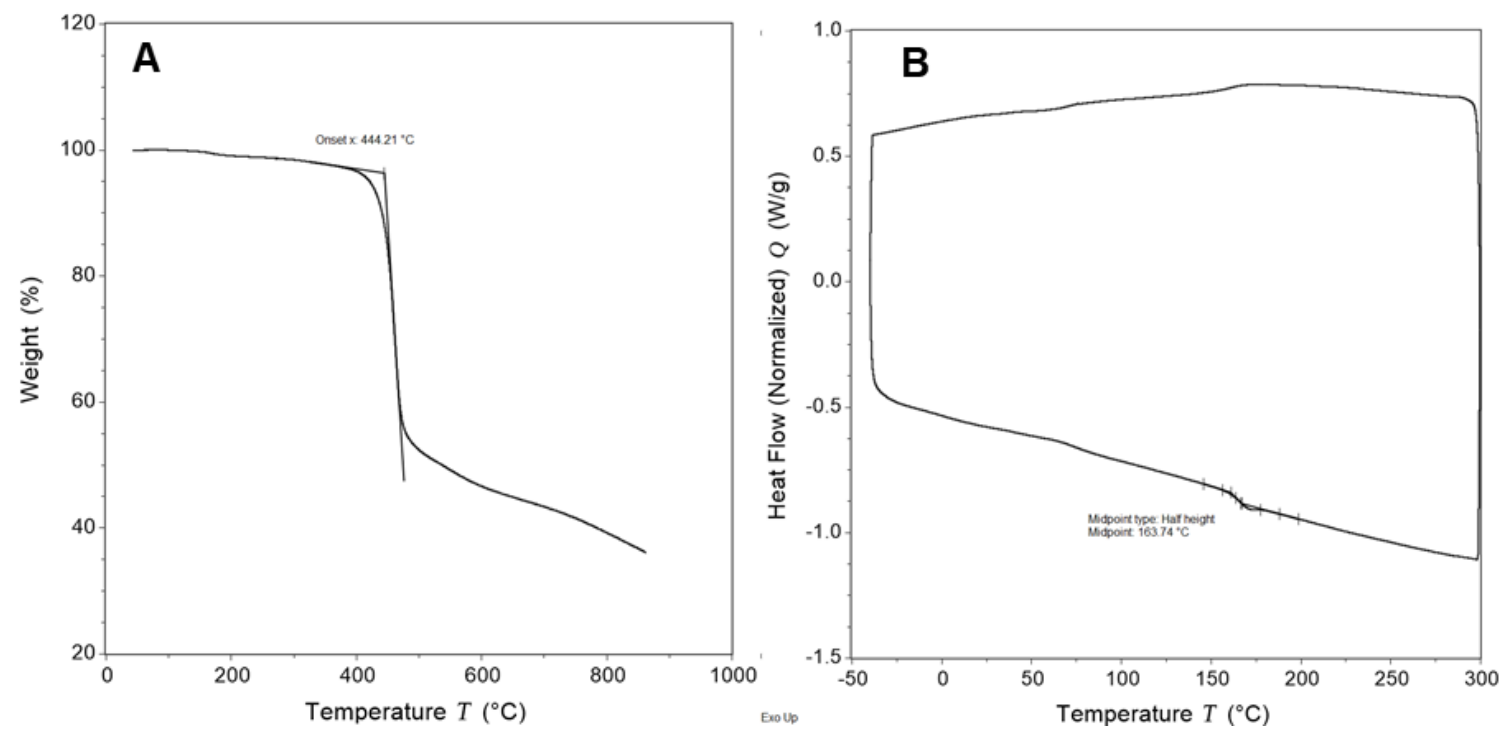

Figure S12 Thermal characterization of 4a. (A) TGA graph acquired under a nitrogen atmosphere and at a rate of $20^{\circ} \mathrm{C} / \mathrm{min}$. (B) DSC graph acquired under a nitrogen atmosphere at a rate of $10{ }^{\circ} \mathrm{C} / \mathrm{min}$, and only the second thermal cycle is shown.
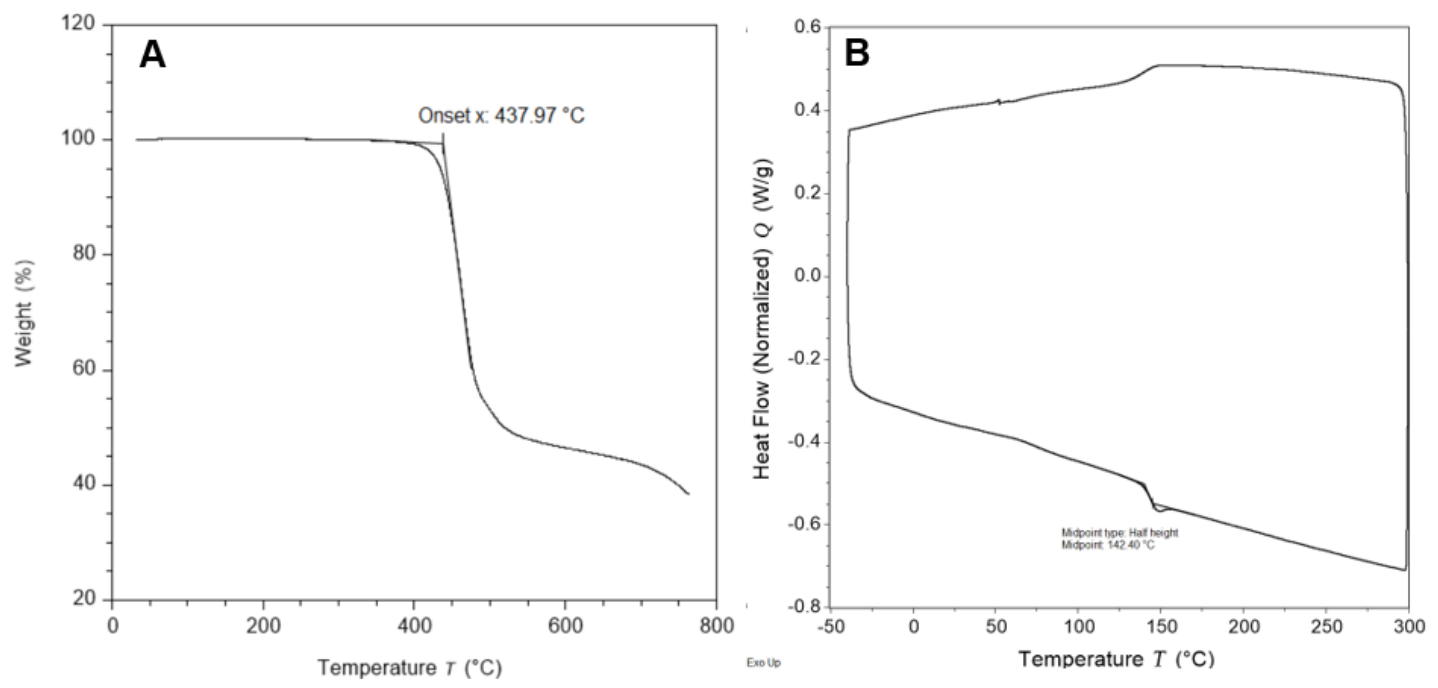

Figure S13 Thermal characterization of 4e. (A) TGA graph acquired under a nitrogen atmosphere and at a rate of $20{ }^{\circ} \mathrm{C} / \mathrm{min}$. (B) DSC graph acquired under a nitrogen atmosphere at a rate of $10{ }^{\circ} \mathrm{C} / \mathrm{min}$, and only the second thermal cycle is shown. 

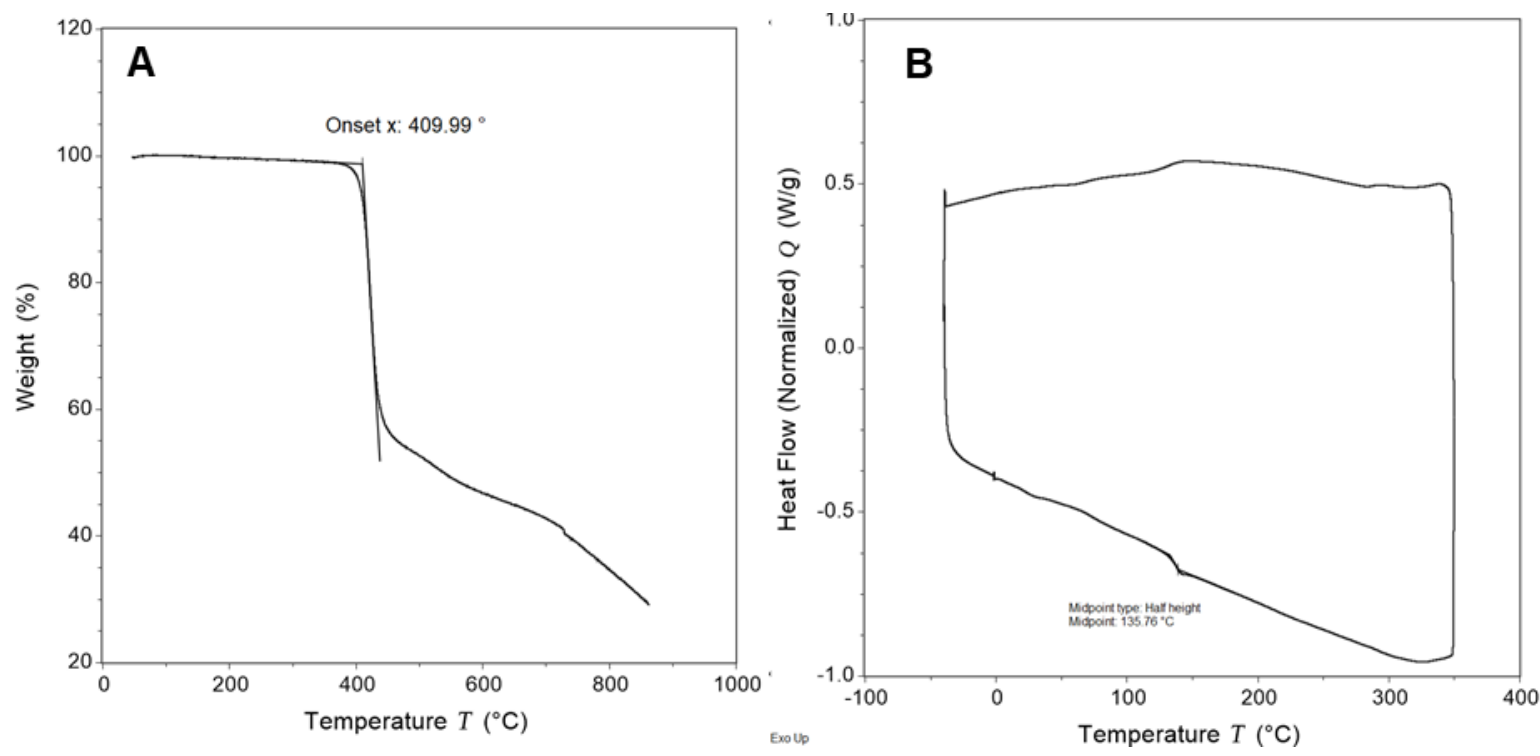

Figure S14 Thermal characterization of $\mathbf{4 f}$. (A) TGA graph acquired under a nitrogen atmosphere and at a rate of $20^{\circ} \mathrm{C} / \mathrm{min}$. (B) DSC graph acquired under a nitrogen atmosphere at a rate of $10{ }^{\circ} \mathrm{C} / \mathrm{min}$, and only the second thermal cycle is shown.
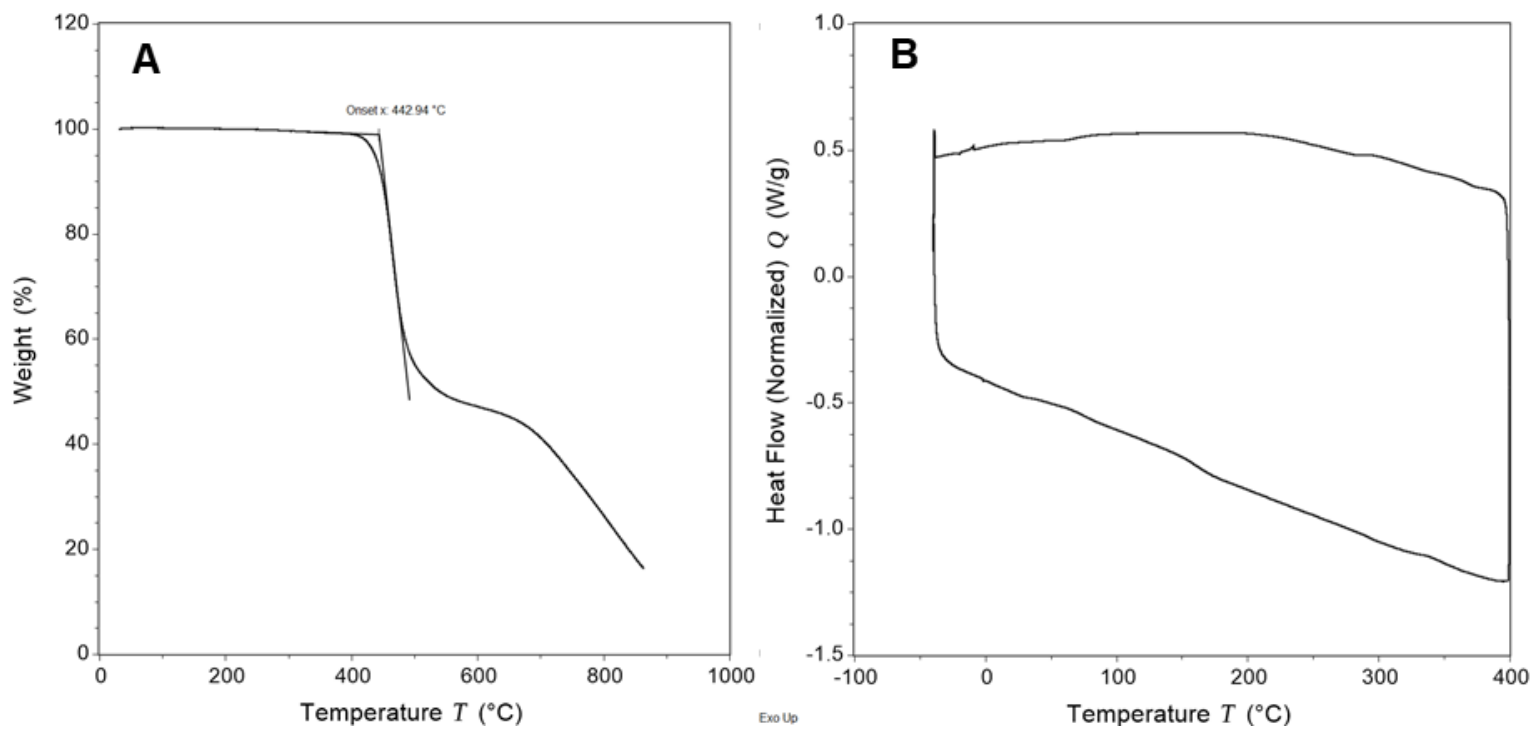

Figure S15 Thermal characterization of 4g. (A) TGA graph acquired under a nitrogen atmosphere and at a rate of $20^{\circ} \mathrm{C} / \mathrm{min}$. (B) DSC graph acquired under a nitrogen atmosphere at a rate of $10{ }^{\circ} \mathrm{C} / \mathrm{min}$, and only the second thermal cycle is shown. 


\section{UV/Vis Characterization}

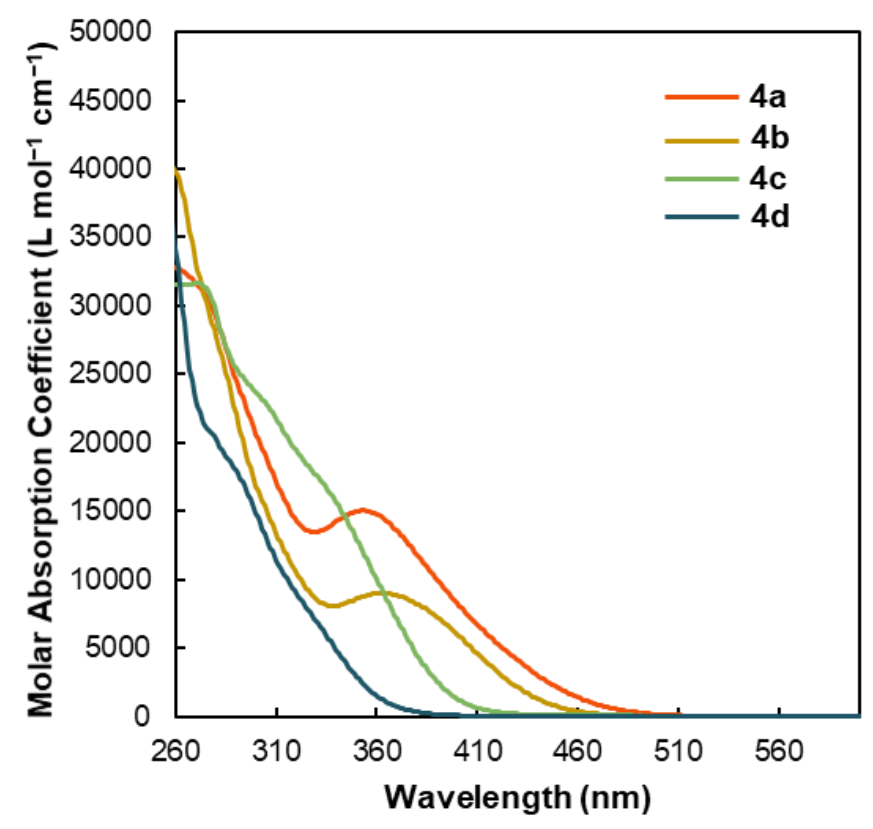

Figure S16 UV-vis spectra of 4a-d in chloroform.

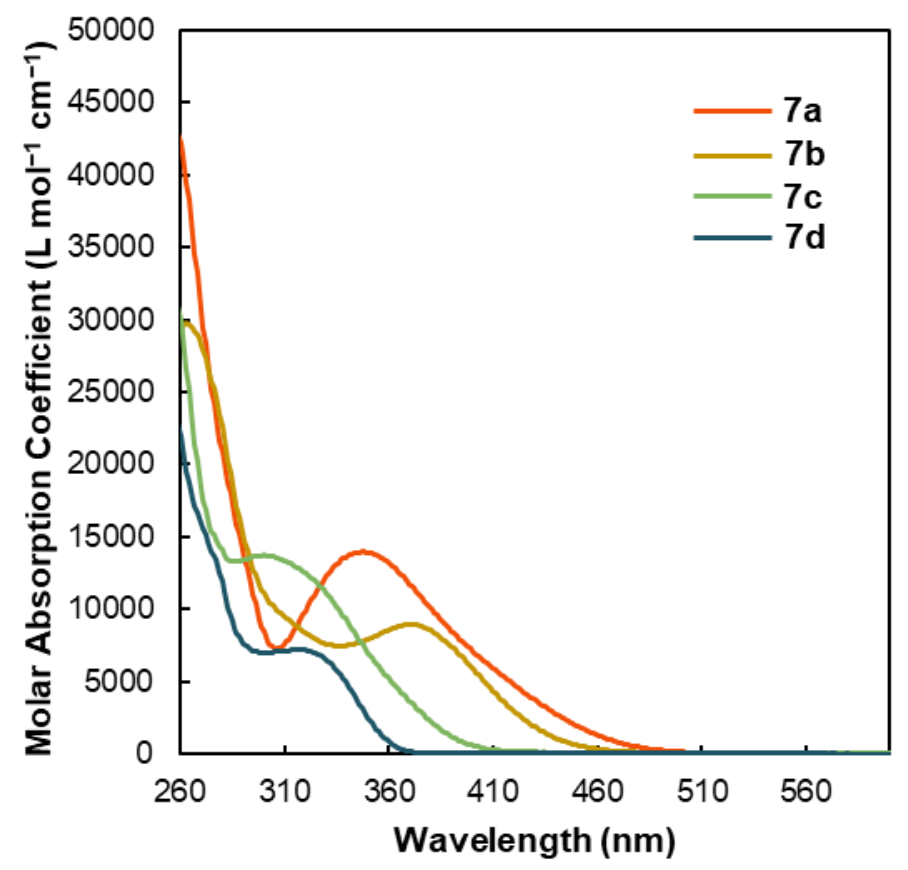

Figure S17 UV-vis spectra of 7a-d in chloroform. 


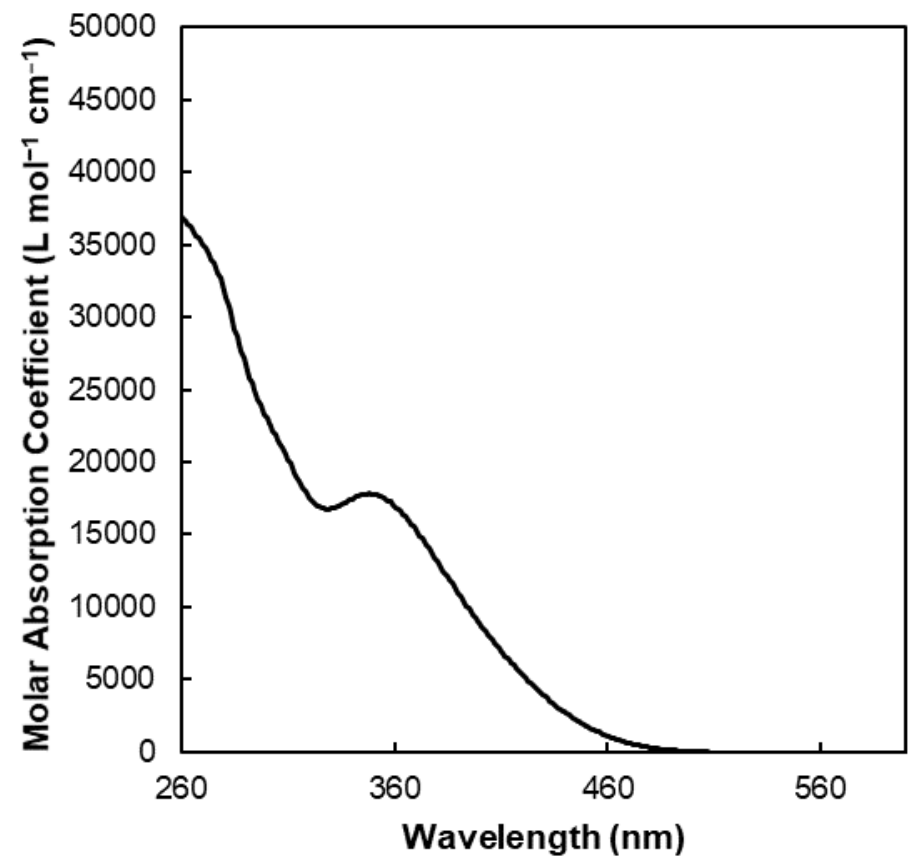

Figure S18 UV-vis spectrum of $4 \mathbf{e}$ in chloroform.

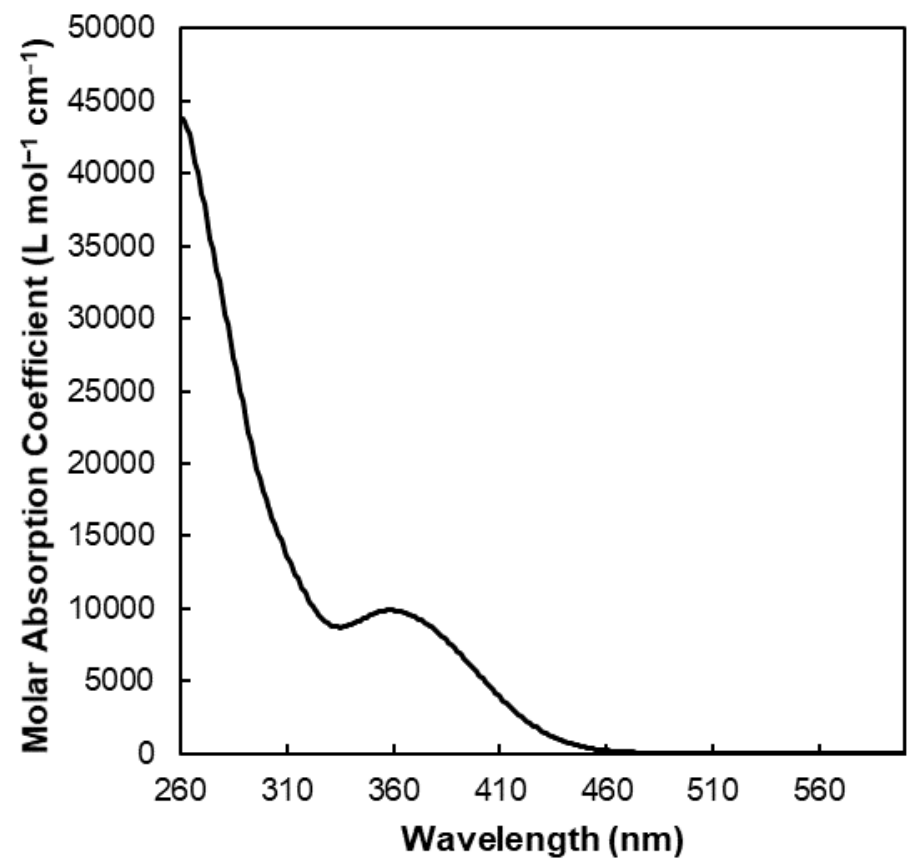

Figure S19 UV-vis spectrum of $\mathbf{4 g}$ in chloroform. 


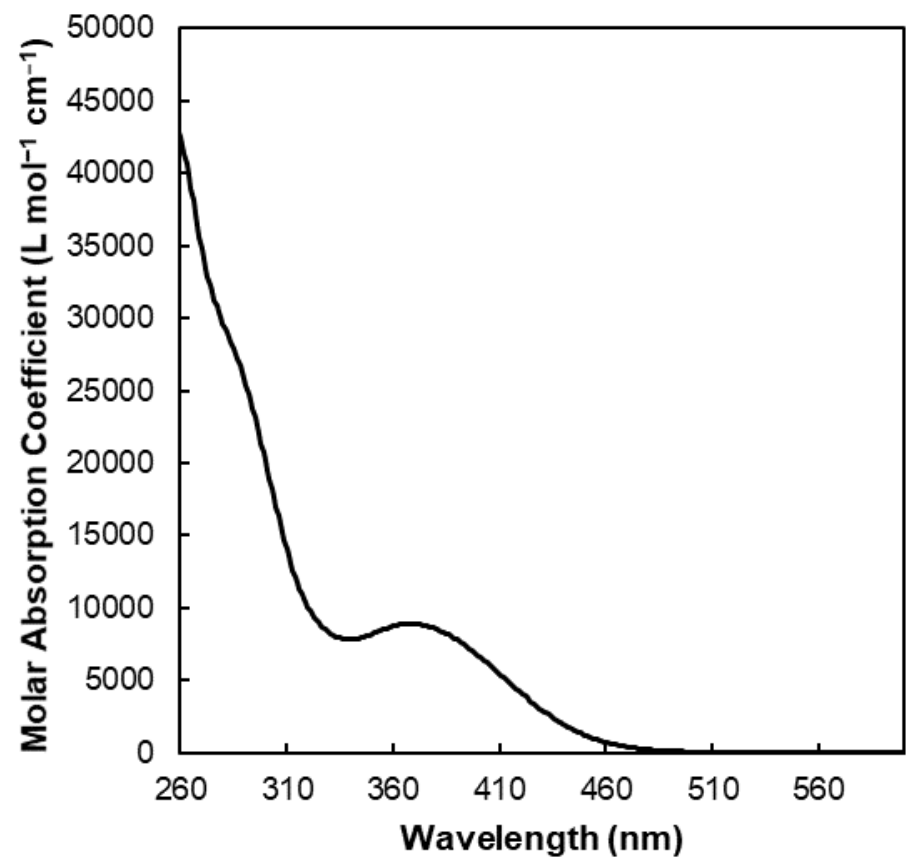

Figure S20 UV-vis spectrum of $\mathbf{4 f}$ in chloroform. 


\section{GPC Characterization}
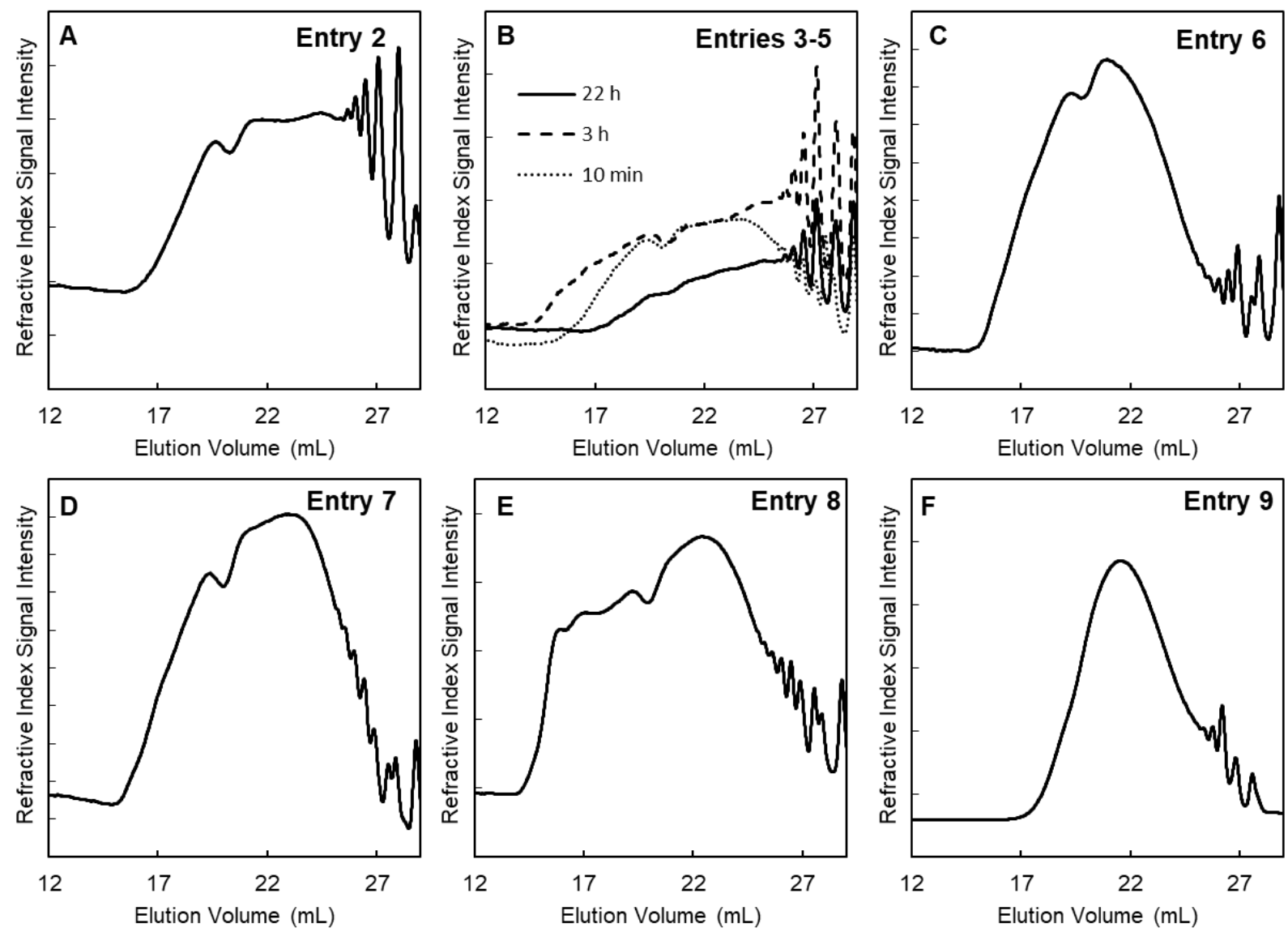

Figure S21 GPC (THF) refractive index detector (RID) signals from which $M_{\mathrm{n}}$ and $Ð$ values were calculated relative to polystyrene standards in Table 1 in the main text for entries (A) 2, (B) 3-5, (C) 6 , (D) 7, (E) 8, and (F) 9 . 

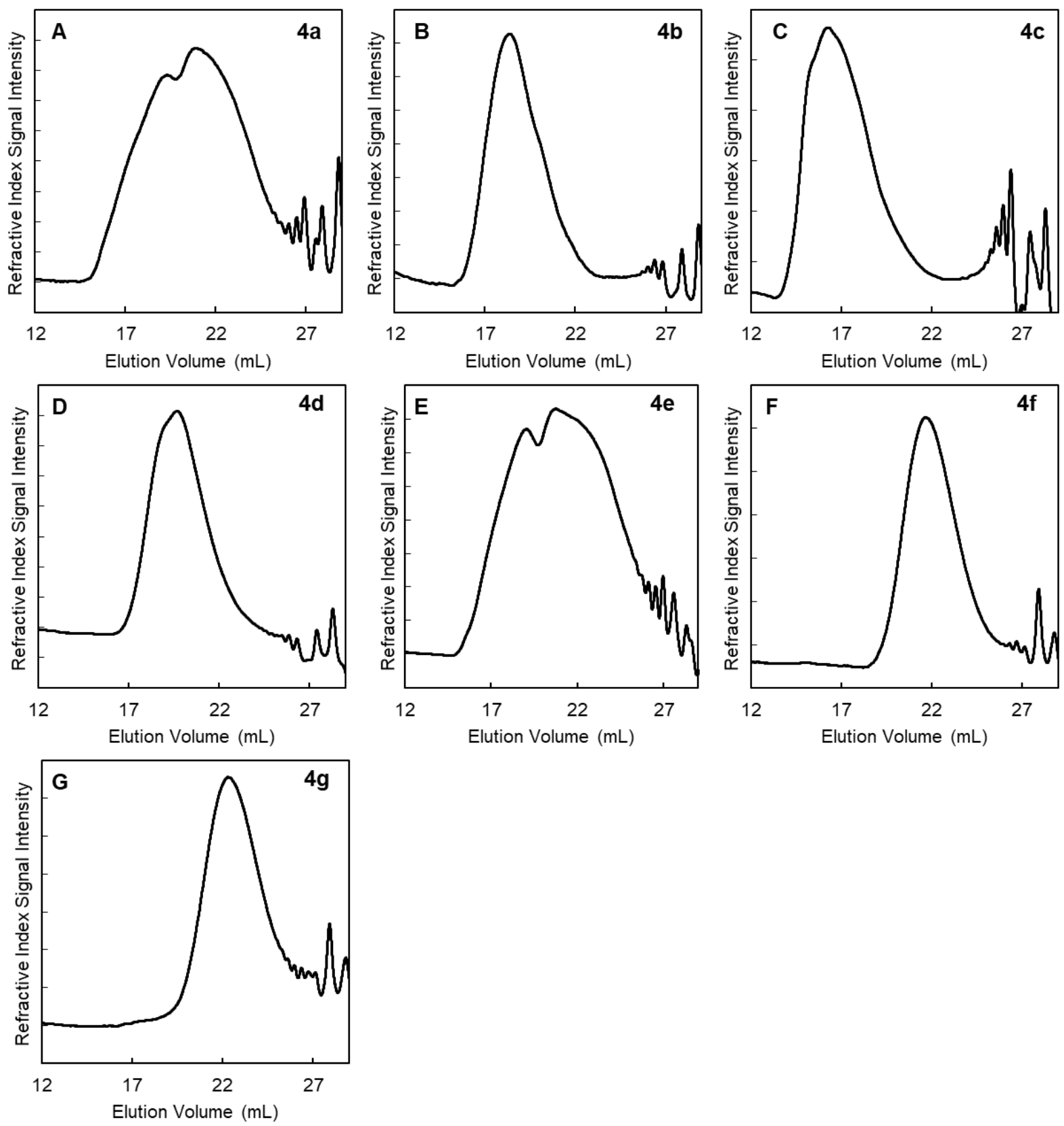

Figure S22 GPC (THF) refractive index detector (RID) signals from which $M_{\mathrm{n}}$ and $Ð$ values were calculated relative to polystyrene standards in Table 2 in the main text for PACs (A) 4a, (B) 4b, (C) $4 \mathbf{c}$, (D) 4d, (E) 4e, (F) 4f, and (G) 4g. 


\section{NMR Characterization}

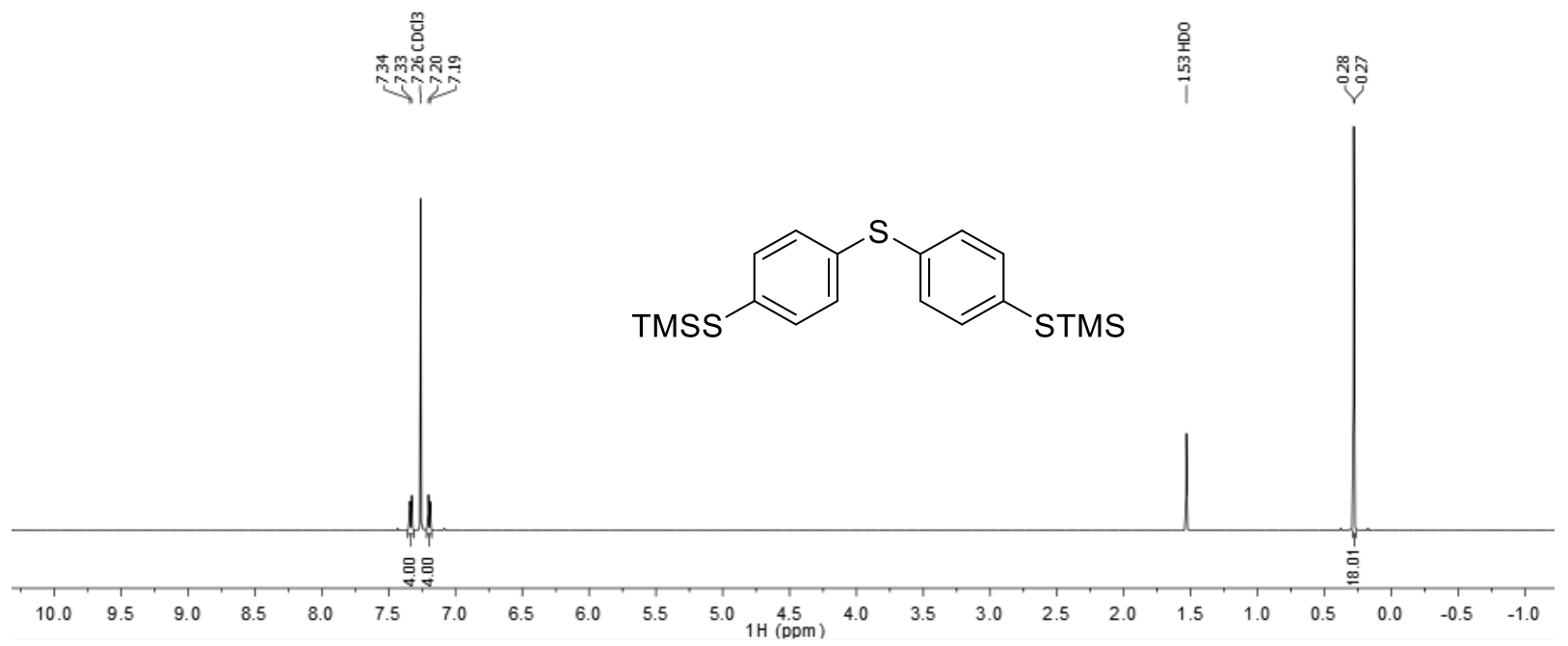

Figure S23 ${ }^{1} \mathrm{H}$ NMR spectrum (600 MHz, Chloroform- $d$ ) of Bis(4-((trimethylsilyl)thio)phenyl)sulfane (2a).
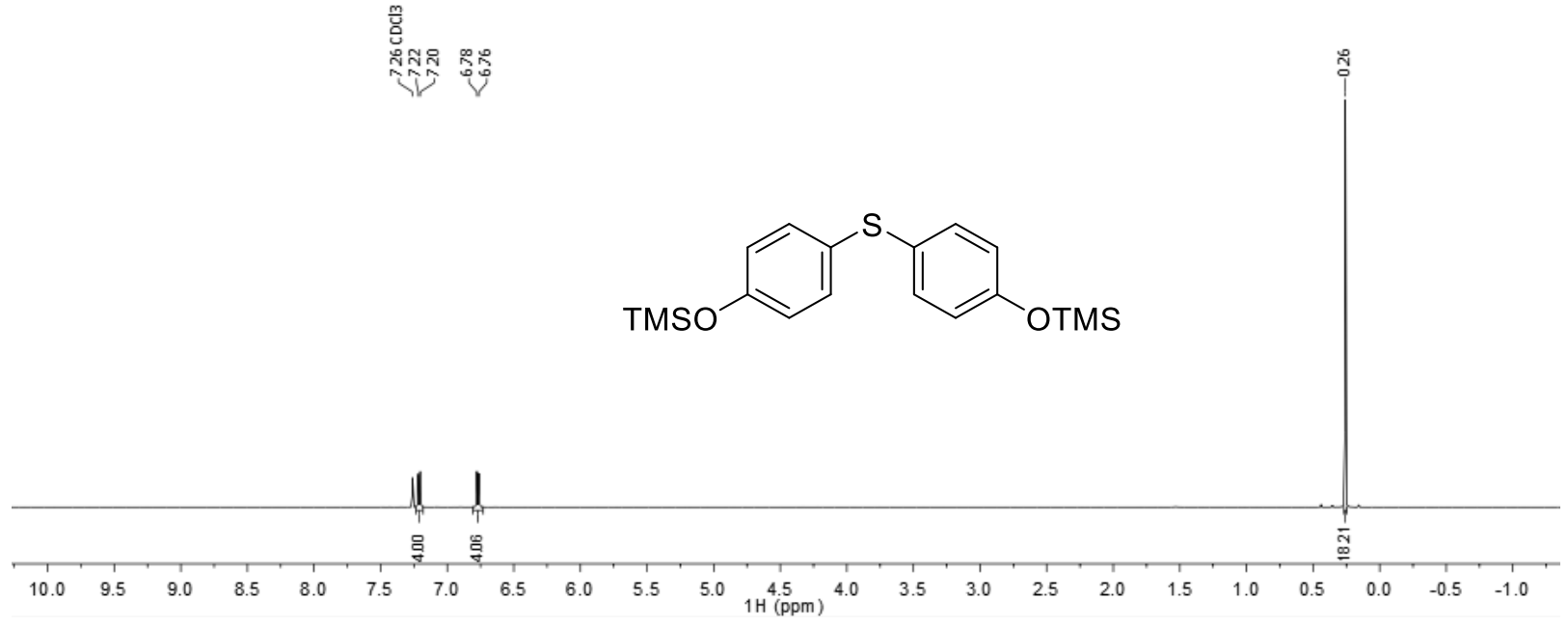

Figure S24 ${ }^{1} \mathrm{H}$ NMR spectrum $(600 \mathrm{MHz}$, Chloroform- $d$ ) of Bis(4-((trimethylsilyl)oxy)phenyl)sulfane (2c). 


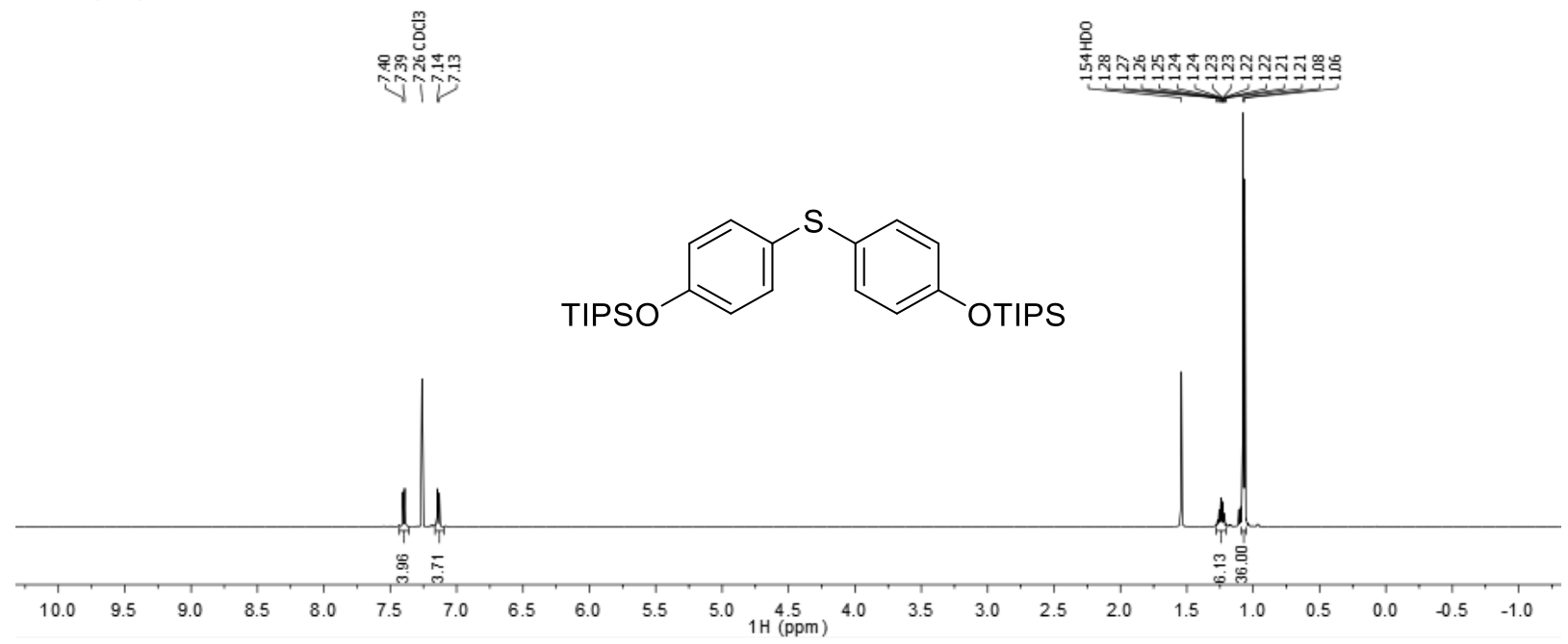

Figure S25 ${ }^{1} \mathrm{H}$ NMR spectrum $(600 \mathrm{MHz}$, Chloroform- $d$ ) of bis(4-

((triisopropylsilyl)oxy)phenyl)sulfane (2b).

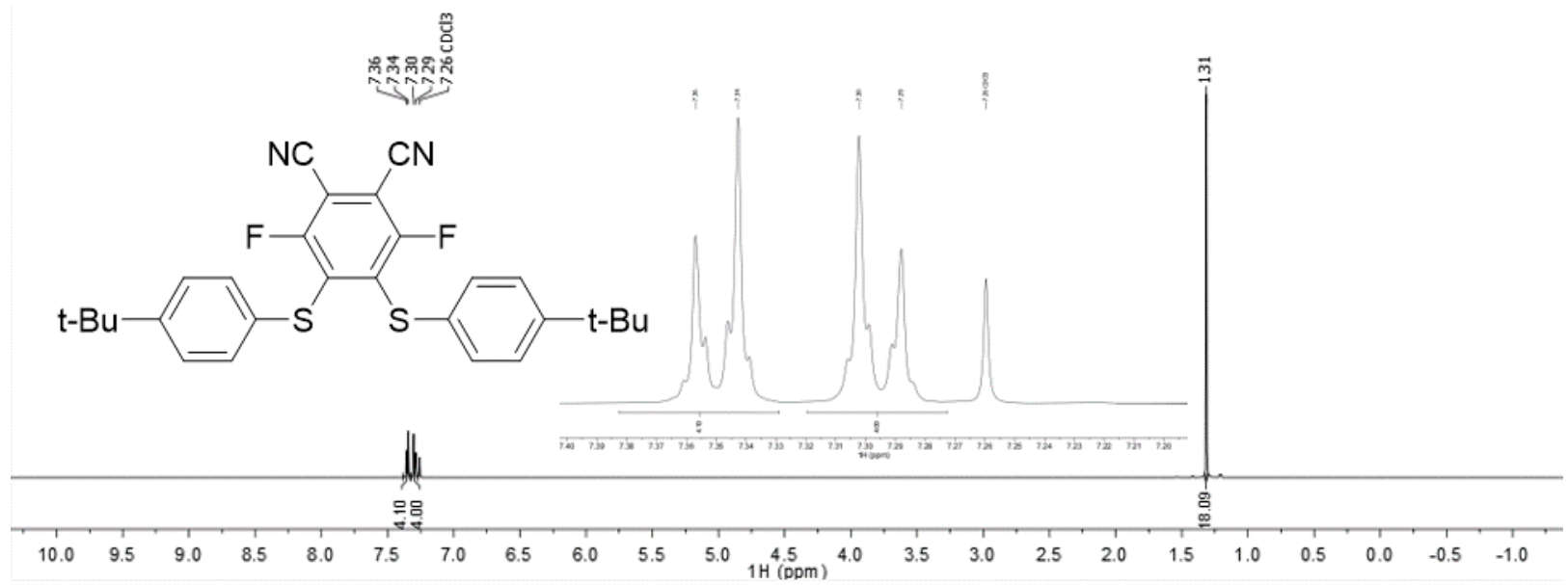

Figure S26 ${ }^{1} \mathrm{H}$ NMR spectrum (600 MHz, Chloroform- $d$ ) of 4,5-bis((4-(tert-butyl)phenyl)thio)-3,6difluorophthalonitrile (3a). 


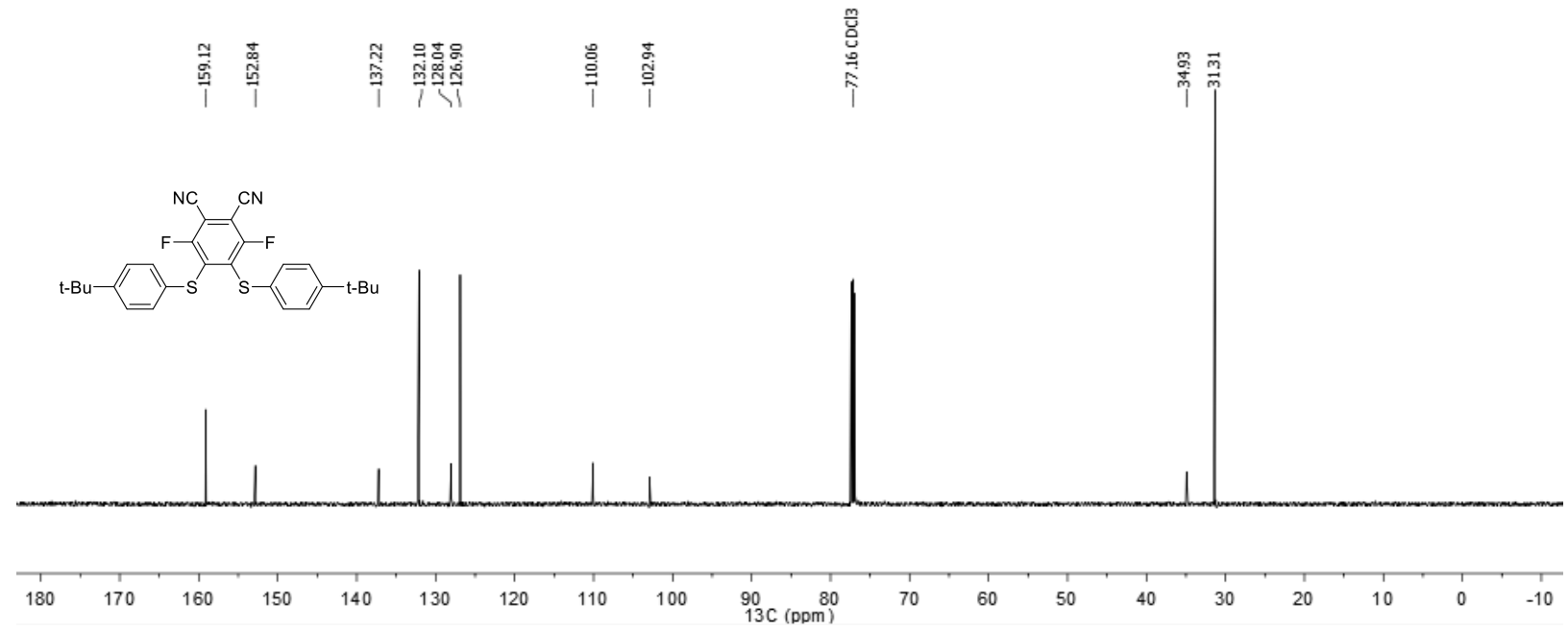

Figure S27 ${ }^{13} \mathrm{C}$ NMR spectrum (151 MHz, Chloroform- $d$ ) of 4,5-bis((4-(tert-butyl)phenyl)thio)-3,6difluorophthalonitrile (3a).

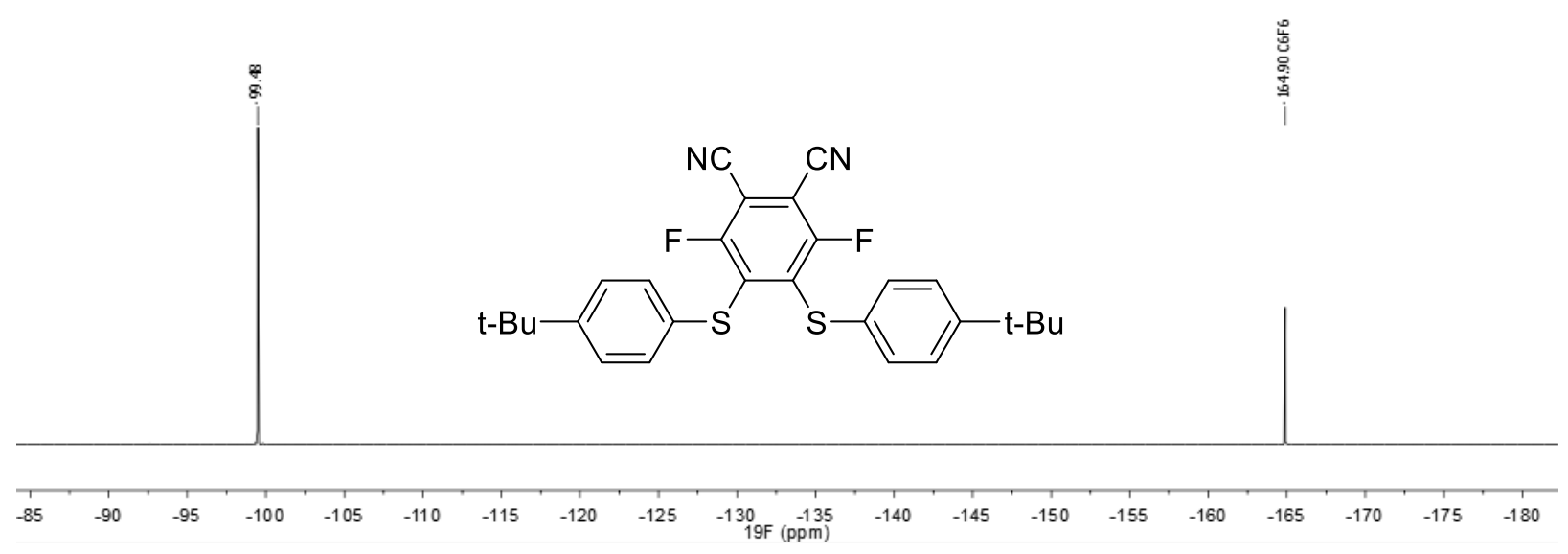

Figure S28 ${ }^{19} \mathrm{~F}$ NMR spectrum (565 MHz, Chloroform- $d$ ) of 4,5-bis((4-(tert-butyl)phenyl)thio)-3,6difluorophthalonitrile (3a). 


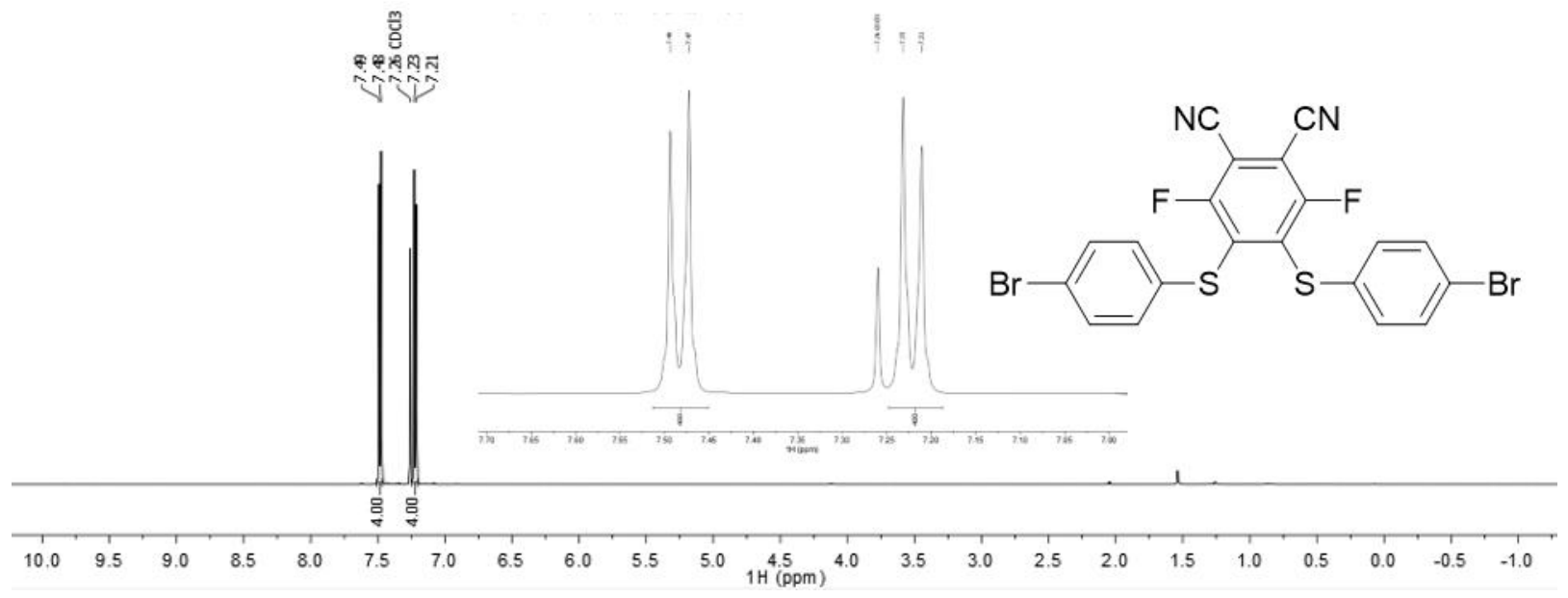

Figure S29 ${ }^{1} \mathrm{H}$ NMR spectrum (600 MHz, Chloroform- $d$ ) of 4,5-bis((4-bromophenyl)thio)-3,6difluorophthalonitrile (3e).

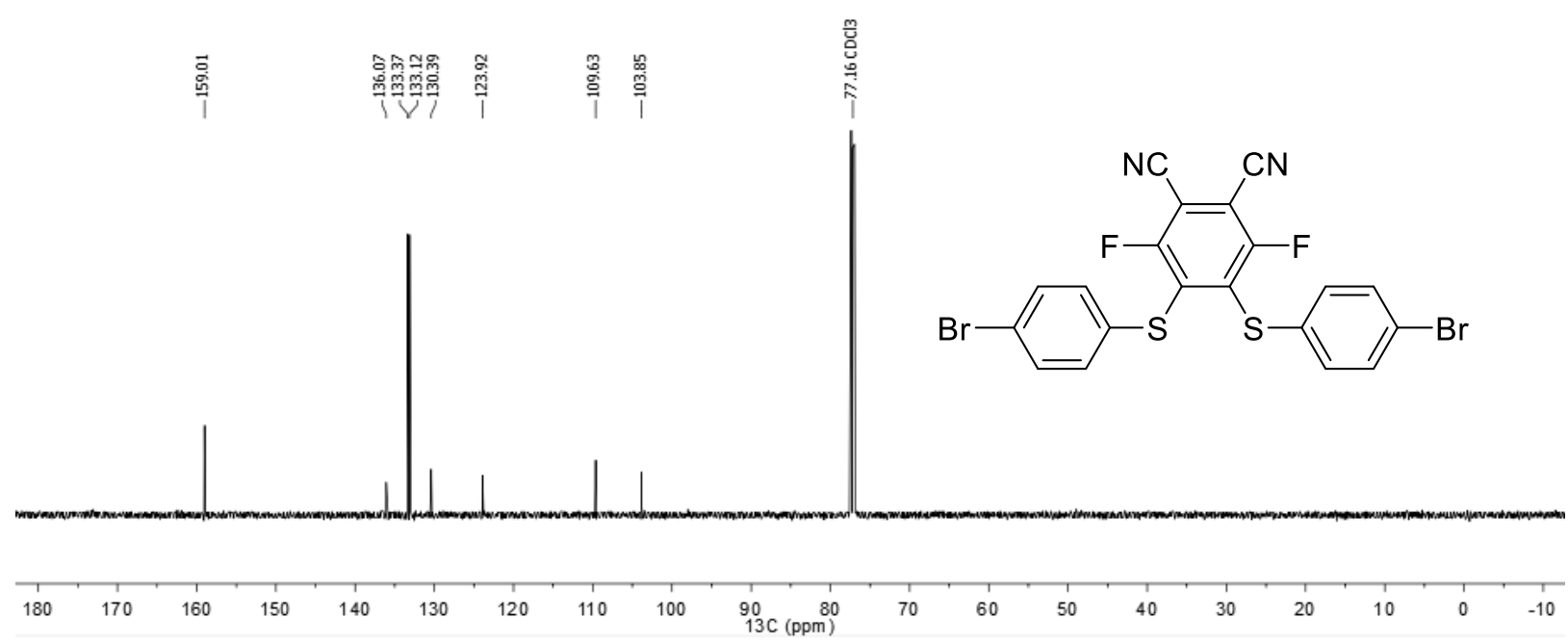

Figure S30 ${ }^{13} \mathrm{C}$ NMR spectrum (151 MHz, Chloroform- $d$ ) of 4,5-bis((4-bromophenyl)thio)-3,6difluorophthalonitrile (3e). 


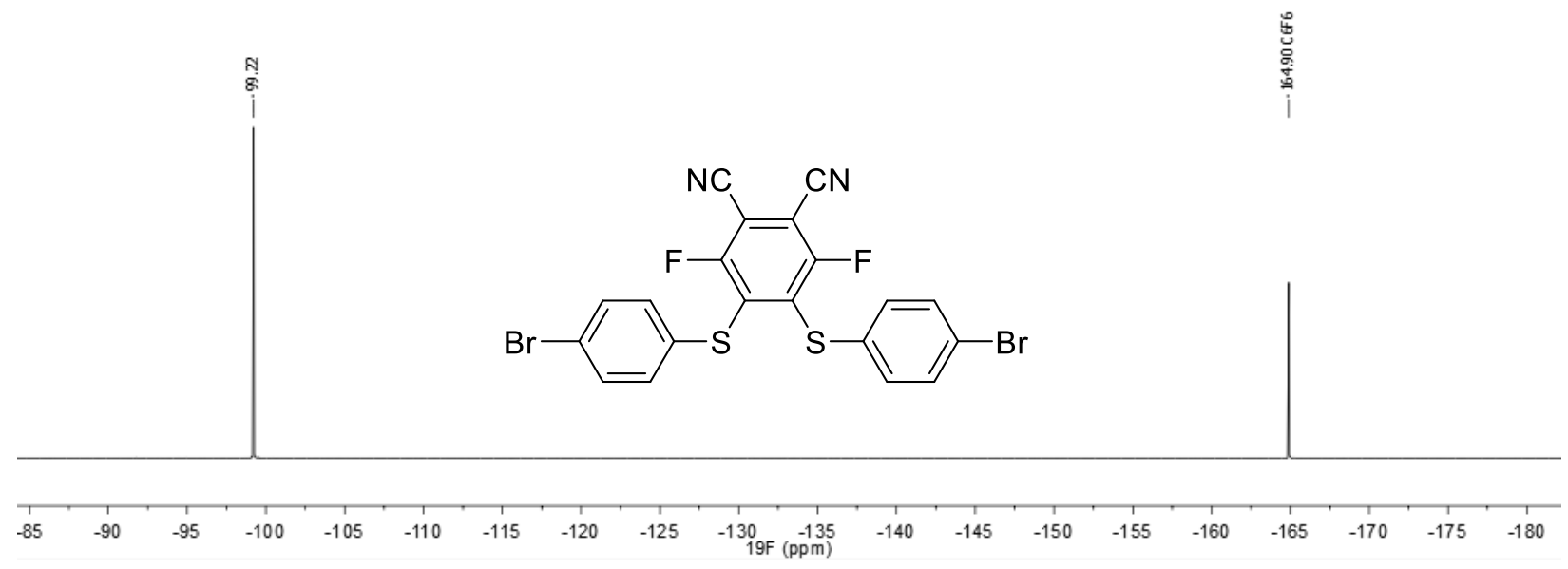

Figure S31 ${ }^{19}$ F NMR spectrum (565 MHz, Chloroform- $d$ ) of 4,5-bis((4-bromophenyl)thio)-3,6difluorophthalonitrile (3e).

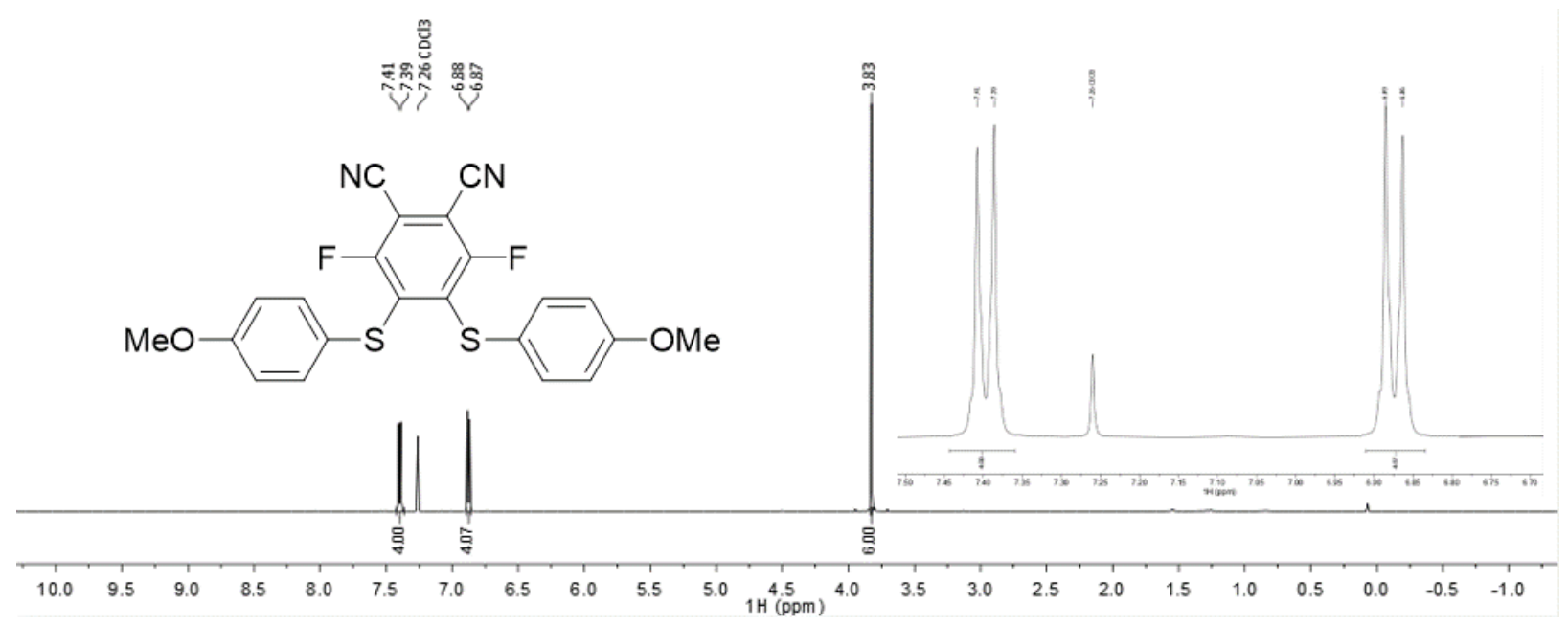

Figure S32 ${ }^{1} \mathrm{H}$ NMR spectrum (600 MHz, Chloroform- $d$ ) of 3,6-difluoro-4,5-bis((4methoxyphenyl)thio)phthalonitrile (3d). 


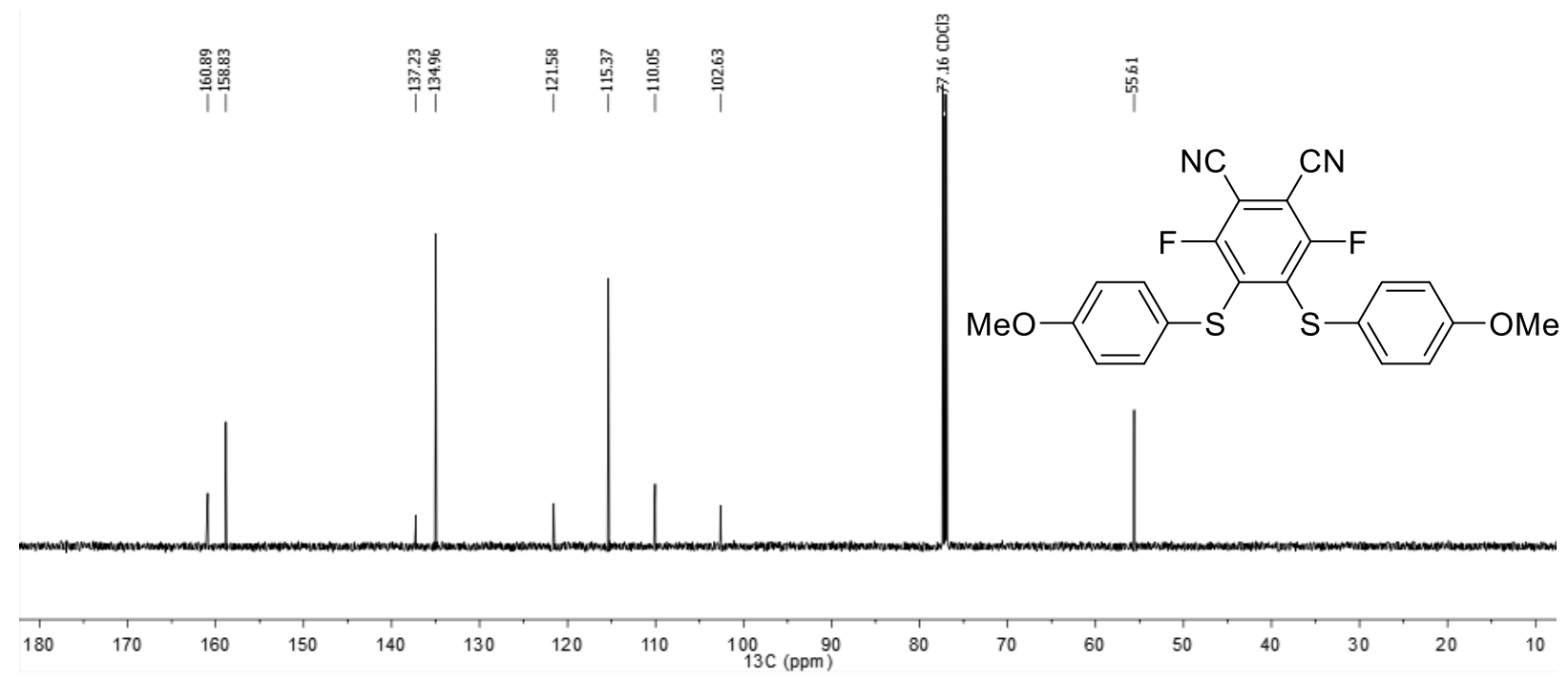

Figure S33 ${ }^{13} \mathrm{C}$ NMR spectrum (151 MHz, Chloroform- $d$ ) of 3,6-difluoro-4,5-bis((4methoxyphenyl)thio)phthalonitrile (3d).

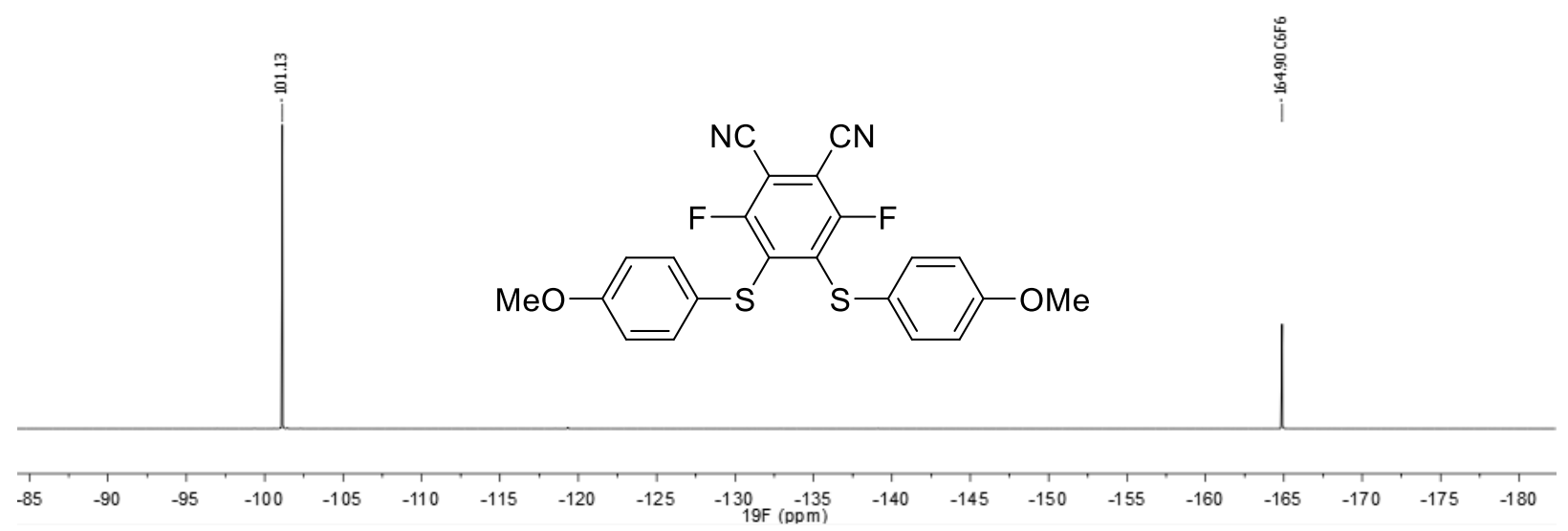

Figure S34 ${ }^{19}$ F NMR spectrum (565 MHz, Chloroform- $d$ ) of 3,6-difluoro-4,5-bis((4methoxyphenyl)thio)phthalonitrile (3d). 


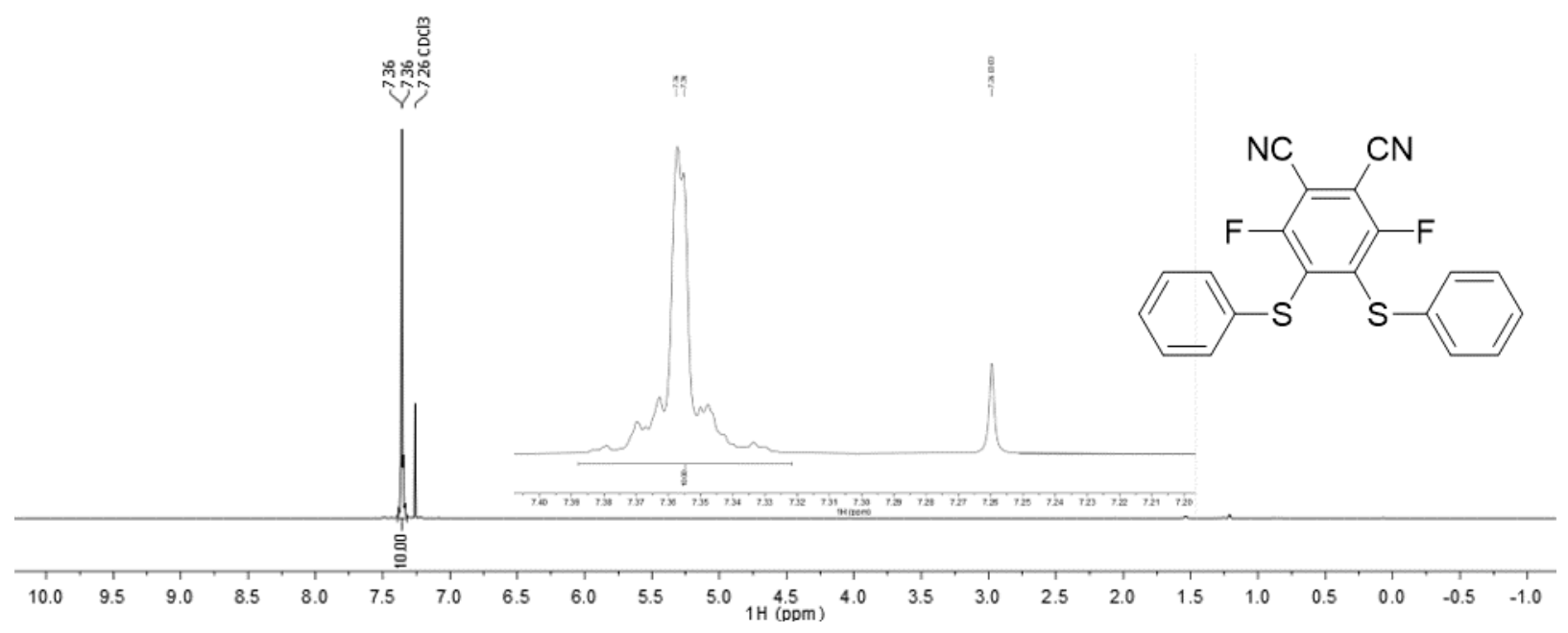

Figure S35 ${ }^{1} \mathrm{H}$ NMR spectrum (600 MHz, Chloroform-d) of 3,6-difluoro-4,5bis(phenylthio)phthalonitrile (3c).

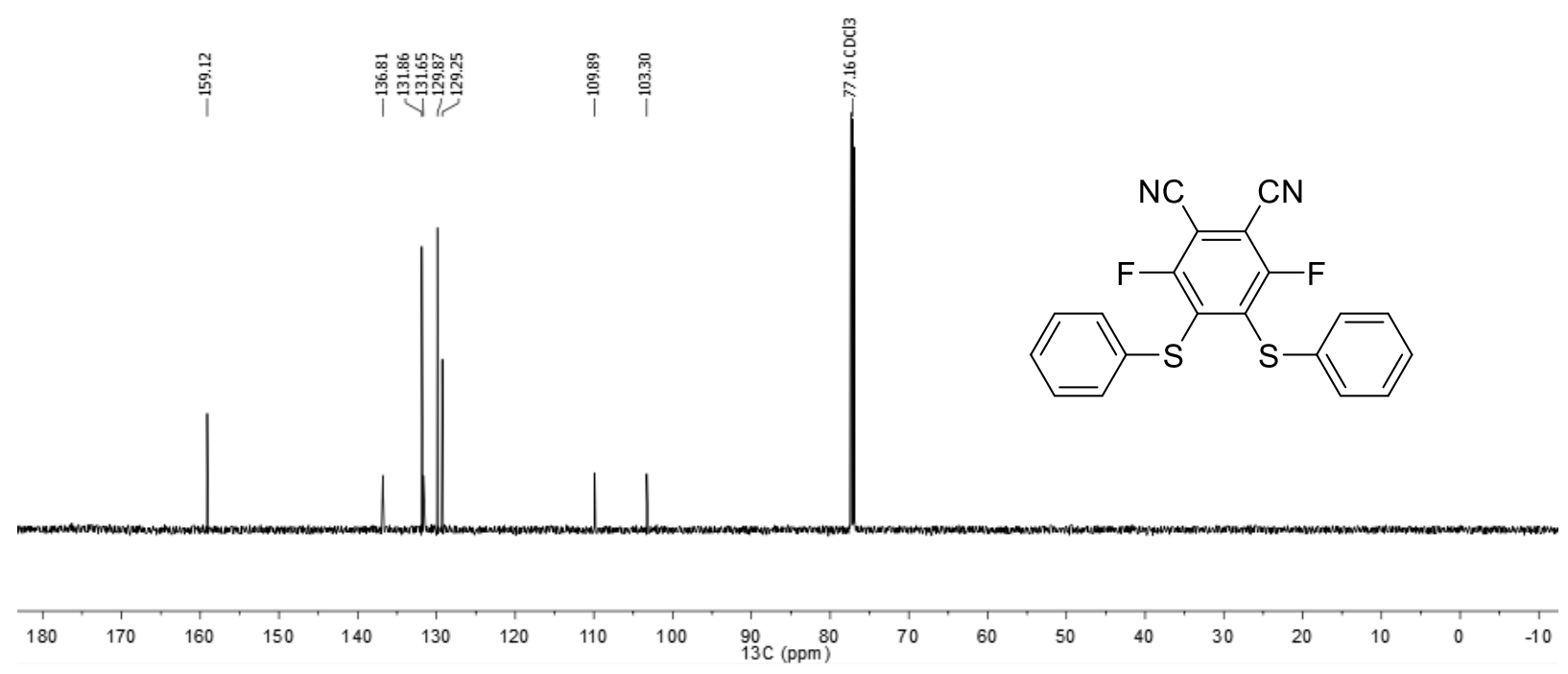

Figure S36 ${ }^{13} \mathrm{C}$ NMR spectrum (151 MHz, Chloroform- $d$ ) of 3,6-difluoro-4,5bis(phenylthio)phthalonitrile (3c). 


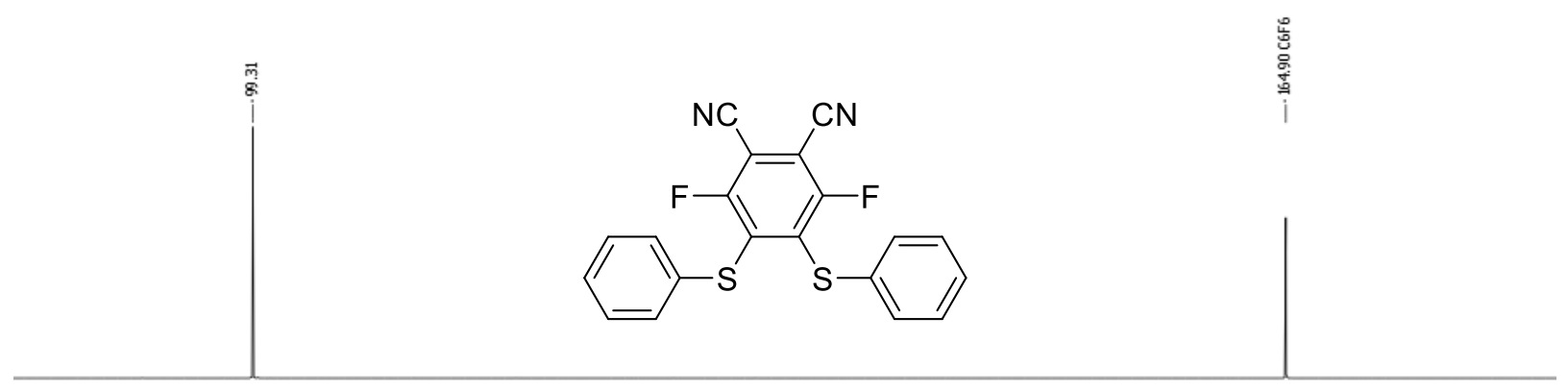

\begin{tabular}{|c|c|c|c|c|c|c|c|c|c|c|c|c|c|c|c|c|c|c|c|}
\hline-85 & -90 & -95 & $\begin{array}{r}1 \\
-100\end{array}$ & $\begin{array}{c}1 \\
-105\end{array}$ & -110 & -115 & -120 & $\begin{array}{l}1 \\
-125\end{array}$ & -130 & $\begin{array}{r}-135 \\
(\mathrm{ppm})\end{array}$ & $\begin{array}{c}1 \\
-140\end{array}$ & $\begin{array}{c}1 \\
-145\end{array}$ & $\begin{array}{c}1 \\
-150\end{array}$ & -155 & $\begin{array}{c}1 \\
-160\end{array}$ & $\begin{array}{c}1 \\
-165\end{array}$ & -170 & $\begin{array}{c}1 \\
-175\end{array}$ & $\begin{array}{l}180 \\
-180\end{array}$ \\
\hline
\end{tabular}

Figure S37 ${ }^{19}$ F NMR spectrum (565 MHz, Chloroform- $d$ ) of 3,6-difluoro-4,5-

bis(phenylthio)phthalonitrile (3c).

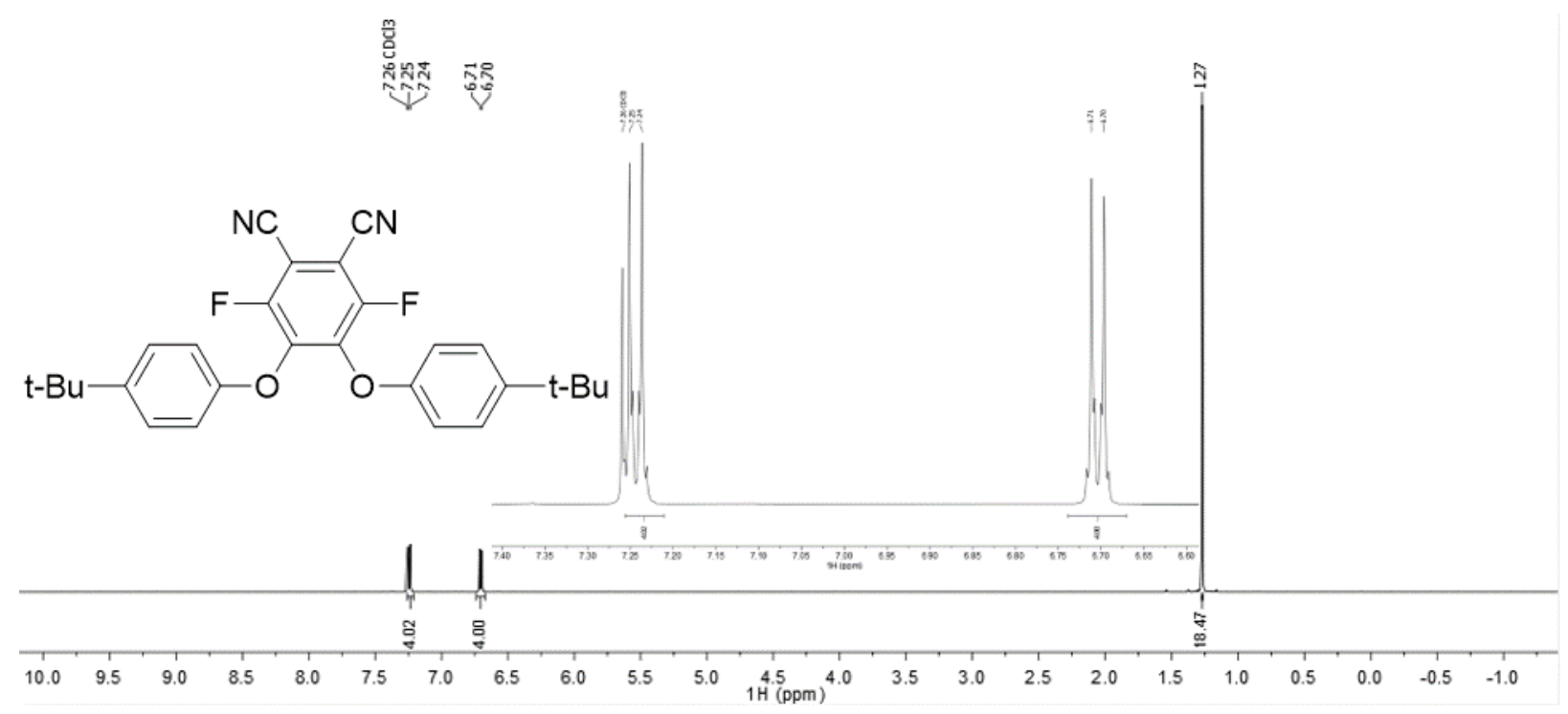

Figure S38 ${ }^{1} \mathrm{H}$ NMR spectrum (600 MHz, Chloroform-d) of 4,5-bis(4-(tert-butyl)phenoxy)-3,6difluorophthalonitrile (3b). 


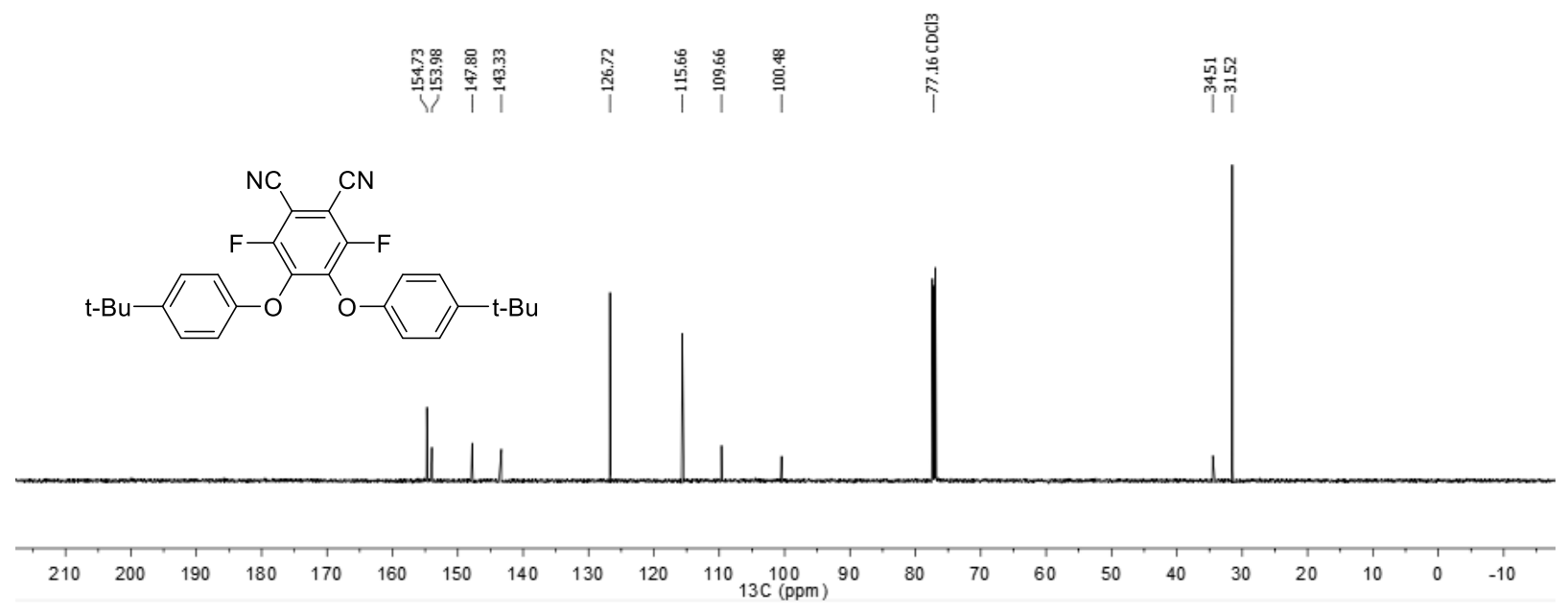

Figure S39 ${ }^{13} \mathrm{C}$ NMR spectrum (151 MHz, Chloroform- $d$ ) of 4,5-bis(4-(tert-butyl)phenoxy)-3,6difluorophthalonitrile (3b).

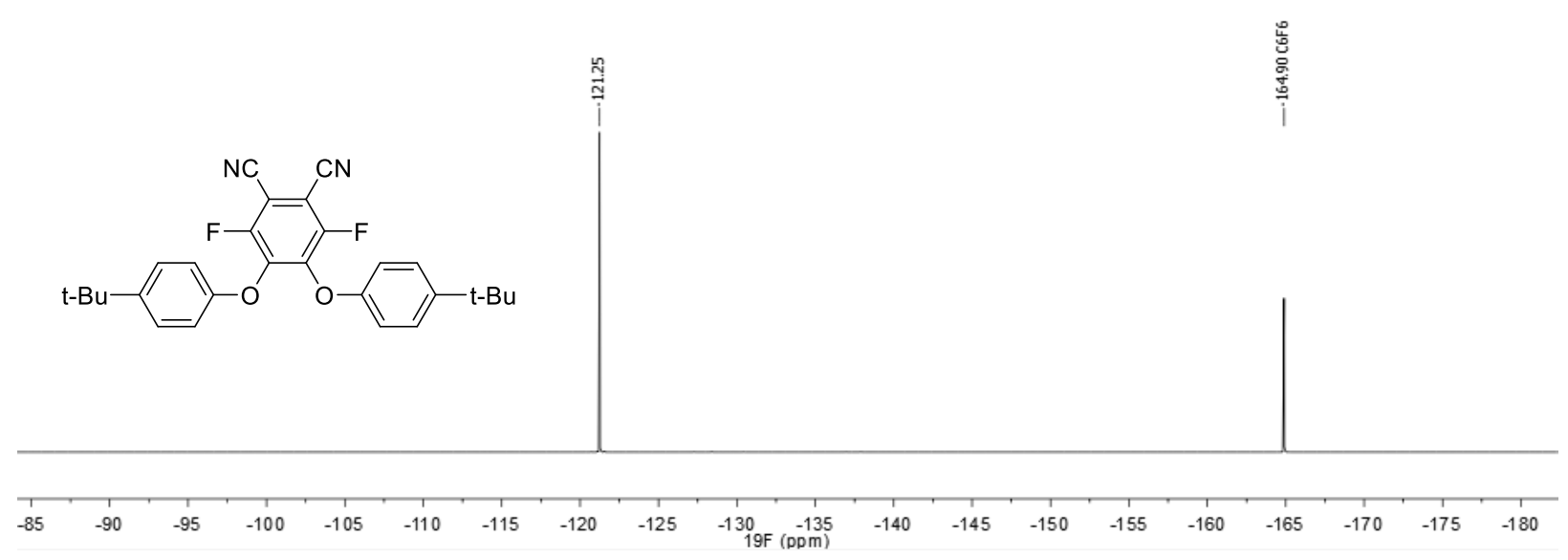

Figure S40 ${ }^{19} \mathrm{~F}$ NMR spectrum (565 MHz, Chloroform- $d$ ) of 4,5-bis(4-(tert-butyl)phenoxy)-3,6difluorophthalonitrile (3b).

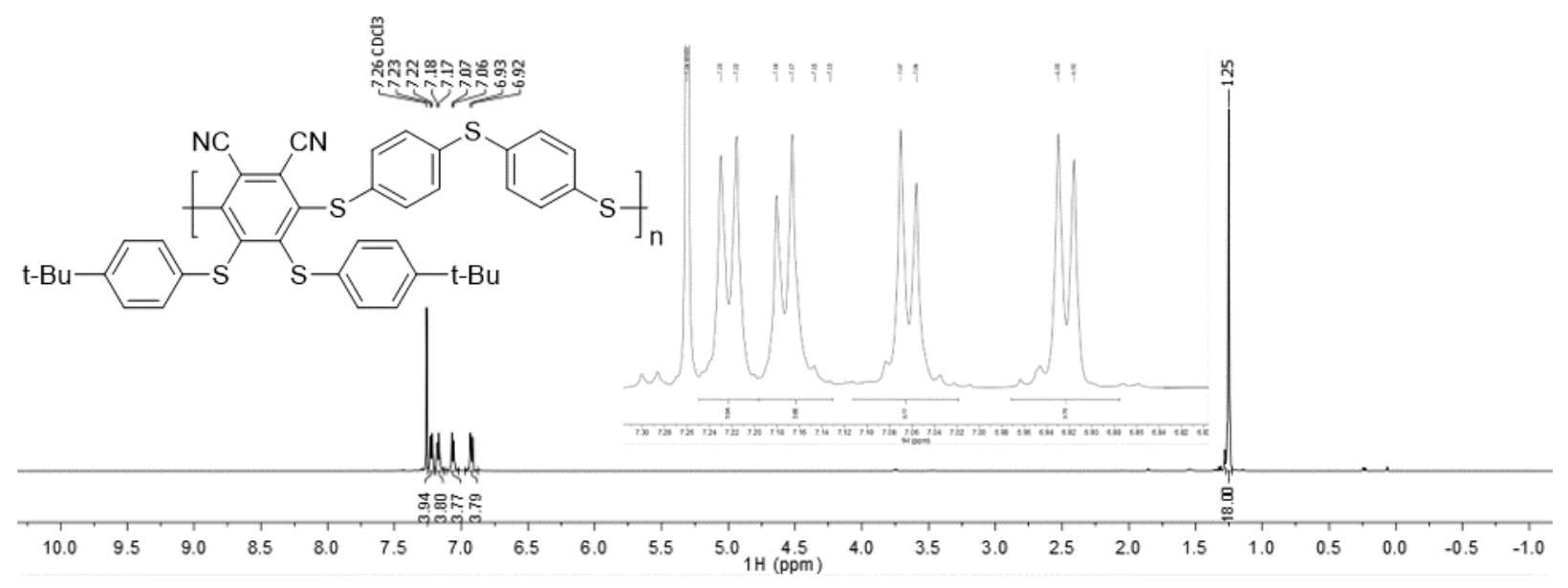

Figure S41 ${ }^{1} \mathrm{H}$ NMR spectrum $(600 \mathrm{MHz}$, Chloroform- $d$ ) of $\mathbf{4 a}$. 


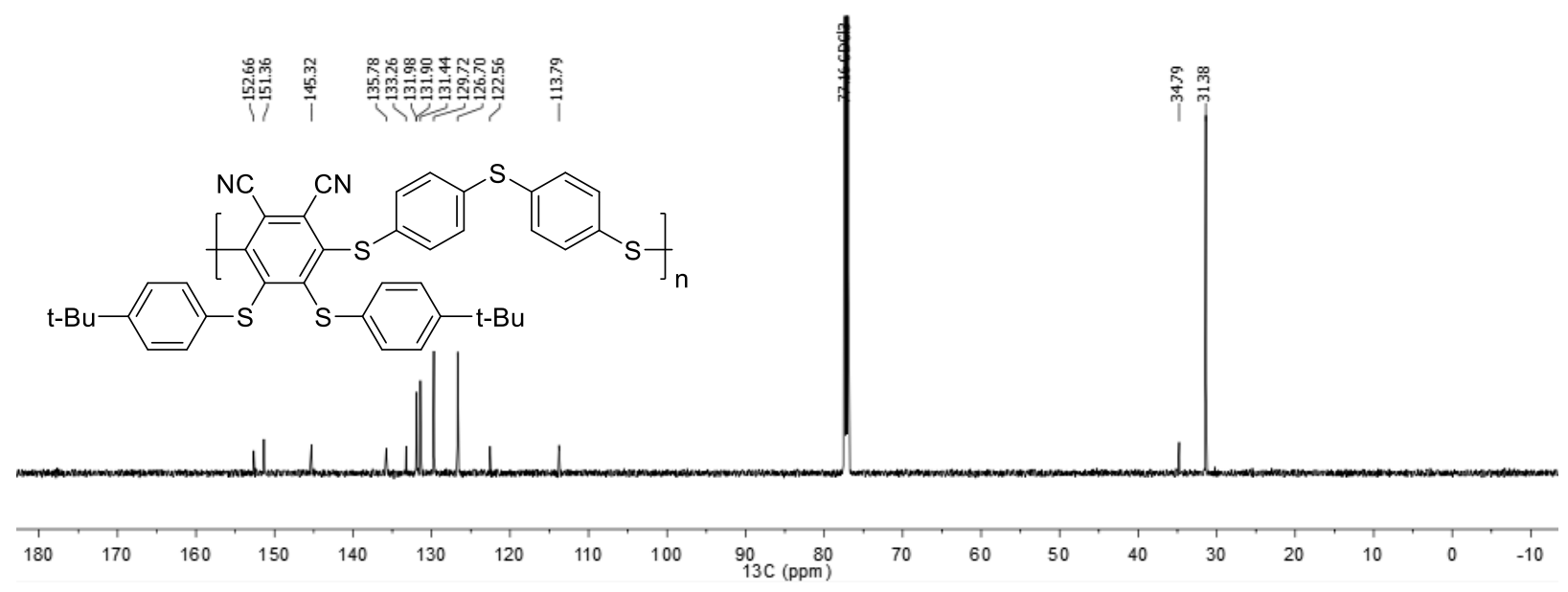

Figure $\mathbf{S 4 2}{ }^{13} \mathrm{C}$ NMR spectrum (151 MHz, Chloroform- $d$ ) of $\mathbf{4 a}$.

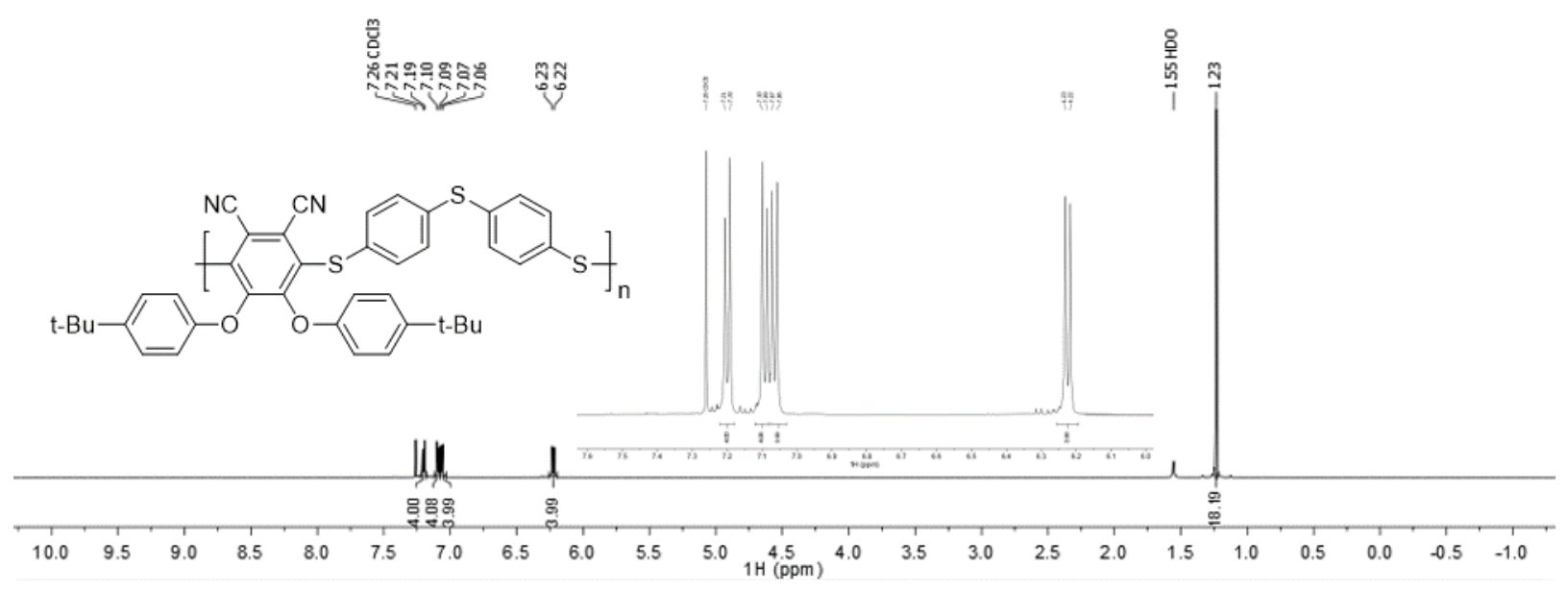

Figure $\mathbf{S 4 3}{ }^{1} \mathrm{H}$ NMR spectrum (600 MHz, Chloroform- $d$ ) of $\mathbf{4 c}$.

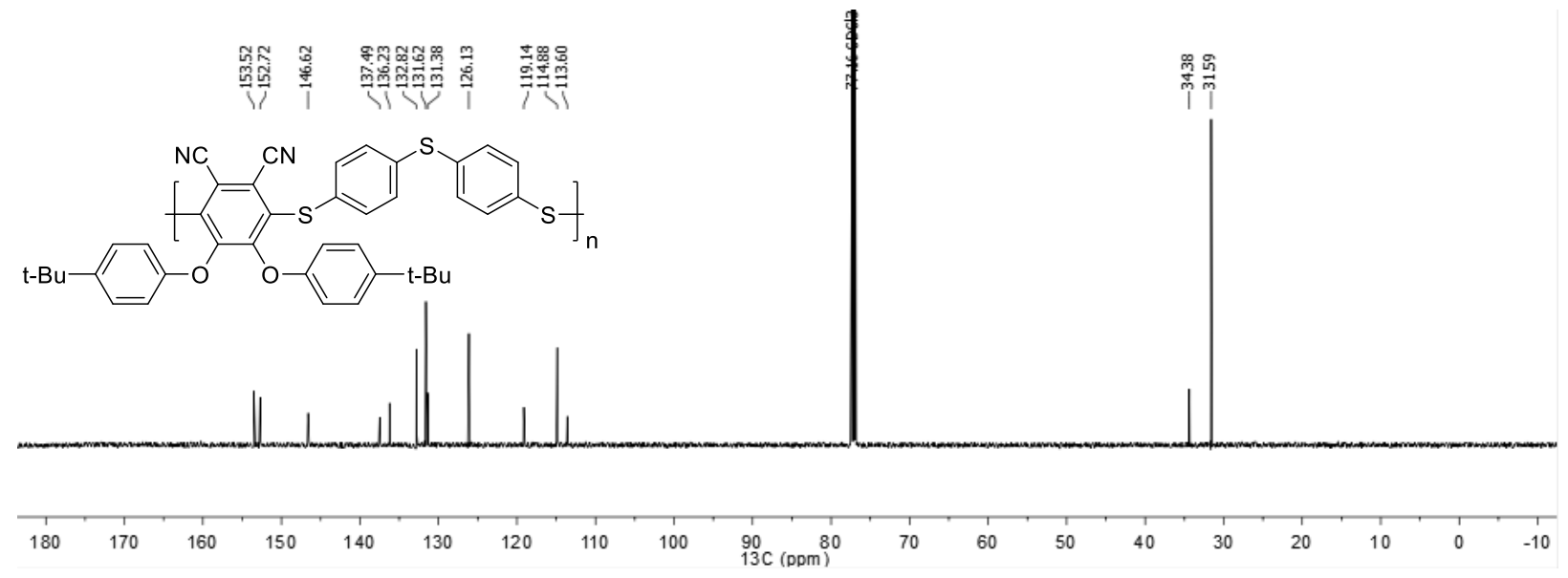

Figure $\mathbf{S 4 4}{ }^{13} \mathrm{C}$ NMR spectrum (151 MHz, Chloroform- $d$ ) of $\mathbf{4 c}$. 


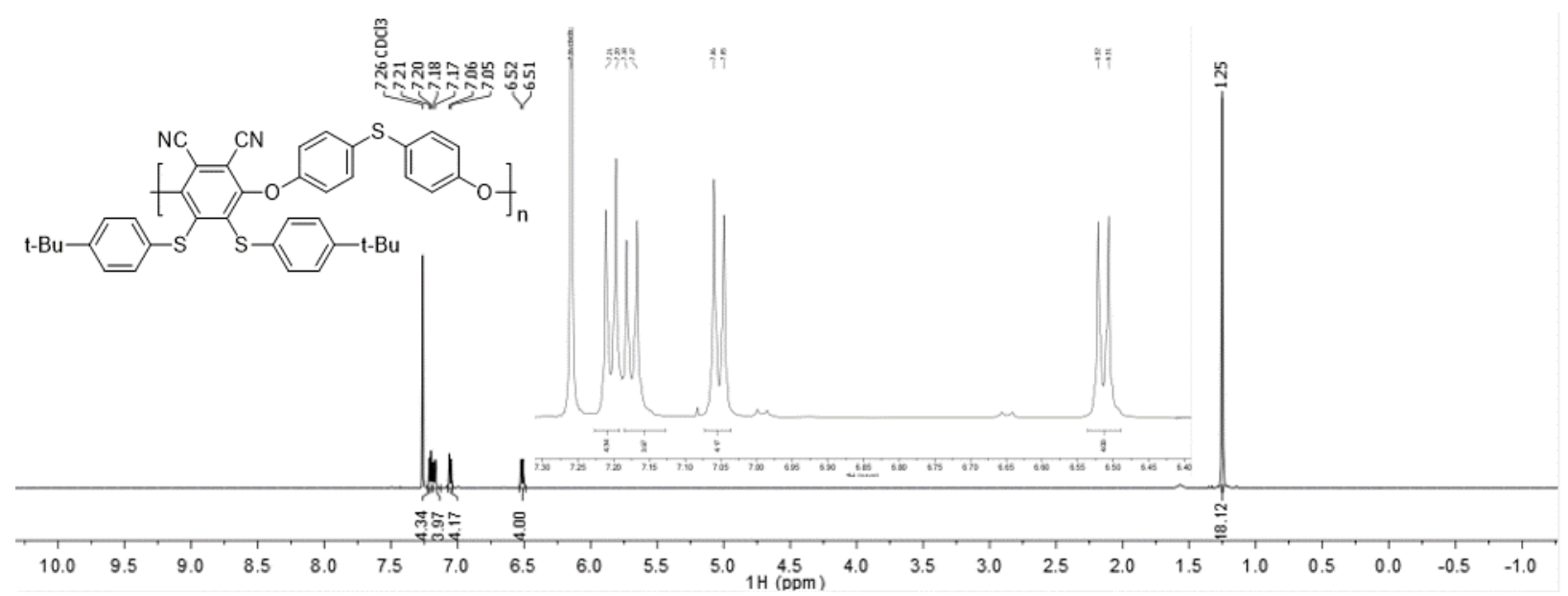

Figure $\mathbf{S 4 5}{ }^{1} \mathrm{H}$ NMR spectrum $(600 \mathrm{MHz}$, Chloroform- $d$ ) of $\mathbf{4 b}$.

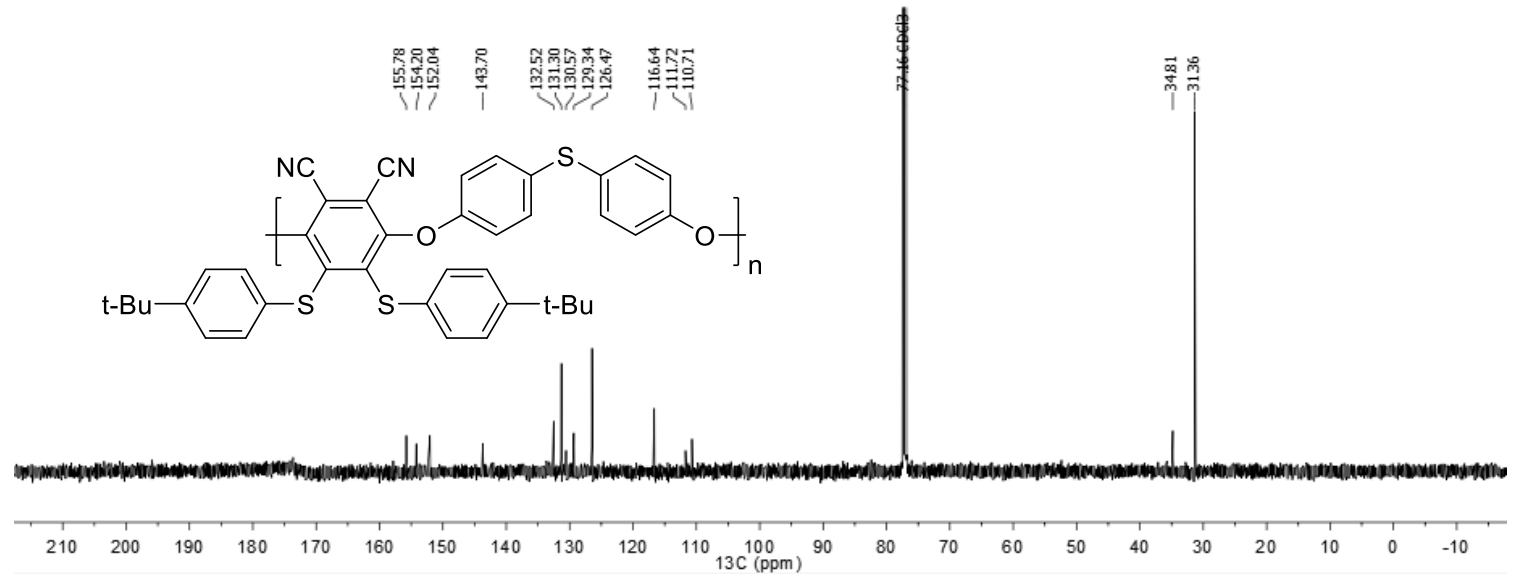

Figure S46 ${ }^{13} \mathrm{C}$ NMR spectrum (151 MHz, Chloroform- $d$ ) of $\mathbf{4 b}$.

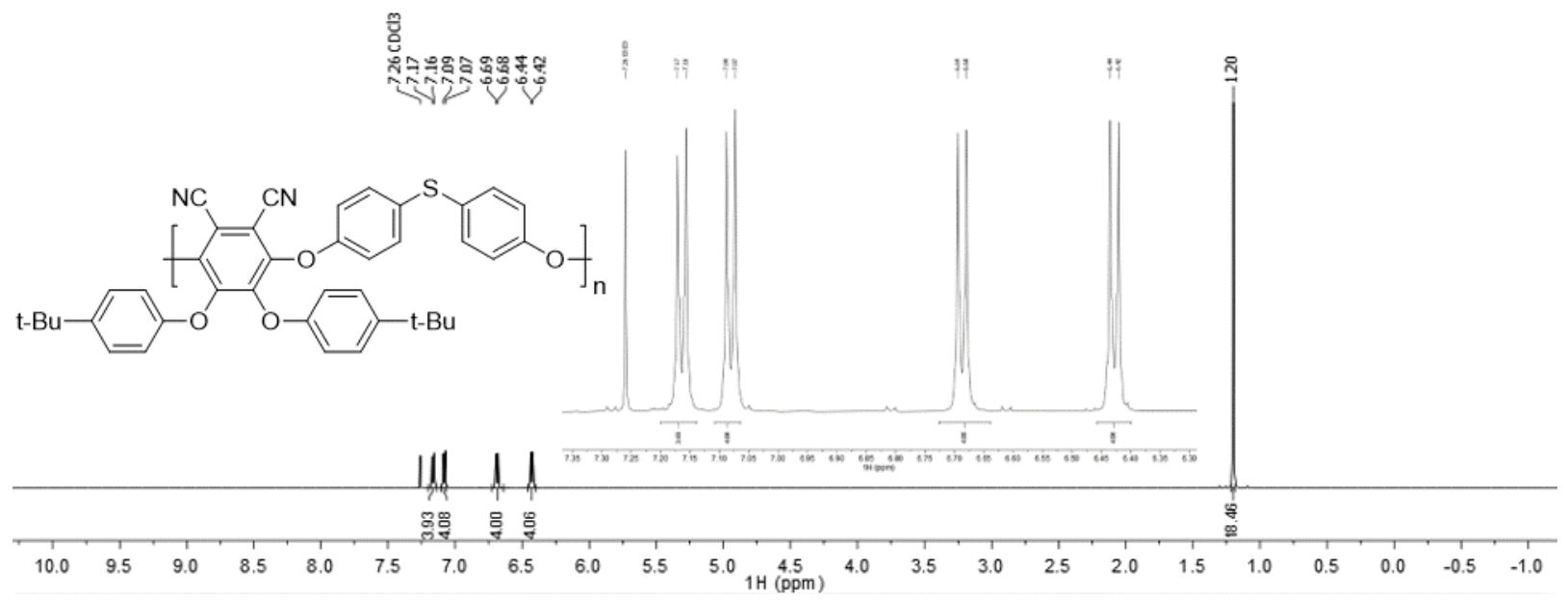

Figure $\mathbf{S 4 7}{ }^{1} \mathrm{H}$ NMR spectrum (600 MHz, Chloroform- $d$ ) of $\mathbf{4 d}$. 


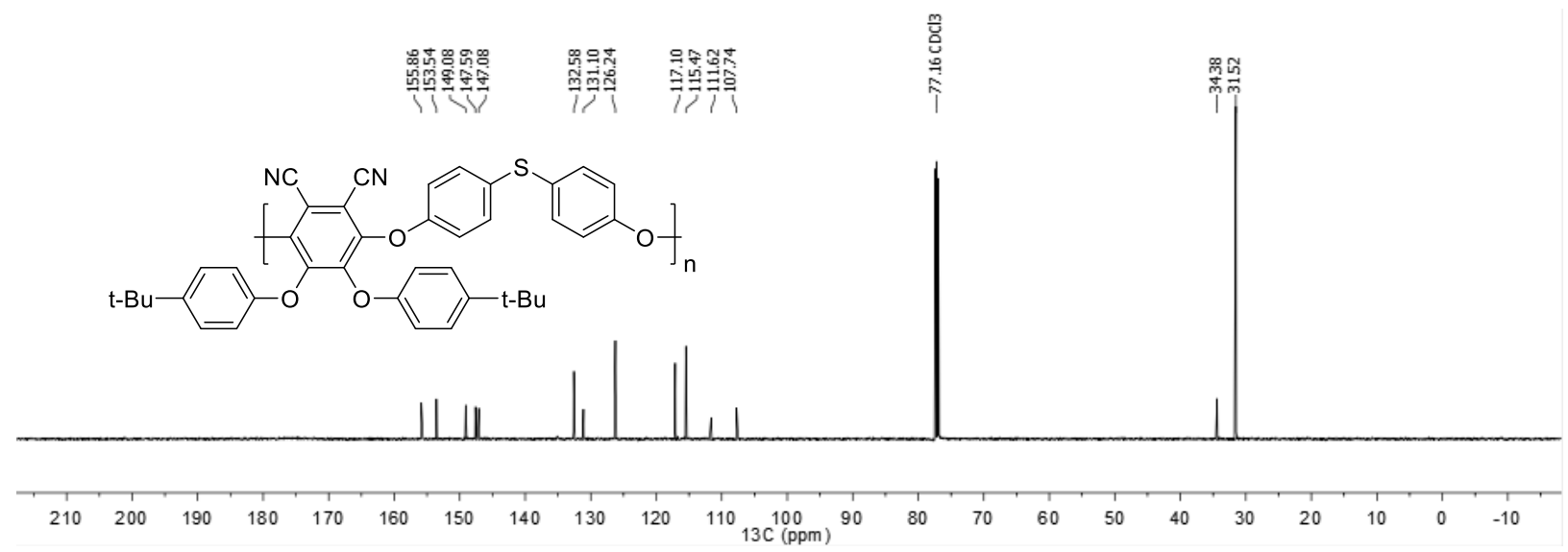

Figure $\mathbf{S 4 8}{ }^{13} \mathrm{C}$ NMR spectrum (151 MHz, Chloroform- $d$ ) of $\mathbf{4 d}$.

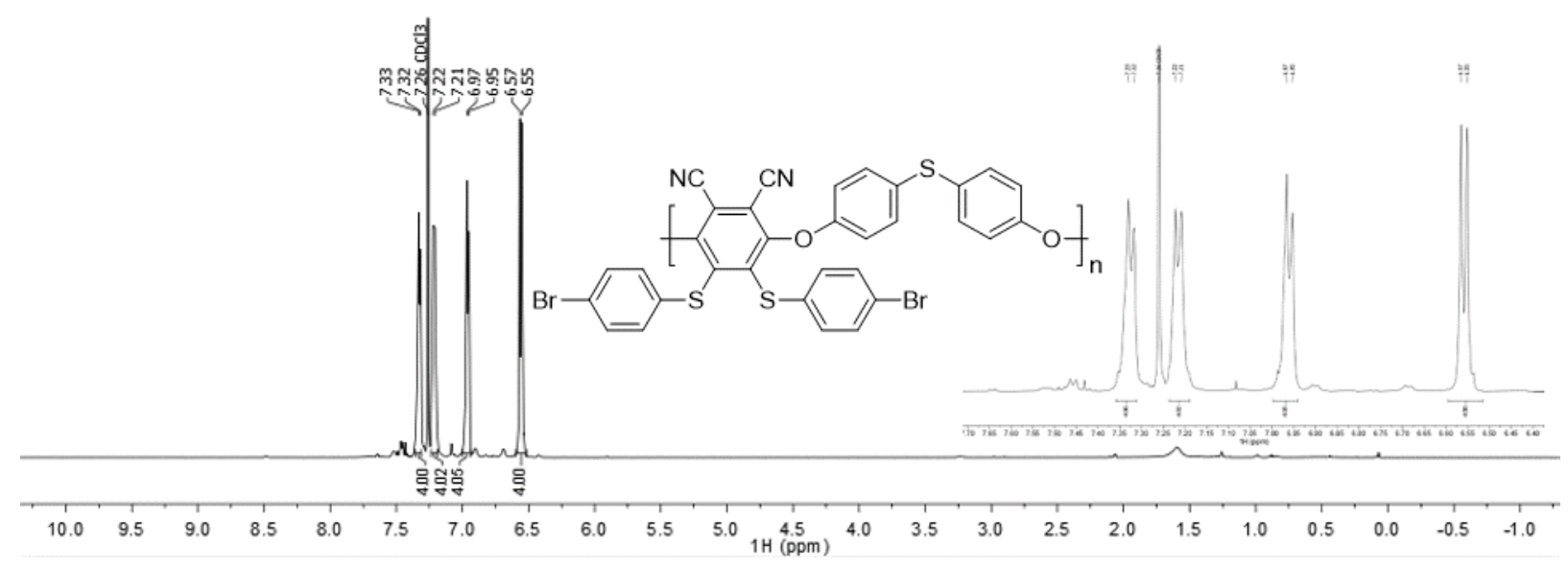

Figure S49 ${ }^{1} \mathrm{H}$ NMR spectrum $(600 \mathrm{MHz}$, Chloroform- $d$ ) of $\mathbf{4 g}$.

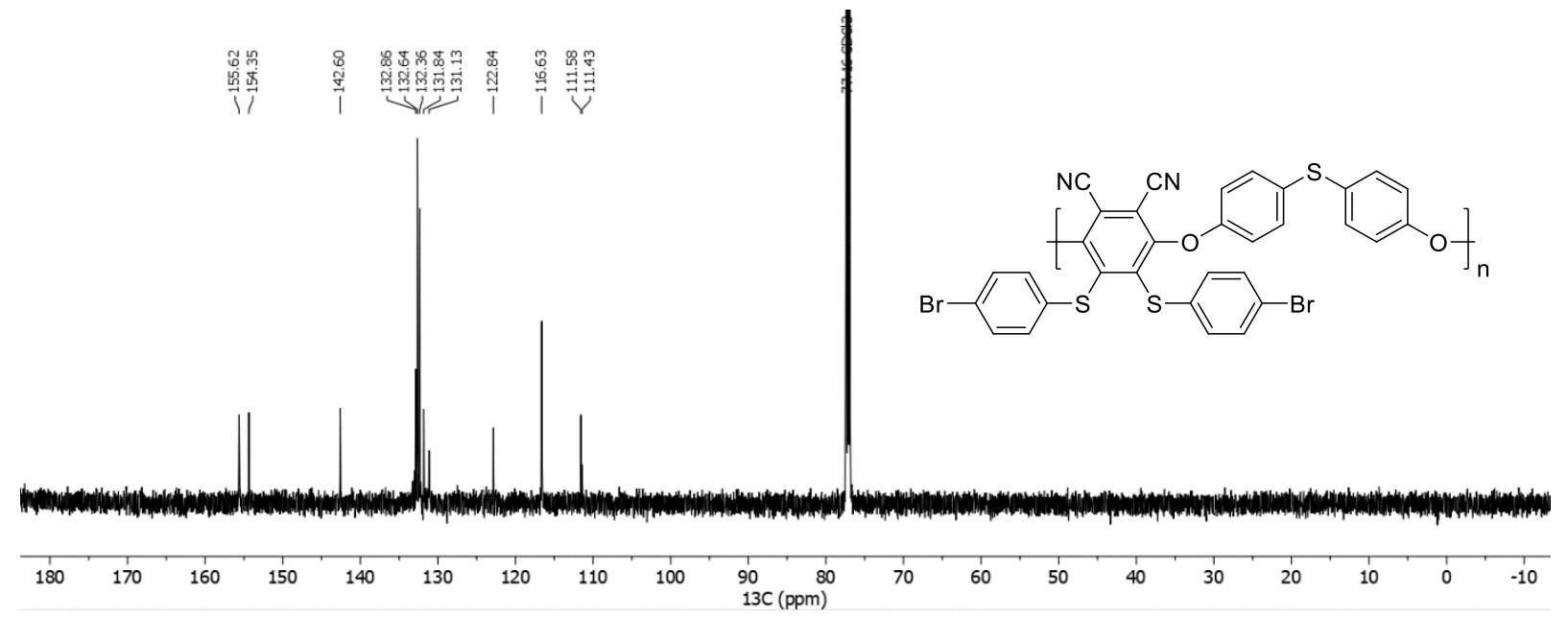

Figure S50 ${ }^{13} \mathrm{C}$ NMR spectrum (151 MHz, Chloroform- $d$ ) of $\mathbf{4 g}$. 


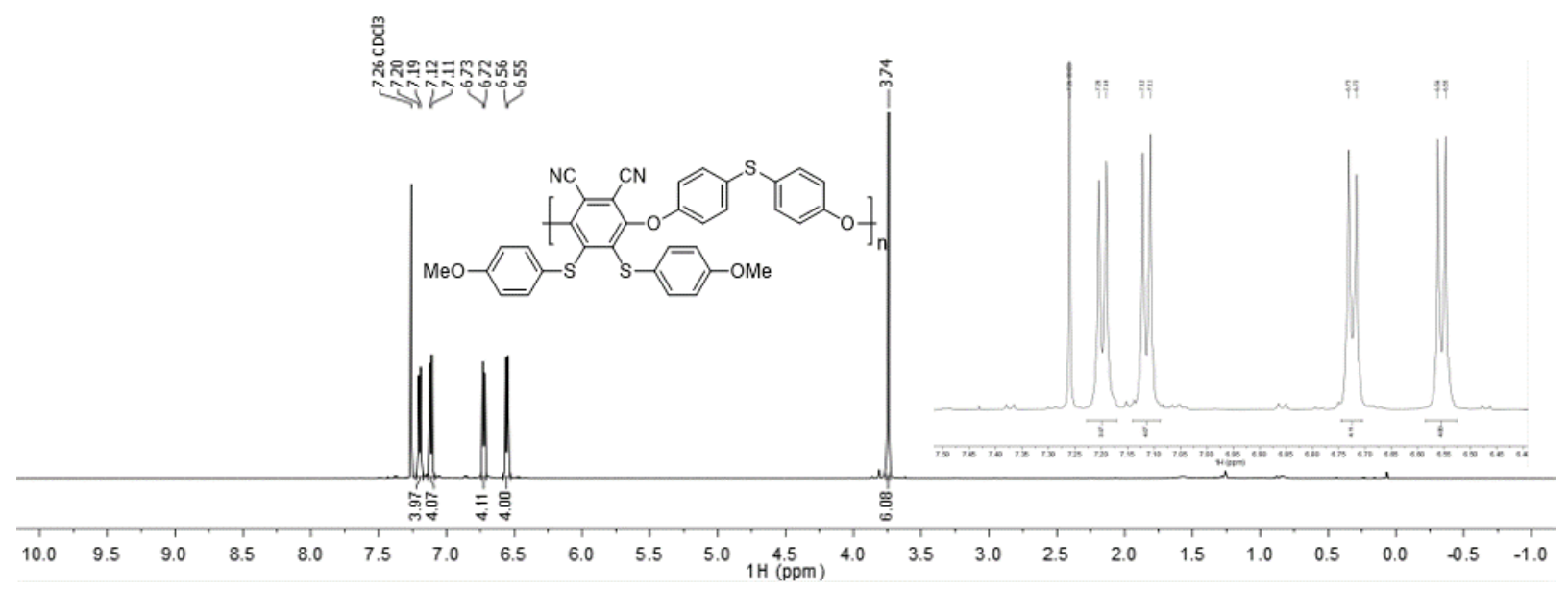

Figure S51 ${ }^{1} \mathrm{H}$ NMR spectrum (600 MHz, Chloroform- $d$ ) of $\mathbf{4 f}$.

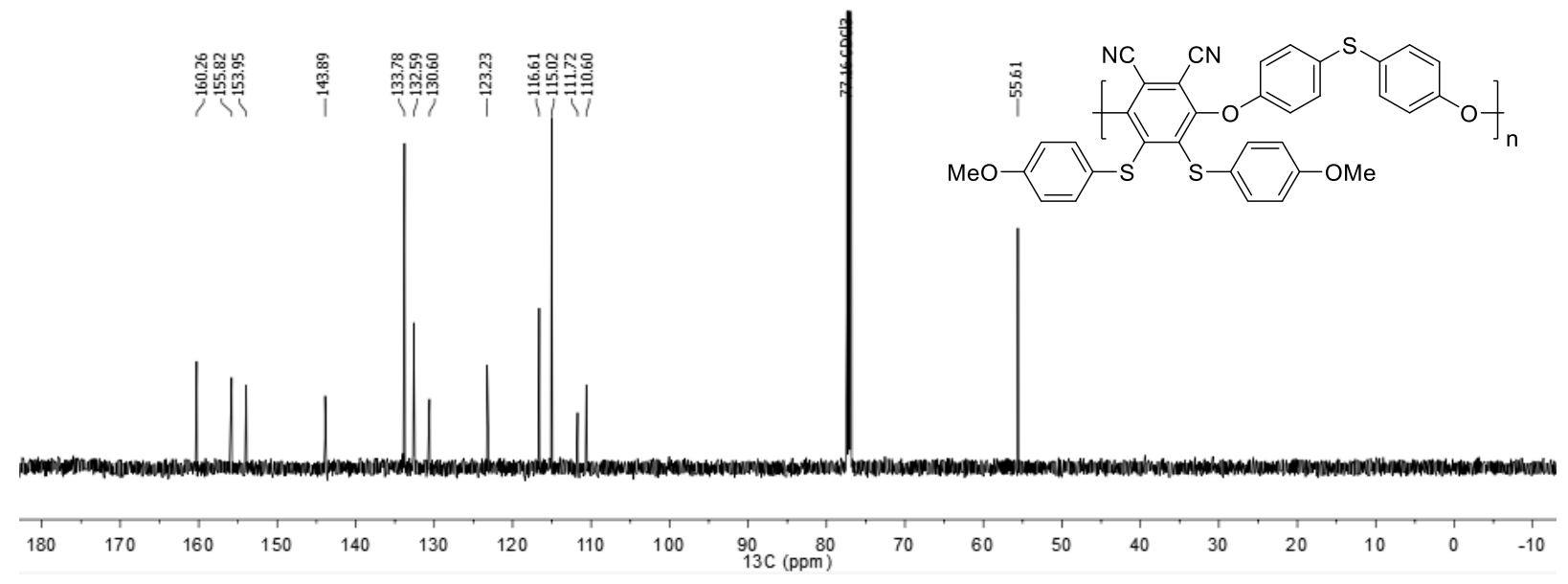

Figure S52 ${ }^{13} \mathrm{C}$ NMR spectrum $(151 \mathrm{MHz}$, Chloroform- $d$ ) of $\mathbf{4 f}$.

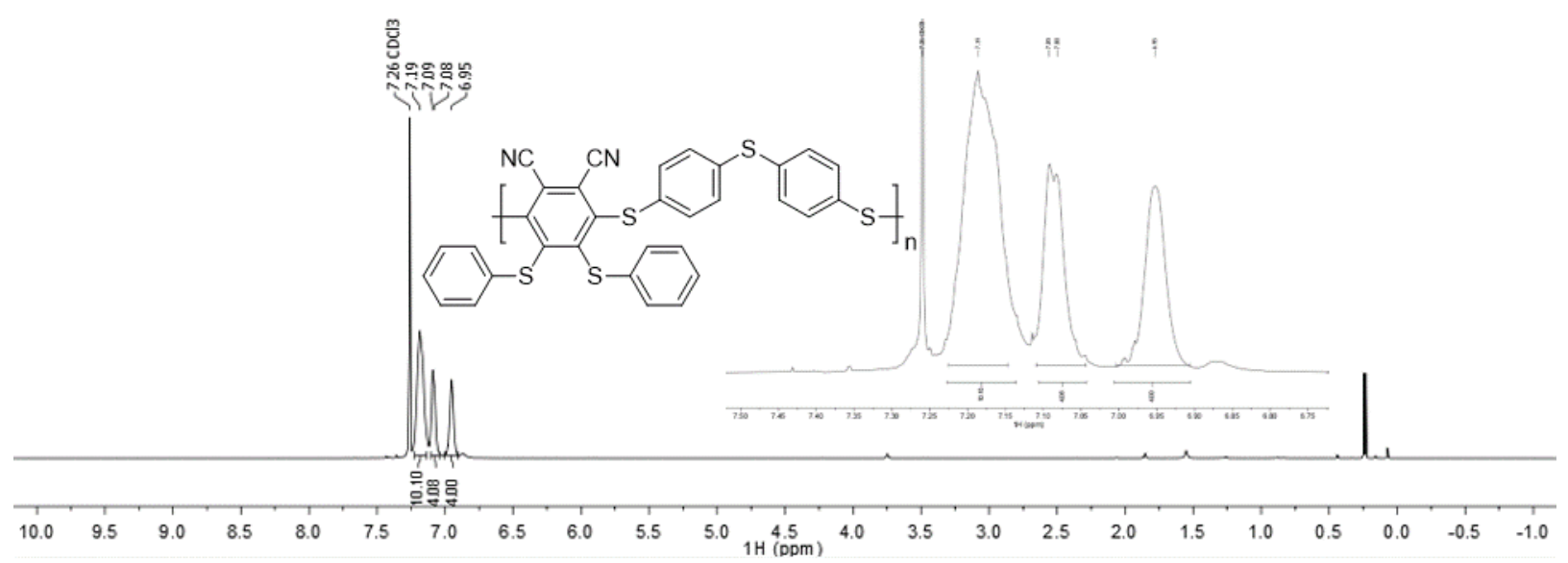

Figure S53 ${ }^{1} \mathrm{H}$ NMR spectrum (600 MHz, Chloroform- $d$ ) of $\mathbf{4 e .}$ 


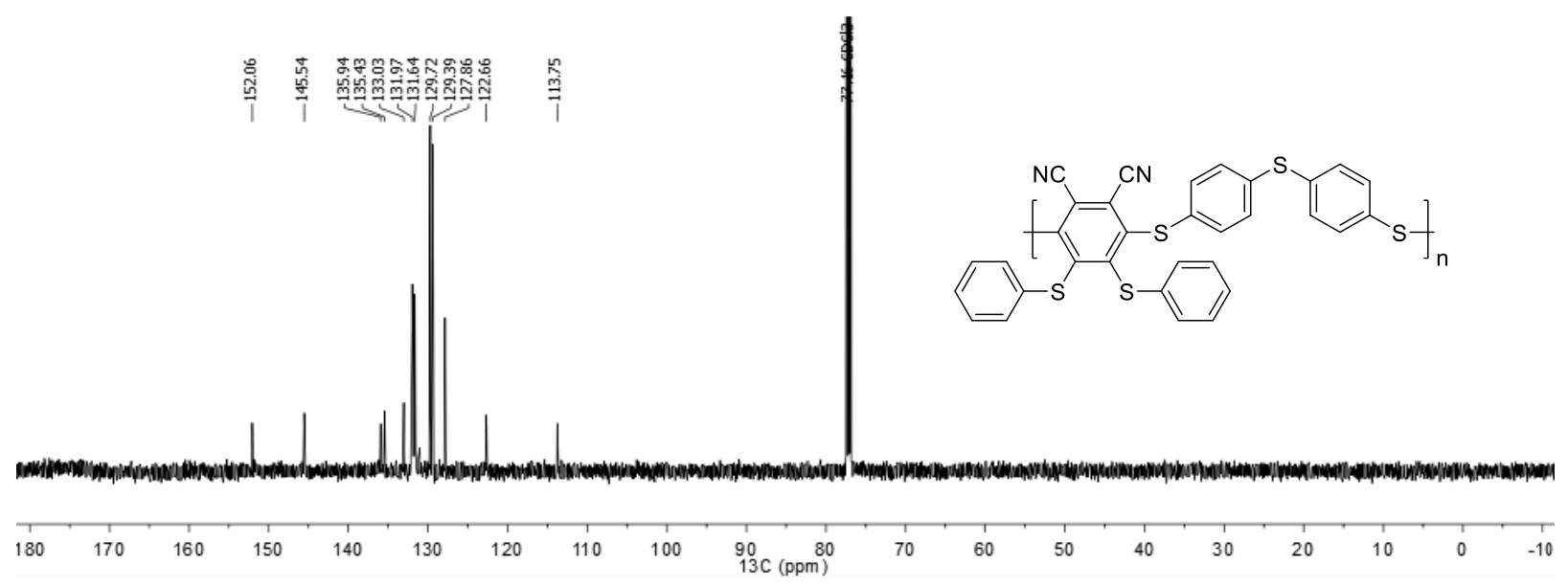

Figure S54 ${ }^{13} \mathrm{C}$ NMR spectrum (151 MHz, Chloroform- $d$ ) of $\mathbf{4 e}$.

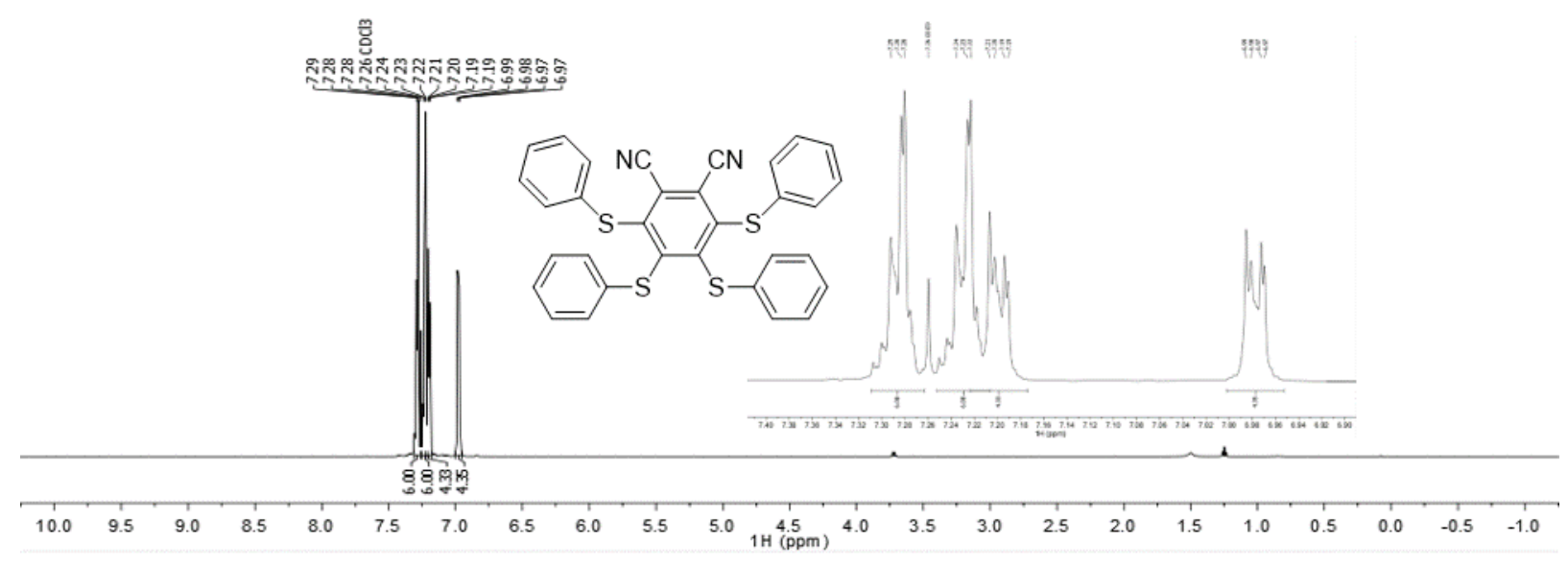

Figure S55 ${ }^{1} \mathrm{H}$ NMR spectrum (600 MHz, Chloroform- $d$ ) of 3,4,5,6-tetrakis(phenylthio)phthalonitrile (7e). 


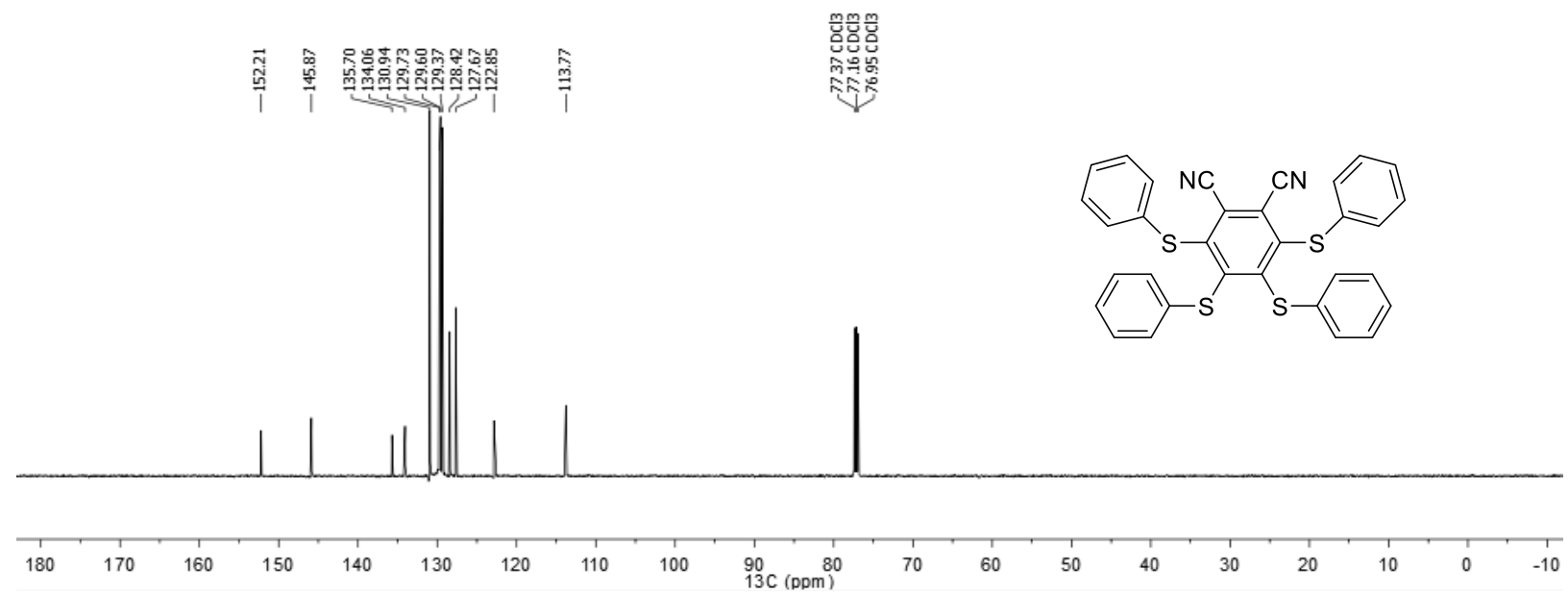

Figure S56 ${ }^{13} \mathrm{C}$ NMR spectrum (151 MHz, Chloroform- $d$ ) of 3,4,5,6-tetrakis(phenylthio)phthalonitrile (7e).

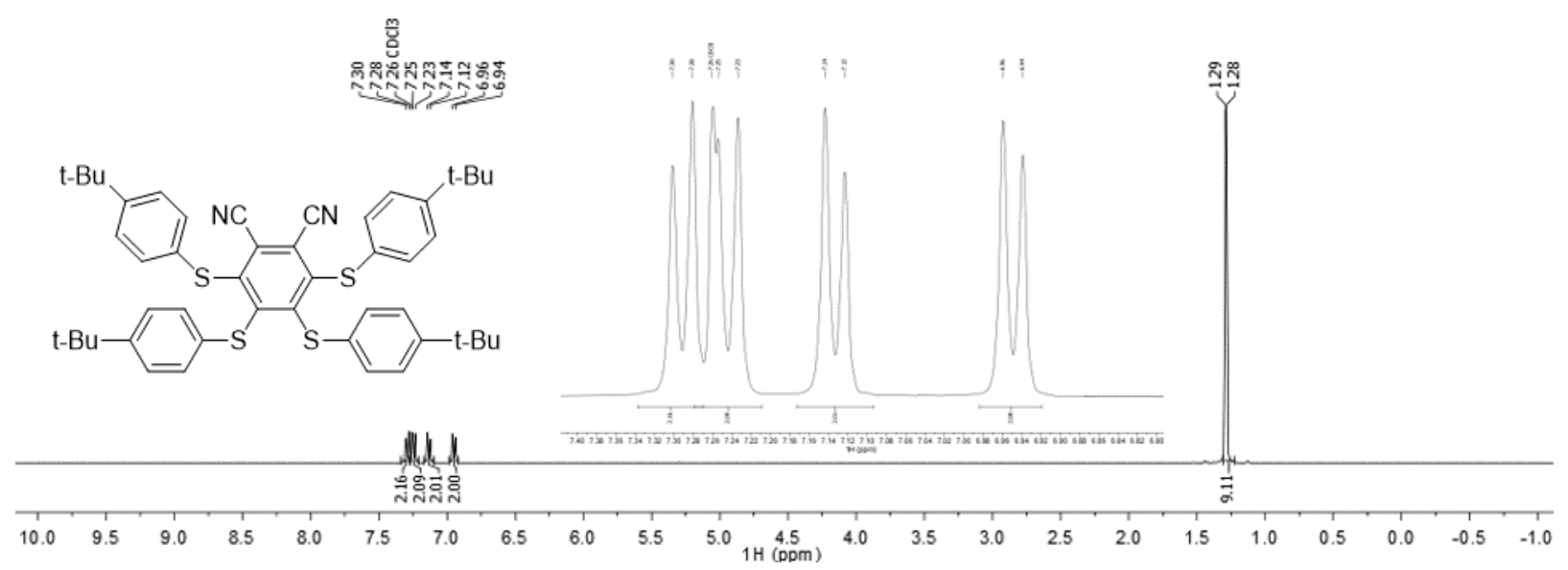

Figure $557{ }^{1} \mathrm{H}$ NMR spectrum (400 MHz, Chloroform- $d$ ) of 3,4,5,6-tetrakis((4-(tertbutyl)phenyl)thio)phthalonitrile (7a).

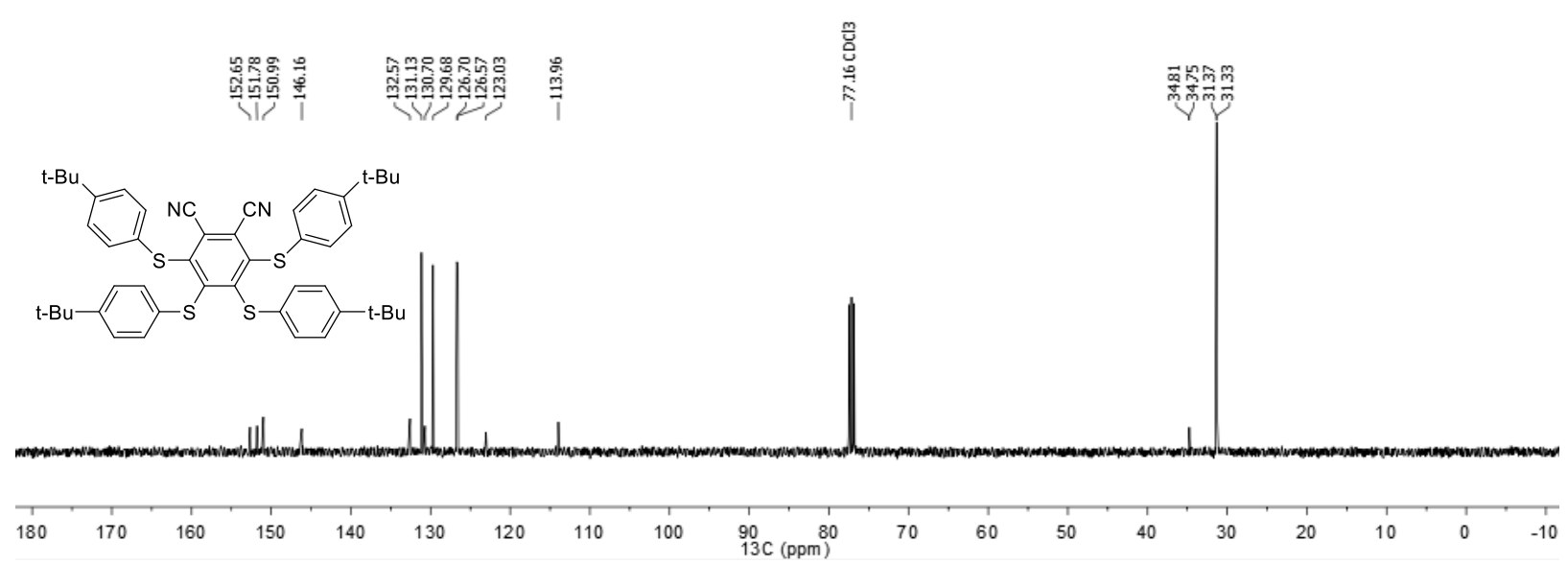

Figure S58 ${ }^{13} \mathrm{C}$ NMR spectrum (101 MHz, Chloroform- $d$ ) of 3,4,5,6-tetrakis((4-(tertbutyl)phenyl)thio)phthalonitrile (7a). 


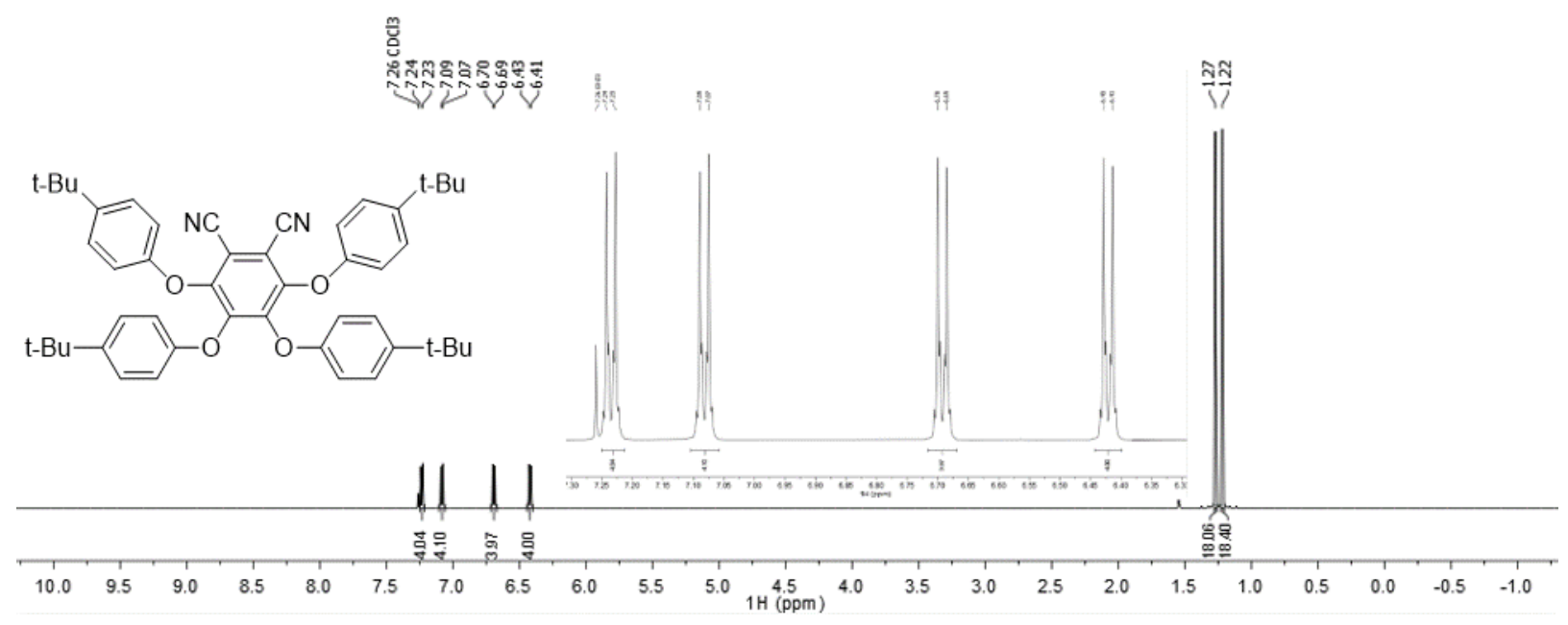

Figure S59 ${ }^{1} \mathrm{H}$ NMR spectrum $(600 \mathrm{MHz}$, Chloroform- $d$ ) of 3,4,5,6-tetrakis(4-(tertbutyl)phenoxy)phthalonitrile (7d).

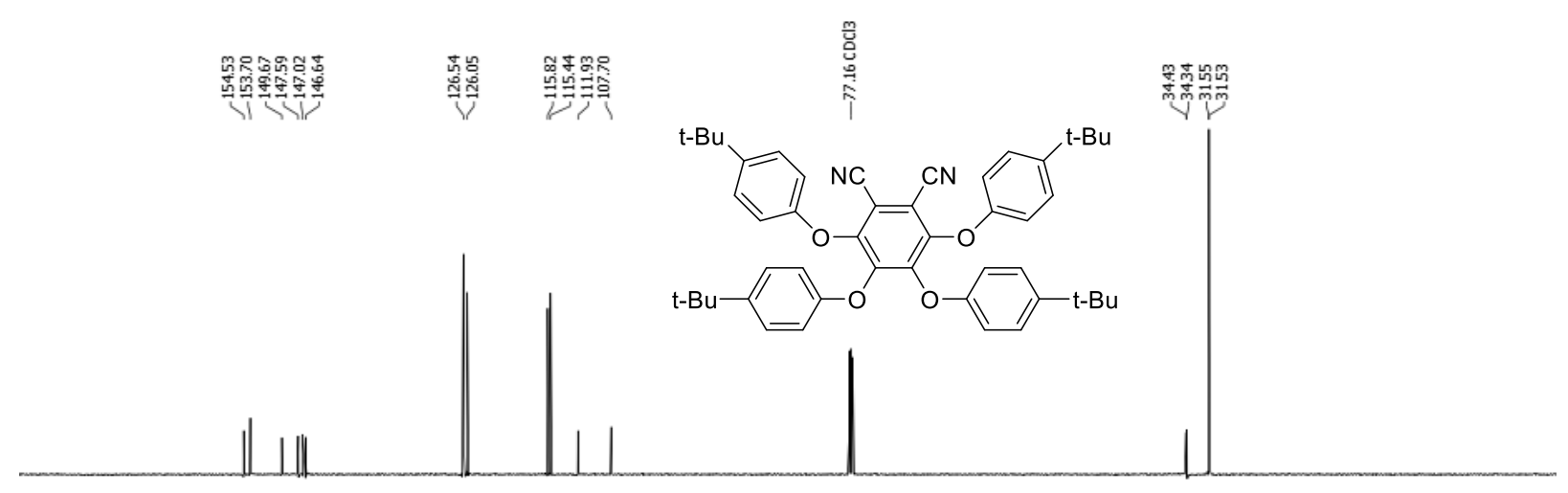

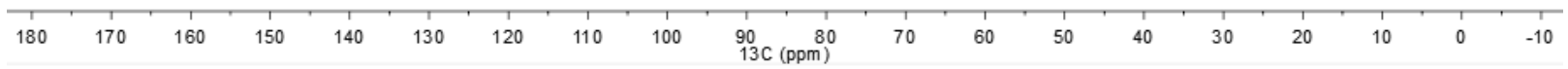

Figure S60 ${ }^{13} \mathrm{C}$ NMR spectrum $(151 \mathrm{MHz}$, Chloroform- $d$ ) of 3,4,5,6-tetrakis(4-(tertbutyl)phenoxy)phthalonitrile (7d). 


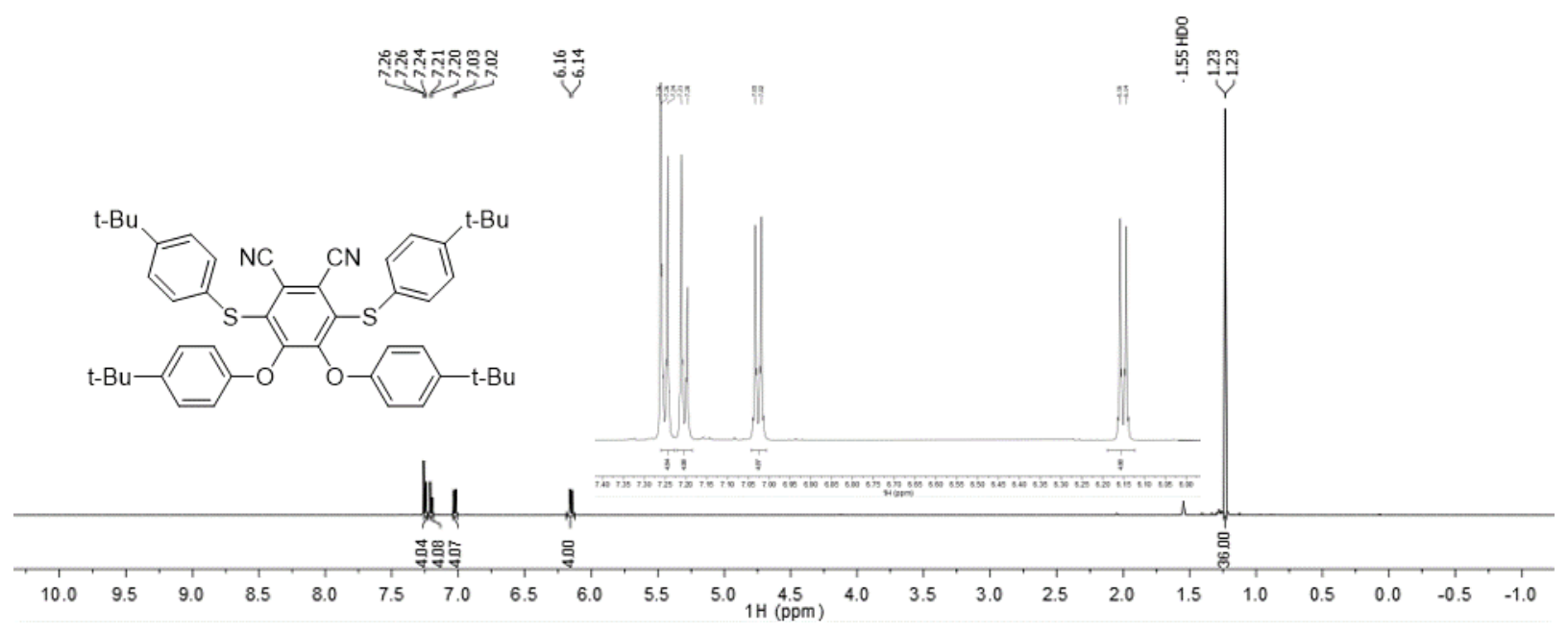

Figure S61 ${ }^{1} \mathrm{H}$ NMR spectrum (600 MHz, Chloroform- $d$ ) of 4,5-bis(4-(tert-butyl)phenoxy)-3,6-bis((4(tert-butyl)phenyl)thio)phthalonitrile (7c).

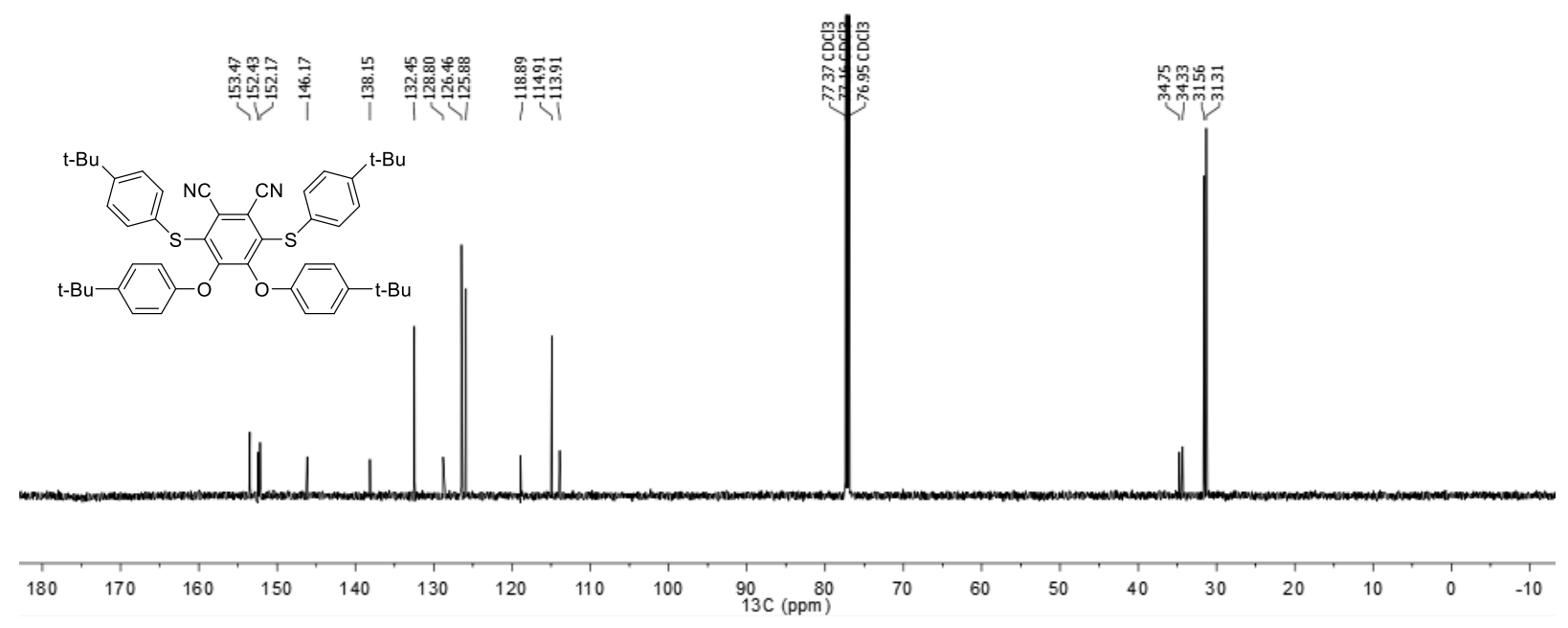

Figure S62 ${ }^{13} \mathrm{C}$ NMR spectrum (151 MHz, Chloroform- $d$ ) of 4,5-bis(4-(tert-butyl)phenoxy)-3,6-bis((4(tert-butyl)phenyl)thio)phthalonitrile (7c). 


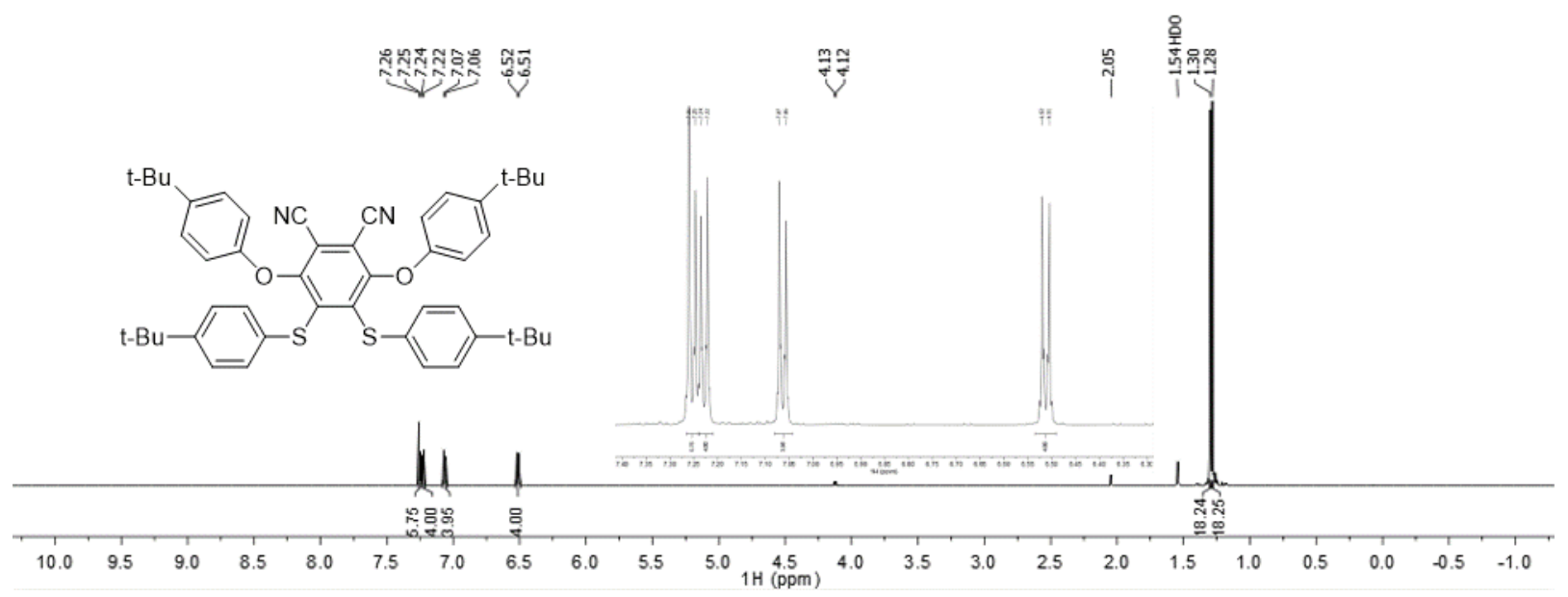

Figure S63 ${ }^{1} \mathrm{H}$ NMR spectrum (600 MHz, Chloroform- $d$ ) of 3,6-bis(4-(tert-butyl)phenoxy)-4,5-bis((4(tert-butyl)phenyl)thio)phthalonitrile (7b). Note: the contaminant at $\delta 4.12$ and 2.05 ppm is ethyl acetate.

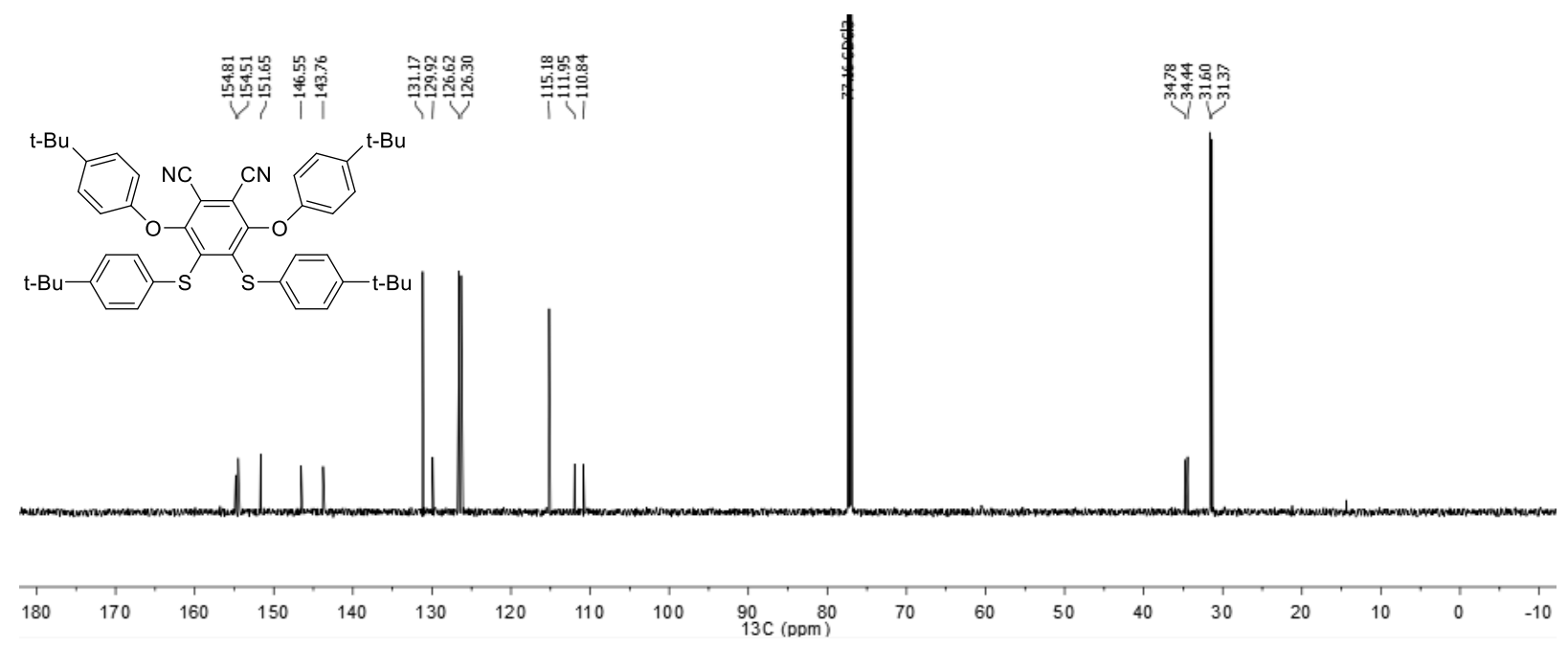

Figure S64 ${ }^{13} \mathrm{C}$ NMR spectrum (151 MHz, Chloroform- $d$ ) of 3,6-bis(4-(tert-butyl)phenoxy)-4,5-bis((4(tert-butyl)phenyl)thio)phthalonitrile (7b).

\section{References}

(1) Park, N. H.; Dos Passos Gomes, G.; Fevre, M.; Jones, G. O.; Alabugin, I. V.; Hedrick, J. L. Organocatalyzed Synthesis of Fluorinated Poly(Aryl Thioethers). Nat. Commun. 2017, 8 (1), 1-6. https://doi.org/10.1038/s41467-017-00186-3.

(2) Birkofer, L.; Stuhl, O. Siliciumorganische Verbindungen : LXXI. Silia-Paracyclophane. $J$. Organomet. Chem. 1979, 177 (2), C16-C18.

(3) Romero, N. A.; Parker, W. O.; Swager, T. M. Functional, Redox-Responsive Poly(Phenylene 
Sulfide)-Based Gels. Macromolecules 2019, 52 (21), 8256-8265.

https://doi.org/10.1021/acs.macromol.9b01855.

(4) Ohno-Okumura, E.; Sakamoto, K.; Kato, T.; Hatano, T.; Fukui, K.; Karatsu, T.; Kitamura, A.; Urano, T. Synthesis of Subphthalocyanine Derivatives and Their Characterization. Dye. Pigment. 2002, 53, 57-65. 